\title{
LIFE CYCLE ASSESSMENT OF VARIOUS NUCLEAR-BASED HYDROGEN AND AMMONIA PRODUCTION METHODS
}

by

\author{
Ali Erdogan Karaca
}

A Thesis Submitted to the Faculty of Graduate and Postdoctoral Affairs in Partial Fulfillment of the Requirements for the Degree of

Master of Applied Science

in

Sustainable Energy

Carleton University

Ottawa, Ontario

(C) Ali Erdogan Karaca, 2019 


\begin{abstract}
In this thesis, a comparative life cycle assessment (LCA) of nuclear-based hydrogen and ammonia production is performed. Environmental impacts of nuclear hydrogen and ammonia production processes are assessed in five different impact categories selected from CML-2001 method. In one scenario BWR-HTE nuclear hydrogen production is compared with PWR-HTE nuclear hydrogen production to reveal the impact of nuclear power plant selection on LCA results. The LCA study of nuclear hydrogen and ammonia production methods is achieved by SimaPro software. Moreover, in the present study, a comparative cost analysis of various nuclear hydrogen production configurations is performed regarding hydrogen generation method, storage, and transportation of hydrogen, and nuclear power plant type. Hydrogen Energy Evaluation Program (HEEP) is utilized for cost analysis of various nuclear hydrogen production scenarios.

According to the results of the performed LCA study, hydrogen and ammonia production via nuclear high-temperature electrolysis (HTE) yields the lowest environmental impacts, whereas nuclear 5-step thermochemical copper-chlorine $(\mathrm{Cu}-\mathrm{Cl})$ cycle method has the highest environmental impacts regarding the selected impact categories. For instance, the GWP of HTE based nuclear hydrogen and ammonia productions are $0.48 \mathrm{~kg} \mathrm{CO}_{2}$-eq and $0.183 \mathrm{~kg} \mathrm{CO}$-eq, whereas 5-step $\mathrm{Cu}-\mathrm{Cl}$ cycle based nuclear hydrogen and ammonia production have the GWP value of $1.35 \mathrm{~kg} \mathrm{CO}$-eq $0.336 \mathrm{CO}_{2}$-eq per $\mathrm{kg}$ hydrogen, respectively. Except for ozone depletion potential (ODP), HTE based nuclear hydrogen production from BWR type reactor yields lower environmental impacts than that of nuclear hydrogen production from PWR type reactor in all selected impact categories.

From the cost assessment study of nuclear hydrogen production, it can be highlighted that APWR based hydrogen production via high-temperature steam reforming is the most costeffective among the selected methods. One kg nuclear hydrogen production from APWR type reactor cost $3.24 \$$, whereas this value for HTGR type reactor is $3.61 \$ / \mathrm{kg}$ of hydrogen.
\end{abstract}

Keywords: Life cycle assessment, environmental impacts, nuclear energy, hydrogen production, ammonia production, cost assessment. 


\section{Acknowledgements}

First and foremost, I would like to express my gratitude to my supervisors, Dr. Ibrahim Dincer and Dr. Junjie Gu for their endless supports throughout my study at Carleton University. I would like to express my special gratefulness once again to Dr. Ibrahim Dincer for his guidance since the day we met. I had been through many challenges during my master study, but dark paths that I had thought would never be bright again became a daylight thanks to his valuable supports.

I would also like to thank my friends at Carleton University and UOIT who offered their endless supports that have contributed to this thesis significantly.

And my family. I cannot express how grateful I am for your belief in me and your support at any time that I struggle. I would like to thank my family; Emine Karaca Colak, Mehtap Karaca, Bora Colak, and especially my mother, Husniye Guler Karaca and my father, Sefket Karaca. Mom and dad, it is the highest honor for me to be your son.

I dedicate this thesis to my family, which is the most precious thing that I have. 


\section{Table of Contents}

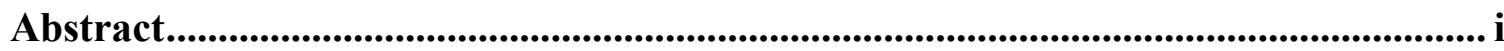

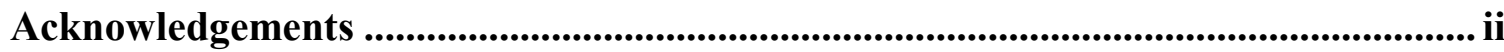

Table of Contents ..........................................................................................................

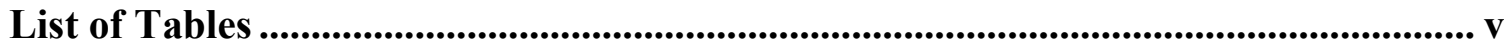

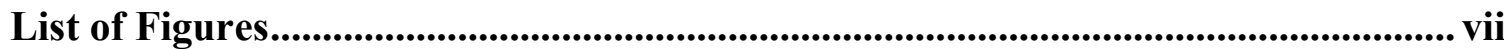

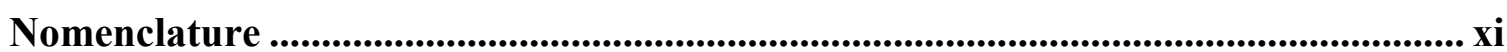

CHAPTER 1: INTRODUCTION......................................................................... 1

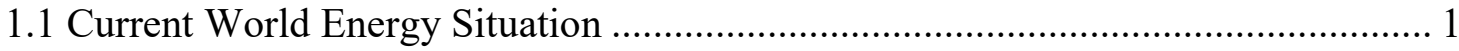

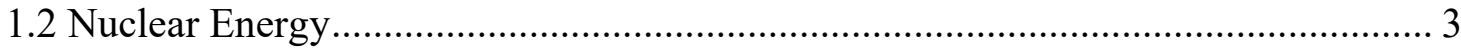

1.3 Hydrogen as an Energy Carrier ................................................................... 5

1.4 Ammonia as an Energy Carrier ....................................................................... 7

1.4.1 Potential Applications for utilizing Ammonia as a Substance ...................... 12

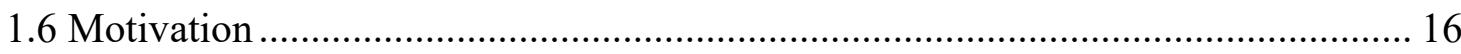

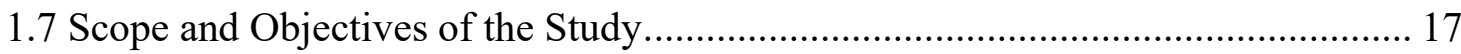

CHAPTER 2: LITERATURE REVIEW ............................................................ 20

2.1 Hydrogen Production ............................................................................... 20

2.1.1 Conventional and High Temperature Water Electrolysis ............................... 22

2.1.2 Thermochemical Water Splitting............................................................ 24

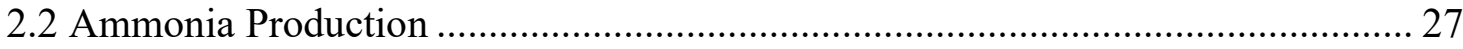

2.2.1 Electrochemical Ammonia Production............................................................... 27

2.2.2 Conventional Methods of Ammonia Synthesis ............................................. 28

2.3 Life Cycle Assessment of Hydrogen and Ammonia Production .......................... 29

2.4 Cost Assessment of Nuclear Based Hydrogen Production ................................... 32

CHAPTER 3: LIFE CYCLE ASSESSMENT ...................................................... 33

3.1 Definition and History of Life Cycle Assessment Technique............................... 33

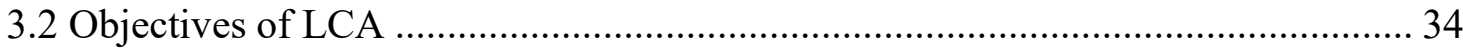

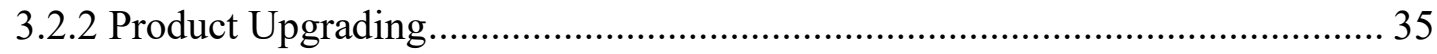

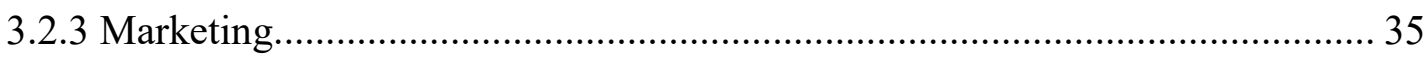

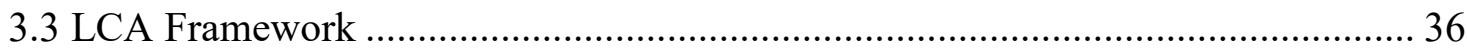

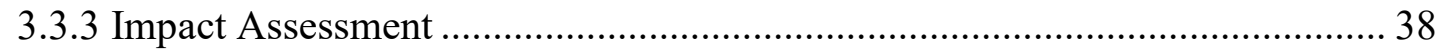




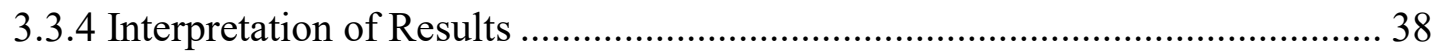

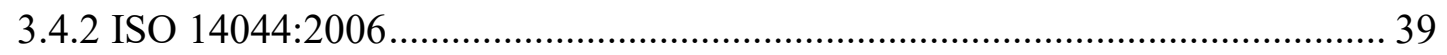

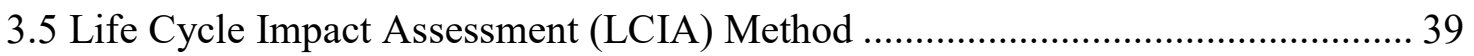

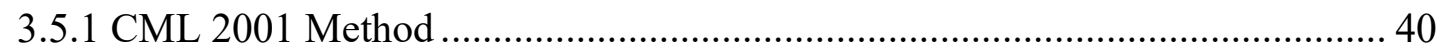

CHAPTER 4: SYSTEM DESCRIPTIONS ............................................................ 43

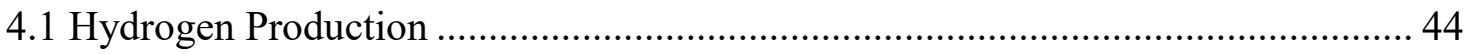

4.1.1 Conventional Water Electrolysis ...................................................................... 45

4.1.2 High Temperature Water Electrolysis (HTE)................................................. 46

4.1.3 5 Step $\mathrm{Cu}-\mathrm{Cl}$ Cycle ................................................................................. 47

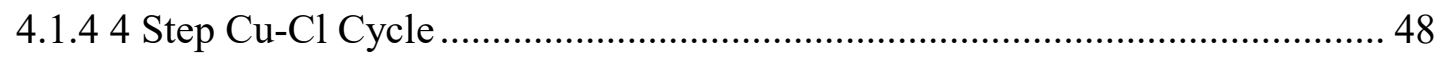

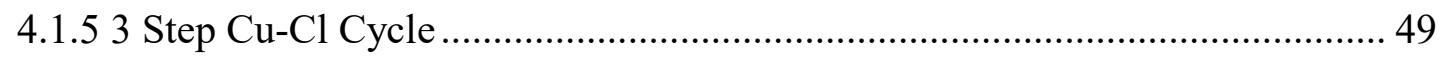

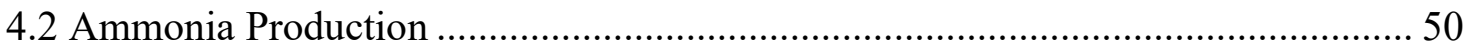

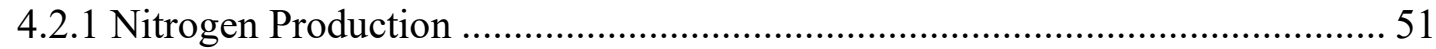

4.2.2 Haber-Bosch Ammonia Synthesis............................................................ 51

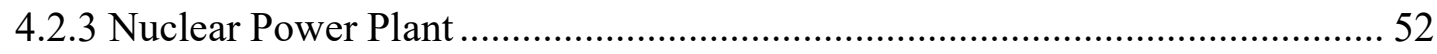

4.3 Hydrogen Economy Evaluation Program (HEEP) …………………………….... 53

CHAPTER 5: RESULTS AND DISCUSSION ...................................................5 58

5.1 LCA Results in terms of Impact Categories ...................................................... 58

5.1.1 Hydrogen Production Results...................................................................... 59

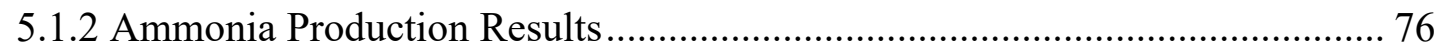

5.1.3 Impact of Nuclear Power Plant Selection on LCA Results .............................. 93

5.2 Cost Analysis of Nuclear-Based Hydrogen Production in the HEEP ..................... 97

5.2.1 Hydrogen Production Method based Cost Comparison …………………….... 98

5.2.2 Hydrogen Storage based Cost Comparison .................................................... 100

5.2.3 NPP Type based Cost Comparison.................................................................. 101

CHAPTER 6: CONCLUSIONS AND RECOMMENDATIONS................................ 103

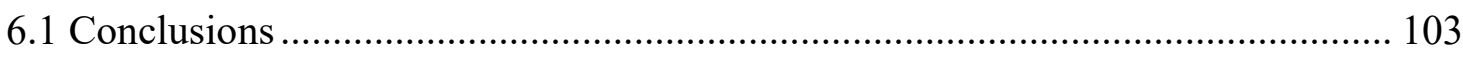

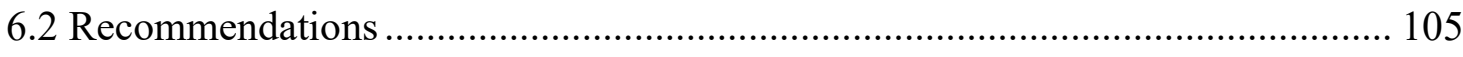

REFERENCES.................................................................................................................... 107 


\section{List of Tables}

Table 1. 1: The ten largest $\mathrm{CO}_{2}$ emitting countries in 2015 (IEA, 2017)........................ 1

Table 1. 2: Comparison of ammonia with other fuels by means of listed characteristics (Modified from Zamfirescu and Dincer, 2008).

Table 1. 3: The effects of various concentration of ammonia (Modified from ASHRAE, 2017).

Table 3. 1: Selected CML 2001 environmental impact categories and their units ..... 40

Table 4. 1: Main inputs and outputs for nuclear based hydrogen production via conventional electrolysis. 46

Table 4. 2: Main inputs and outputs for nuclear-based hydrogen production via high temperature electrolysis 46

Table 4. 3: Steps and reactions in the five $\mathrm{Cu}-\mathrm{Cl}$ cycle for water decomposition 47

Table 4. 4: Main inputs and outputs of nuclear-based hydrogen production via 5 step $\mathrm{Cu}$ -

$\mathrm{Cl}$ cycle 48

Table 4. 5: Steps and reactions occuring in the 4 step $\mathrm{Cu}-\mathrm{Cl}$ cycle for water decompostion 48

Table 4. 6: Main inputs ad outputs of nuclear-based hydrogen production via 4 step $\mathrm{Cu}-$ $\mathrm{Cl}$ cycle.

Table 4. 7: Steps and reactions occuring in the 3 step $\mathrm{Cu}-\mathrm{Cl}$ cycle for water decompostion

Table 4. 8: Main inputs and outputs of nuclear hydrogen production via 3 step $\mathrm{Cu}-\mathrm{Cl}$

cycle

Table 4. 9: Main inputs and outputs for nuclear-based ammonia production via HaberBosch process. 52

Table 4. 10: Hydrogen production plants details used in the HEEP software................. 54

Table 4. 11: Hydrogen storage details used in the HEEP software. ............................... 54

Table 4. 12: Hydrogen transportation details used in the HEEP software........................ 55

Table 4. 13: Nuclear power plants details used in the HEEP software........................... 55

Table 4. 14: Other cost and operating parameters used in the HEEP software............... 56 
Table 5. 1: Environmental Impacts of various nuclear-based hydrogen production

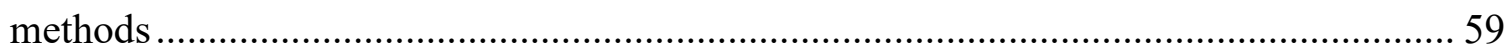

Table 5. 2: Environmental impacts of nuclear-based ammonia production methods....... 76 Table 5. 3: LCA results comparison of BWR-HTE and PWR-HTE nuclear hydrogen

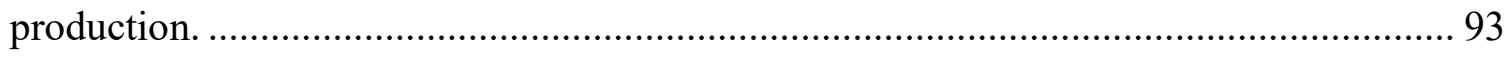




\section{List of Figures}

Figure 1. 1: Global total primary energy supply by fuel in 2015. (Modified from IEA, 2017) 2

Figure 1. 2: Comparison of volumetric energy densities and specific energy densities of various fuels (Adapted from Zamfirescu and Dincer, 2008). 8

Figure 3. 1: ISO 14040 standard LCA framework 37

Figure 4. 1: Simplified overwiev of hydrogen and ammonia production methods......... 43

Figure 4. 2: Simplified overwiev of the system used for the LCA. ................................... 44

Figure 4. 3: The schematic of a conventional water electrolysis unit. (Adapted from Zeng

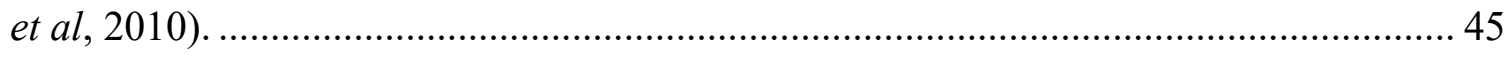

Figure 4. 4: Simple layout of nuclear-based ammonia production via HTE. ................... 50

Figure 4. 5: Simple schematic of Haber-Bosch ammonia production process ( Adapted from Yusuf Bicer, 2017) .......................................................................................... 52

Figure 5. 1: Comparison of LCA results of nuclear-based hydrogen production methods

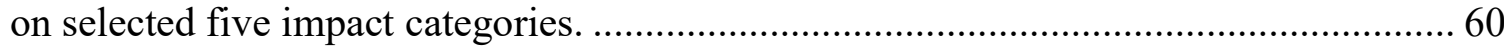
Figure 5. 2: Abiotic depletion potential (ADP) of nuclear-based hydrogen production methods

Figure 5. 3: Major contributors of abiotic depletion potential (ADP) of nuclear-based hydrogen production via high temperature electrolysis (HTE).

Figure 5. 4: Contribution of various sub-processes to abiotic depletion potential of nuclear-based HTE

Figure 5. 5: LCA process flowchart for abiotic depletion (ADP) of PWR HTE based hydrogen production (cut-off 7\%).

Figure 5. 6: Acidification Potential (AP) of nuclear-based hydrogen production methods. 
Figure 5. 7: The share of various sub-processes in acidification potential (AP) of nuclearbased hydrogen production via thermoelectrical conventional electrolysis (CE). 65

Figure 5. 8: Contribution of various sub-processes to AP of the thermoelectrical

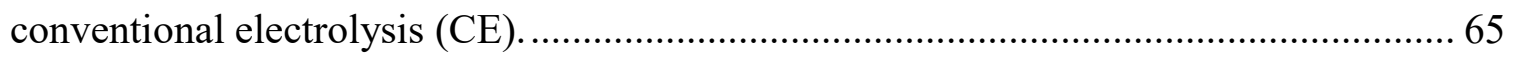

Figure 5. 9: LCA process flow chart for acidification potential (AP) of hydrogen

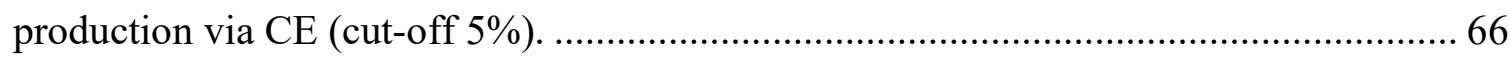

Figure 5. 10: Global warming potential (GWP) of nuclear-based hydrogen production

methods.

Figure 5. 11: The share of different sub-processes in greenhouse gas emissions of for nuclear-based hydrogen production via 3 step $\mathrm{Cu}-\mathrm{Cl}$ cycle.

Figure 5. 12: The contribution of sub-processes to GWP of nuclear-based hydrogen production via thermochemical 3 step $\mathrm{Cu}-\mathrm{Cl}$ cycle....

Figure 5. 13: Major contributors to global warming potential (GWP) of nuclear-based hydrogen production via 3 step $\mathrm{Cu}-\mathrm{Cl}$ cycle (cut-off $5 \%$ ).

Figure 5. 14: Ozone layer depletion potential (ODP) of nuclear-based hydrogen production methods.

Figure 5. 15: The share of sub-processes for ODP of hydrogen production via thermochmical 4 step $\mathrm{Cu}-\mathrm{Cl}$ cycle. 71

Figure 5. 16: The main contributors of ODP for 4 step $\mathrm{Cu}-\mathrm{Cl}$ cycle and their contribution.

Figure 5. 17: LCA process flow chart for ozone depletion potential (ODP) of hydrogen production via 4 step $\mathrm{Cu}-\mathrm{Cl}$ cycle (cut-off $12 \%$ ). 72

Figure 5. 18: Human toxicity potential (HTP) of nuclear-based hydrogen production mehods.

Figure 5. 19: The share of sub-processes for HTP of hydrogen production via thermochemical 5 step $\mathrm{Cu}-\mathrm{Cl}$ cycle.

Figure 5. 20: Main contributors of HTP for nuclear-based hydrogen production via thermochemical 5 step $\mathrm{Cu}-\mathrm{Cl}$ cycle.

Figure 5. 21: LCA process flow chart for human toxicity potential (HTP) of hydrogen production via 5 step $\mathrm{Cu}-\mathrm{Cl}$ cycle (cut-off $3 \%$ ) 
Figure 5. 22: Comparison of LCA results of nuclear-based ammonia production methods on selected five impact categories.

Figure 5. 23: Abiotic depletion potential (ADP) of nuclear-based ammonia production methods. 78

Figure 5. 24: The share of sub-processes for ADP of nuclear-based ammonia production via thermoelectrical high temperature electrolysis.

Figure 5. 25: Main contributors of ADP for nuclear-based ammonia production via thermoelectrical high temperature electrolysis (HTE)......

Figure 5. 26: LCA process flow chart for abiotic depletion potential (ADP) of ammonia production via HTE (cut-off 10\%).

Figure 5. 27: Acidification potential (AP) of nuclear-based ammonia production methods.

Figure 5. 28: The share of sub-processes for AP of nuclear-based ammonia production

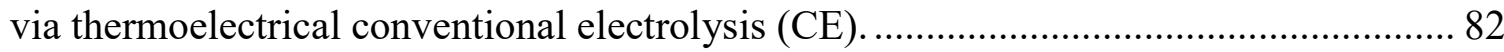

Figure 5. 29: Main contributors of AP for nuclear-based ammonia production via thermoelectrical Conventional Electrolysis (CE).

Figure 5. 30: LCA process flow chart for acidification potential (AP) of ammonia production via conventional electrolysis (CE) (cut-off 5\%).

Figure 5. 31: Global warming potential (GWP) of nuclear-based ammonia production methods. 84

Figure 5. 32: The share of sub-processes for GWP of nuclear-based ammonia production via thermochemical 3 step $\mathrm{Cu}-\mathrm{Cl}$ cycle.

Figure 5. 33: Main contributors of GWP for nuclear-based ammonia production via thermochemical 3 step $\mathrm{Cu}-\mathrm{Cl}$ cycle.

Figure 5. 34: LCA process flow chart for global warming potential (GWP) of ammonia production via 3 step $\mathrm{Cu}-\mathrm{Cl}$ cycle (cut-off $5 \%$ ).

Figure 5. 35: Ozone depletion potential (ODP) of nuclear-based ammonia production methods.

Figure 5. 36: The share of sub-processes for ODP of nuclear-based ammonia production via thermochemical 4 step $\mathrm{Cu}-\mathrm{Cl}$ cycle. 88 
Figure 5. 37: Main contributors of ODP for nuclear-based ammonia production via

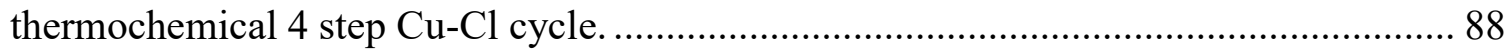

Figure 5. 38: LCA process flow chart for ozone depletion potential (ODP) of ammonia production via 4 step $\mathrm{Cu}-\mathrm{Cl}$ cycle (cut-off $5 \%$ ). 89

Figure 5. 39: Human toxicity potential (HTP) of nuclear-based ammonia production methods.

Figure 5. 40: The share of sub-processes for HTP of nuclear-based ammonia production via thermochemical 5 step $\mathrm{Cu}-\mathrm{Cl}$ cycle. .91

Figure 5. 41: Main contributors of HTP for nuclear-based ammonia production via thermochemical 5 step $\mathrm{Cu}-\mathrm{Cl}$ cycle.

Figure 5. 42: LCA process flow chart for ozone depletion potential (ODP) of ammonia production via 4 step $\mathrm{Cu}-\mathrm{Cl}$ cycle (cut-off $5 \%$ ). 92

Figure 5. 43: Main ODP contributor sub-processes of BWR-HTE based nuclear hydrogen production. 94

Figure 5. 44: LCA results comparison between hydrogen production via BWR HTE .... 95 Figure 5. 45: LCA process flow chart for ozone depletion potential (ODP) of hydrogen

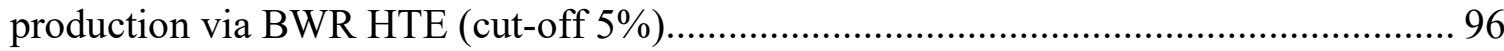
Figure 5. 46: Comparison of nuclear based hydrogen production costs........................ 98 Figure 5. 47: Contribution percentages of plant units on nuclear-based HTSE hydrogen production cost 99

Figure 5. 48: Cost breakup for one hydrogen production via thermochemical S-I cycle. 99 Figure 5. 49: HTSE hydrogen production costs in respect to hydrogen storage tecnique. 100

Figure 5. 50: HTSE hydrogen production cost based on the type of NPPs. 101 


\section{Nomenclature}

$C_{H 2} \quad$ Levelized hydrogen cost

$E\left(t_{0}\right) \quad$ The present values of expenditures

$G_{H 2}\left(t_{0}\right)$ The present value of gross hydrogen generation for time $t_{0}$

\section{Subscripts}

$\mathrm{H}_{2} \mathrm{GP} \quad$ Hydrogen production and storage

$\mathrm{H}_{2} \mathrm{~T} \quad$ Hydrogen transportation

NPP Nuclear Power Plant

$r \quad$ Real discount rate

Acronyms

AECL Atomic Energy of Canada Limited

ADP Abiotic resource depletion potential

AFMC Ammonia fueled alkaline membrane fuel cell

AP Acidification potential

APWR Advance pressurize water reactor

BARC BHABHA Atomic Research Centre

BG Biomass gasification

BWR Boiling water reactor

CANDU Canadian Deuterium Uranium Reactor

CE Conventional Electrolysis

CFC Chlorofluorocarbon

CG Coal gasification

CML Institute of Environmental Sciences, Leiden University

CNG Compressed natural gas 
$\mathrm{Ce}-\mathrm{Cl}$ Cerium-chlorine

$\mathrm{Cu}-\mathrm{Cl}$ Copper-chlorine

$\mathrm{Cu}-\mathrm{SO}_{4} \quad$ Copper- sulfate

DC Direct Current

$\mathrm{Fe}-\mathrm{Cl} \quad$ Iron-chlorine

GFR Gas-cooled fast reactor

GHG Greenhouse gas

GIF Generation IV International Forum

GWP Global warming potential

HEEP Hydrogen Economy Evaluation Program

H-EL Hydropower and electrolysis

HTP Human toxicity potential

HTGR High temperature gas-cooled reactor

HTR_K High temperature reactor

HTSE High-temperature steam electrolysis

IAEA International Atomic Energy Agency

ICE Internal combustion engine

IEA International Energy Agency

ISO International Organization for Standardization

LCA Life cycle assessment

LCIA Life cycle impact assessment

LFR Load-cooled fast reactor

LPG Liquefied petroleum gas 


\begin{tabular}{ll} 
MSR & Molten salt reactor \\
NG & Natural gas \\
NPP & Nuclear power plant \\
ODP & Ozone depletion potential \\
PEM & Polymer electrolyte membrane \\
PEMFC & Proton exchange membrane fuel cell \\
POX & Partial oxidation of hydrocarbons \\
PV-EL & Photovoltaics and electrolysis \\
PHWR & Pressurized heavy water reactor \\
PWR & Pressurized water reactor \\
SCWR & Super critical water reactor \\
SMR & Steam methane reforming \\
SFR & Sodium-cooled fast reactor \\
S-I & Sodium-iodine \\
SOFC & Solid oxide fuel cell \\
SSAS & Solid-state ammonia synthesis \\
V-Cl & Vanadium-chlorine \\
VHTR & Very high temperature reactor \\
W-EL & Wind power and electrolysis \\
WMO & World Meteorological Organization \\
YSZ & Yttria-stabilized zirconia \\
\hline
\end{tabular}




\section{CHAPTER 1: INTRODUCTION}

In the introductory chapter, the energy situation of the world is explained. Regarding the current status and future studies, nuclear energy is referred to under a subtitle. The importance of alternative energy resources in mitigating the consumption of fossil fuels is emphasized by a particular focus on hydrogen and ammonia.

\subsection{Current World Energy Situation}

Greenhouse gas emissions from human activities are the most significant driver of observed climate change since the turn of the century. Worldwide, net greenhouse gas emissions increased by 35 percent from 1990 to 2010 (IEA, 2017). The major contributor to this consequence was fossil fuel based energy production and consumption activities. To protect the planet as well as human health and welfare, mitigation of fossil fuel consumption is vital. Thus, countermeasures for a reduction in greenhouse gas emissions would include increasing the use of non-fossil energies.

Table 1. 1: The ten largest $\mathrm{CO}_{2}$ emitting countries in 2015 (IEA, 2017).

\begin{tabular}{|c|c|c|c|}
\hline $\begin{array}{c}2015 \text { total } \\
\text { emissions } \\
\text { country } \\
\text { rank }\end{array}$ & Country & $\begin{array}{c}\mathbf{2 0 1 5} \text { total CO2 emissions } \\
\text { from fuel combustion } \\
\text { (MMT) }\end{array}$ & $\begin{array}{c}\text { 2015 CO2 emissions per } \\
\text { capita from fuel } \\
\text { combustion (MT) }\end{array}$ \\
\hline 1 & China & 9084 & 6.59 \\
\hline 2 & U.S.A & 4998 & 15.53 \\
\hline 3 & India & 2066 & 1.58 \\
\hline 4 & Russia & 1469 & 10.19 \\
\hline 5 & Japan & 1142 & 8.99 \\
\hline 6 & Germany & 730 & 8.93 \\
\hline 7 & South Korea & 585 & 11.58 \\
\hline 8 & Iran & 552 & 6.98 \\
\hline 9 & Canada & 549 & 15.32 \\
\hline 10 & Saudi Arabia & 531 & 16.85 \\
\hline
\end{tabular}




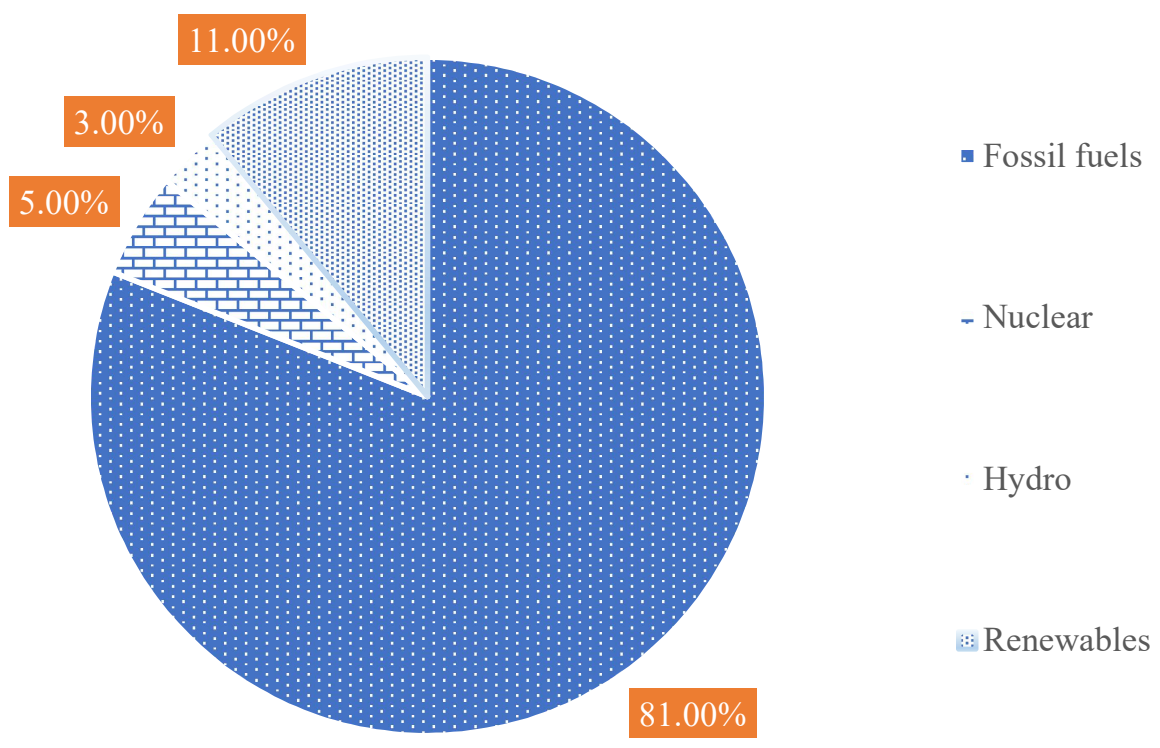

Figure 1. 1: Global total primary energy supply by fuel in 2015. (Modified from IEA, 2017)

In 2015, the world's total primary energy supply was more than 13 billion tons of oil equivalent (toe). The breakdown by energy resources displays a dominant contribution of fossil fuels around $81 \%$ where nuclear represented nearly $5 \%$ of the total energy supply (IEA, 2017). Energy demand in the world depends on population growth and economic development. According to IEA's recent statement (IEA, 2017), the world energy demand rises more slowly than in the past, but still will increase by $30 \%$ by 2040 . Economic developments and population growth across the globe imply the availability of costeffective and environmentally benign energy sources. Therefore, a future energy economy will need to replace oil and reduce greenhouse gas (GHG) emissions. In this regard, nuclear power, which is considered as carbon-free since the energy production process does not emit any carbon atom directly, may play a significant role in future energy economics as electricity and process heat supplier in a great variety of industrial processes, including large-scale hydrogen or ammonia production.

\section{Canada's Energy Situation}

Canada is one of the largest producers and exporters of energy in the world. Canada's total energy production reached almost 507 Mtoe in 2010, while its total energy consumption was around 182 Mtoe. In 2010, the largest source of energy consumption was refined 
petroleum products (41\%), while natural gas accounted for 31\% and electricity, $24 \%$ (Environment and Climate Change Canada, 2016). Electricity production in Canada has been dominated by hydroelectricity, with nuclear and fossil fuels holding a $15-25 \%$ share each over the past two decades. Canada has the second-largest petroleum deposits in the world (after Saudi Arabia), and the second-largest producer and exporter of uranium with 22\% of global production in 2017 (Environment and Climate Change Canada, 2018). However, the development of oil sands projects has been sharply criticized for its impact on the environment and its intensive use of both water and natural gas.

Under the Paris climate change agreement, Canada has pledged to reduce its emissions by 30 percent from the 2005 level by 2030 (Environment and Climate Change Canada, 2016). However, Canada's latest greenhouse gas inventory report to the United Nations (Environment and Climate Change Canada, 2018), reveals that Canada is still away from meeting its commitments. The report shows that emissions are starting to trend downward, but not at the rate needed to meet the Paris Agreement targets. To meet the Paris Agreement targets, Canada cannot produce more than 517 million tons of emissions in 2030. However, according to the report, Canada emitted 704 million tons of emissions in 2016. While emissions are down 1.4 percent from the year before, the decrease is not enough to meet 2030 targets. The growth in oil sands exploitation and road transportation are pointed as significant contributors to this situation. Consequently, the replacement/mitigation of fossil fuel use and its applications and, in this respect, the research and implementation of alternative energy carriers such as hydrogen or ammonia and their applications are of considerable importance within Canada.

\subsection{Nuclear Energy}

Limited fossil fuel sources and environmental issues are likely to increase the non-fossil energy forms in the long run. Despite its low growth at present, nuclear power is foreseen by energy authorities as an essential option in the future representing carbon-free renewable energy. According to a statement by IAEA, in 2016, there were 448 operational nuclear power reactors across the globe with a total net installed capacity of $391 \mathrm{GW}(\mathrm{e})$, and 61 units with the total capacity of $61 \mathrm{GW}(\mathrm{e})$ were under construction. The share of nuclear power in the world electricity production breakdown accounted for around $11 \%$ in 
2016 (IAEA, 2016). Nuclear energy contributes to sustainable developments since it is an energy source with no greenhouse gas (GHG) emissions and donates to improve national energy security. Moreover, nuclear energy is capable of competing with fossil-fueled power facilities due to its baseload production characteristic with the low fuel cost helping to stabilize the electricity price within the energy mix.

It is a fact that nuclear technology is an indispensable alternative to achieving the future global greenhouse gas emission target while providing sufficient energy. However, insistent public concerns must be recognized about nuclear facilities. Fukushima Daiichi Nuclear disaster, happening in 2011 in Japan, intensified debates about nuclear technology and its future. To keep the nuclear option alive, the nuclear industry must continue to develop the next generation of nuclear power plants in order to achieve higher efficiency and more reliable safety, while working safely with existing facilities. In 2001, the Generation IV (Gen-IV) International Forum (GIF) was established to develop a group of next-generation nuclear reactors, and six different reactor types were determined. These are namely very-high-temperature reactor (VHTRs), sodium-cooled fast reactors (SFRs), supercritical-water-cooled reactors (SCWRs), gas-cooled fast reactors (GFRs), lead-cooled fast reactors (LFRs), and molten salt reactors (MSRs). The aim is to make these reactors operational by 2030 or earlier (GIF, 2010). New and revolutionary concept Generation IV reactors are considered in many jurisdictions with a focus on sustainability, economics, safety, and proliferation resistance (GIF, 2017).

Nuclear energy comes from fission reaction, consuming uranium (or thorium shortly). When a uranium nucleus absorbs a neutron, it becomes unstable and splits. The splitting uranium nucleus emits high-temperature heat. A heat transfer fluid transports this heat to a secondary system for further use. Traditionally, nuclear heat is utilized in electrical power production processes. It is also possible to employ some of the high-temperature heat from a nuclear reactor in hydrogen generation facilities. Due to baseload characteristics, nuclear power plants could cooperate well with hydrogen production plants that use off-peak electricity and excess heat from nuclear power plants, thereby increasing the overall efficiency of the system. Nuclear energy may be a future alternative for hydrogen production, as it can operate large-scale hydrogen production without greenhouse gas 
emissions. All types of nuclear reactors would be used for such a production process as they could supply sufficient electrical and thermal power.

\section{Nuclear Energy in Canada}

The Canadian nuclear industry was established in 1942 when a decision was made to develop a design for a heavy water nuclear reactor and to build Canada's first nuclear power plant. The so-called 20 MWe Nuclear Power Demonstration Reactor started operation in 1962. The concept successfully demonstrated the unique approach of on-power refueling using natural uranium fuel and heavy water as a moderator and coolant. Currently, nuclear power accounts for around 15 percent of Canada's electricity from 17 units with a capacity of 14.071 GW (Natural Resource Canada, 2018). The renewed interest in nuclear energy has been driven by increased demand and the desire to meet Canada's $\mathrm{CO}_{2}$ emissions mitigation targets.

Nuclear power is the source of low $\mathrm{CO}_{2}$-emitting energy that represented the $60 \%$ of the Ontario's electricity generation and around 15\% of Canada's total electricity production in 2015 (Ontario Ministry of Energy, 2017). The existing reactors in Ontario are considered mainly as GEN- II designs. Generation-III reactors are currently being considered for construction with the goal of an evolutionary improvement in safety and economics as compared to existing Generation-II stations. Moreover, Canada, as a member of GIF, focuses on the development of a pressure-tube type SCWR concept with heavy water moderation based on the pressurized heavy water reactor (PHWR) or Canadian Deuterium Uranium Reactor (CANDU) technologies.

\subsection{Hydrogen as an Energy Carrier}

With more focus on energy security concerns, global population growth, economic development, reducing the momentum of climate change and our dependency on fossil fuels, researches are more driven towards strengthening renewable energy solutions in the long term. Hydrogen and hydrogen carriers are considered as promising solutions as a medium for storage and transportation of energy. Hydrogen is the most common element on earth and water is the most common source of hydrogen. The heating value per unit of hydrogen weight is much higher than that of conventional fuels. Hydrogen, however, cannot easily be kept in condensed phase because its density is too low. Therefore, the 
calorific value of hydrogen per unit volume, regardless of its storage method, is the lowest compared to conventional fuels. However, the efficiency of hydrogen-powered power generation systems is much higher than that of traditional fuels, which compensates for the problem of the low hydrogen storage density (Naterer et al., 2010).

Storage and transportation of hydrogen is an essential issue regarding safety and cost because hydrogen is in gas form under ambient pressure and temperature, and requires specific conditions to store safely and economically. Hydrogen storage takes place either by compression at very high pressures ( 800 bar) or by liquefaction at cryogenic temperatures (below $-150^{\circ} \mathrm{C}$ ). Liquefaction increases the price of hydrogen by at least 30 percent per kilogram, and if the storage tank is maintained at cryogenic temperatures, the price increases even more (Zamfirescu and Dincer, 2009). The compression process of hydrogen is also expensive because hydrogen's flammability limits are wide presenting high explosion risks; therefore extra safety measures have to be taken into account for hydrogen distribution, which also makes a significant contribution to hydrogen storage cost.

Because of difficulties in storing hydrogen in compact form, the energy density of hydrogen per unit volume is extremely low compared to other conventional fuels used in automotive applications. For example, hydrogen has four times lower volumetric energy density compared to gasoline when hydrogen is stored in liquid form at $-235^{\circ} \mathrm{C}$, which is impractical for long-term for vehicular applications, or 16 times less when hydrogen is stored at $25^{\circ} \mathrm{C}$ and 200 bar pressure (Zamfirescu and Dincer, 2008). Because of the reasons described above, the hydrogen economy currently appears to be impracticable. All these disadvantages of hydrogen can, however, be eliminated with a suitable storage medium, such as ammonia.

\section{Canada's R\&Ds on Nuclear-based Hydrogen Production Concept}

In Canada, hydrogen is currently produced at a rate of 3 million t/a. Thirty-five percent of this hydrogen is used for chemicals, 24 percent for refining, 23 percent for heavy oil upgrading and 18 percent for chemical by-products (Baindur, 2008). Hydrogen R\&D activities have been launched by the National Research Council within the Fuel Cell and Hydrogen Programme and have been managed by Natural Resources Canada since 1985. 
As a prominent result of researches, Canada developed the world's first fuel cell bus in 1993 based on Ballard's polymer electrolyte membrane (PEM) fuel cells, and the hydrogenous low-temperature water electrolyzer (Scepanovic, 2003).

Canada, a founding member of GIF, has selected to develop the Generation IV supercritical water reactor (SCWR) based on the CANDU system. The use of the Canadian SCWR for hydrogen production is considered a realistic short term approach. In the context of GenIV reactors, more attention is being paid to cogeneration-facility researches in Canada. Atomic Energy of Canada Limited (AECL) studies to link GEN-4 SCWRs with a hydrogen production plant employing a $\mathrm{Cu}-\mathrm{Cl}$ thermochemical cycle. The study intends to enable cogeneration of electricity and $\mathrm{H}_{2}$ via very high temperatures supplied from SCWR reactors (Naterer et al., 2010).

\subsection{Ammonia as an Energy Carrier}

Ammonia is recognized as a promising clean energy carrier and hydrogen storage medium since ammonia is capable of environmentally benign combustion, exhausting water, and nitrogen only. The essential appealing of ammonia in the context of sustainable development is to have existing distribution infrastructure to deliver it in large scales. The existing industry has enough experience to handle ammonia safely because ammonia is one of the most synthesized chemicals in the world. Ammonia oxidation generates the same amount of water and nitrogen used during the ammonia synthesis. Ammonia can, therefore, be considered a completely recyclable carbon-free fuel.

Ammonia storage occurs in the same manner as propane at 8.6 bar of vapor pressure at 20 ${ }^{\circ} \mathrm{C}$. Besides, ammonia has a high energy content per volume unit comparable to gasoline. Ammonia is, therefore, an attractive option as a transport fuel. Compared to hydrogen, ammonia's energy cost per storage unit is three times lower. Furthermore, ammonia transport is much safer and more practical than hydrogen since ammonia has a narrow flammability range and ammonia leakage can be detected easily due to its characteristic smell. Ammonia has a high volumetric energy density comparable to conventional fuels such as gasoline, liquefied petroleum gas (LPG), compressed natural gas (CNG). Fig. 1 shows the volumetric density vs. Gravimetric energy density of different fuels and ammonia. 


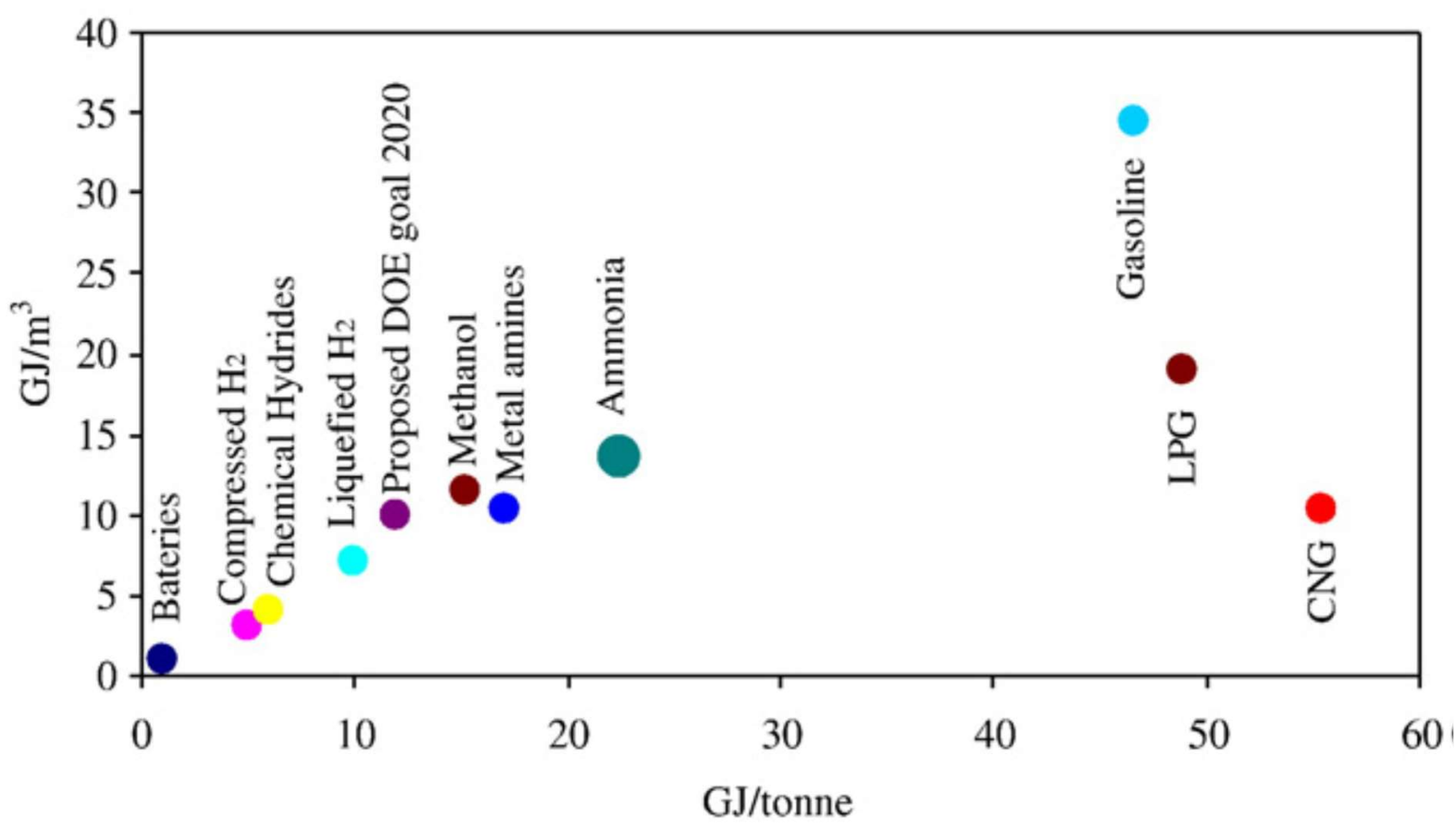

Figure 1.2: Comparison of volumetric energy densities and specific energy densities of various fuels (Adapted from Zamfirescu and Dincer, 2008).

In Figure 1.2, the vertical axis is the volumetric energy density of the fuels, and the horizontal axis means the energy densities. It is essential to compare ammonia with other conventional fuels with volumetric and specific energy densities in order to reveal ammonia capacity as a sustainable fuel. In energy storage applications, energy density refers to the energy storage mass to the storage facility volume, e.g., a fuel tank. Higher energy density implies that more energy can be stored or transported for the same volume; therefore more useful work can be done with the same amount of fuel with higher energy density. Specific/gravimetric energy density means fuel energy per unit mass. In the fig. 1, ammonia is represented vertically at $13.6 \mathrm{GJ} / \mathrm{m}^{3}$ and horizontally at $22.5 \mathrm{GJ} /$ tonne, making ammonia an appealing substance as a fuel.

The initial use of ammonia as fuel falls back to 1940s. The first utilization of ammonia as fuel took place in Belgium in 1943 (Hofstrand, 2009). During WW2, ammonia fueled motor-buses were utilized, and they made thousands of kilometers. The main problem with ammonia utilization as fuel in conventional ICE is that ammonia has low combustion intensity such as high ignition temperatures and slow burning speeds; therefore ammonia 
utilization via ICEs requires unique design characteristics. Instead of these complexities, the industrial market preferred to keep going with conventional fossil fuel-based ICEs. Moreover, low prices and relatively easier production processes of fossil fuels made alternative energy carriers impossible to challenge fossil fuels. However, today, energy resources are considered from the perspective of pollution, the gradual depletion of natural resources and import dependency. In this context, ammonia is one of the best alternatives to mitigate fossil fuel dependency as it is clean and utilizes water and air as feedstock which is available everywhere. Therefore, the timing is perfect for emphasizing ammonia's potential as an energy carrier.

Due to its carbon-free combustion characteristic, ammonia is getting more attention in today's clean energy context. Moreover, since WW2, further studies have been practiced by many researchers regarding the utilization of ammonia as fuel which has proven the feasibility of ammonia fuel for transportation applications. Ammonia is a promising alternative fuel to conventional ones concerning cost as well. As mentioned earlier, ammonia's cost per volume of stored energy is much cheaper than that of hydrogen. Beyond that, ammonia appears to be the least expensive fuel concerning \$ per GJ stored on board (Table 1.2). Table 1.2 indicates the data on the characteristics of listed fuels, which were compiled from Zamfirescu and Dincer (2008); fuel and storage's types, fuel pressures in the tank, fuel densities in the tank, energy densities, specific volumetric costs, and specific energy costs of listed fuels and ammonia.

It can be seen from Table 1.2 that the energy density of ammonia is three times less than that of gasoline. On the other hand, the specific volumetric cost of gasoline is very high. Besides its high specific costs, gasoline emits a significant amount of $\mathrm{CO}_{2}$ and other pollutants when decomposed in an ICE, whereas ammonia does not contain any carbon atom and its combustion is a carbon-free process which may be pointed out as the most appealing characteristic of ammonia on the top of all. However, the toxicity problem of ammonia may be seen as a drawback in vehicular storage. Leakage of ammonia in case of a car crash may cause side effects to the living species. Innovative ways of ammonia storage can solve this problem. Zamfirescu \& Dincer (2008) address the metal amine onboard storage of ammonia to overcome this obstacle. Ammonia can only be released at 
high temperatures (at $350{ }^{\circ} \mathrm{C}$ or more) in metal amine storage. On the other hand, the needed energy for ammonia release may lead to a specific energetic cost increase to 17.5 $\$ / G J$ that can be seen in Table 1.2 .

Table 1. 2: Comparison of ammonia with other fuels by means of listed characteristics (Modified from Zamfirescu and Dincer, 2008).

\begin{tabular}{|c|c|c|c|c|c|}
\hline Fuel/ Storage & $\begin{array}{c}\text { Pressure } \\
\text { (bar) }\end{array}$ & $\begin{array}{l}\text { Density } \\
\left(\mathrm{kg} / \mathrm{m}^{3}\right)\end{array}$ & $\begin{array}{l}\text { Energy } \\
\text { density } \\
\left(\mathbf{G J} / \mathbf{m}^{3}\right)\end{array}$ & $\begin{array}{c}\text { Specific } \\
\text { volumetric } \\
\text { cost }\left(\$ / \mathbf{m}^{3}\right)\end{array}$ & $\begin{array}{l}\text { Specific } \\
\text { energetic cost } \\
\text { (\$/GJ) }\end{array}$ \\
\hline $\begin{array}{c}\text { Gasoline, } \mathrm{C}_{8} \mathrm{H}_{18} / \text { liquid } \\
\text { tank }\end{array}$ & 1 & 736 & 34.4 & 1000 & 29.1 \\
\hline $\begin{array}{l}\mathrm{CNG}, \mathrm{CH}_{4} / \text { integrated } \\
\text { storage system }\end{array}$ & 250 & 188 & 10.4 & 400 & 38.3 \\
\hline $\begin{array}{c}\text { LPG, } \mathrm{C}_{3} \mathrm{H}_{8} / \text { pressurized } \\
\text { tank }\end{array}$ & 14 & 388 & 19 & 542 & 28.5 \\
\hline $\begin{array}{l}\text { Methanol, } \mathrm{CH}_{3} \mathrm{OH} / \\
\text { liquid tank }\end{array}$ & 1 & 749 & 11.4 & 693 & 60.9 \\
\hline $\begin{array}{l}\text { Hydrogen, } \mathrm{H}_{2} / \text { metal } \\
\text { hydrides }\end{array}$ & 14 & 25 & 3.6 & 125 & 35.2 \\
\hline $\begin{array}{l}\text { Ammonia, } \mathrm{NH}_{3} / \\
\text { pressurized tank }\end{array}$ & 10 & 603 & 13.6 & 181 & 13.3 \\
\hline $\begin{array}{l}\text { Ammonia, } \mathrm{NH}_{3} / \text { metal } \\
\text { amines }\end{array}$ & 1 & 610 & 10.4 & 183 & 17.5 \\
\hline
\end{tabular}

Ammonia is one of the most commonly used and synthesized chemicals in the world. Due to all appealing features stated earlier, ammonia can be one of the vital substance for the future economy including transportation, energy sector, refrigeration, agriculture. Today, ammonia synthesis consumes roughly $1.2 \%$ of total global energy while contributing $0.93 \%$ of greenhouse gas (GHG) emissions (Gilbert and Thornley, 2010). Natural gas is the primary feedstock of ammonia production for today. Renewable technologies, such as nuclear power, may be adopted in ammonia production processes to mitigate the GHG emissions during a large scale ammonia production for the future economy. Nuclear power is considered as one of the renewable energy sources because the energy production process within a nuclear power plant (NPP) does not produce direct emissions. Moreover, current NPPs mostly operate as base-load, which means that the plant operates in the same 
manner without considering the rate of energy demand. Therefore, excess thermal and electrical energy occur during an NPP's operation. Combining an NPP with an ammonia production plant may increase the base-load output so that the overall cost of electricity decreases (Bicer et al., 2017). Because of high thermal and electrical energy outputs, nuclear-based ammonia production is a promising method for a large-scale ammonia production, which is also investigated in this study.

Ammonia can be synthesized by extracting nitrogen from air and hydrogen from water, for which any type of energy sources can supply energy. For such operation, the Haber-Bosch synthesis process is a mature technology, which was invented by Fritz Haber and Carol Bosch in 1913 (Modak, 2002). Today, around 90\% of ammonia synthesis in the world is realized by the Haber-Bosch process. The current study also utilizes The Haber-Bosch process for ammonia synthesis. Haber-Bosch Process combines hydrogen derived from water with nitrogen from the air into ammonia. The reaction given below happens at a pressure between 100 and 250 bars, and a temperature between $350^{\circ} \mathrm{C}$ and $550{ }^{\circ} \mathrm{C}$ (Morgan et al., 2014). The equation indicates that the reaction is reversible, and the production of ammonia is exothermic, releasing energy. Since the reaction happens at high temperatures (between $350{ }^{\circ} \mathrm{C}$ and $550{ }^{\circ} \mathrm{C}$ ), excess heat may be utilized to feed system back via the Rankine cycle to enhance system efficiency.

$$
\mathrm{N}_{2}(\mathrm{~g})+3 \mathrm{H}_{2}(\mathrm{~g}) \leftrightarrow 2 \mathrm{NH}_{3}(\mathrm{~g}) \quad \Delta \mathrm{H}_{\mathrm{f}}^{\circ}=-92.5 \mathrm{~kJ}
$$

In the Haber-Bosch process, required nitrogen may be supplied through cryogenic air separation. Cryogenic air separation is presently considered as the most efficient process for generating a significant amount of nitrogen for ammonia synthesis, as it also is utilized in the current study. The air separation unit produces nitrogen required for the production of ammonia from air and around $78 \%$ of air consist of nitrogen molecules. The cryogenic air separation is a conventional and commercially employed method in the production of nitrogen on a large scale. The cryogenic air separation consists of three primary processes; cleaning the air, liquefying the air, and distillation of the liquid air. The process ends up with around 99\% pure nitrogen product (ECI, 2016).

For hydrogen production in a large-scale, the most promising hydrogen cycles are copperchlorine $(\mathrm{Cu}-\mathrm{Cl})$ cycle, Cerium-Chlorine $(\mathrm{Ce}-\mathrm{Cl})$ cycle, Iron-Chlorine $(\mathrm{Fe}-\mathrm{Cl})$ cycle, 
Vanadium-Chlorine ( $\mathrm{V}-\mathrm{Cl})$ cycle, Copper-Sulfate $\left(\mathrm{Cu}-\mathrm{SO}_{4}\right)$ cycle, Hybrid-Chlorine cycle (Naterer et al., 2009). Most of these cycles require very high process heats. Compared to others, $\mathrm{Cu}-\mathrm{Cl}$ is a promising alternative and more likely process since it requires lower temperatures $\left(550^{\circ} \mathrm{C}\right)$. For such operation, NPPs may supply efficient and sustained energy. However, thermochemical cycle based hydrogen production processes is more realistic and practicable if they are considered with next-generation reactor concepts which operate with higher temperatures. Another way of hydrogen production via NPPs is electrolysis. Electrolysis must be considered in two main categories; conventional electrolysis which utilizes electrical energy to decompose water into hydrogen and oxygen, and high-temperature electrolysis which partly uses thermal energy to decrease electrical energy usage in electrolysis process of water. For hydrogen supply to ammonia synthesis, $\mathrm{Cu}-\mathrm{Cl}$ thermochemical cycle, conventional electrolysis, and high-temperature electrolysis are investigated separately in this study and required thermal and electrical energy is supplied from NPPs.

\subsubsection{Potential Applications for utilizing Ammonia as a Substance}

Ammonia-fueled ICE Application

Since it contains high octane, ammonia is an appropriate fuel for internal combustion engines (ICE). However, the state of this art may require some adjustments in ICE technology. When ammonia is combusted in an ICE, the combustion produces a flame with a relatively low ignition speed. The low combustion rate of ammonia induces combustion to be inconsistent under high engine speed operating conditions. The Caterpillar Corporation comes up with two solutions to this problem in their patent. One solution is to employ a liquid combustion promoter. However, this approach carries additional complexity, weight, and cost to the system. The second approach of the patent to the problem is to use hydrogen as a combustion promoter. The fixed proportion of the ammonia can be cracked into hydrogen and nitrogen via an onboard reformer placed between the fuel tank and the engine. However, the patent states that the fluctuating amount of the required promoter with varying engine loads and speed can cause control issues (Gong et al., 2010). Ammonia energy advocates look forward to using ammonia in ICEs, but as of today, ammonia fueled ICE concept requires further feasibility studies. 


\section{Ammonia-fed Fuel Cell Applications}

Ammonia can also be used for the use of fuel cells. It can be decomposed through ammonia electrolysis, and a high quantity of hydrogen substances can become useful work through fuel cells. An ammonia-fed solid oxide fuel cell (SOFC) is described as the most efficient way of utilizing ammonia in a fuel cell directly (Afif et al., 2016). The first ammonia-fed SOFC research was conducted by Vayenas and Farr, which was based on yttria-stabilized zirconia (YSZ) electrolyte and platinum electrodes for cogeneration of electricity and nitric oxide (Vayenas et al., 1980). If an iron-based catalyst is used as an anode to facilitate the decomposition of ammonia, the reaction occurs as follow, in which NO bearing on the anode side is avoided (Wojcik et al., 2003):

$$
2 \mathrm{NH}_{3} \rightarrow \mathrm{N}_{2}+3 \mathrm{H}_{2}
$$

It is recommended to run an ammonia fuel cell at high temperature since the thermal decomposition of ammonia becomes significant at a temperature above $500{ }^{\circ} \mathrm{C}$ (Lan et al., 2014). However, high operational temperatures bring challenges by means of performance durability and costing on fabricating of the cells.

Low-temperature proton exchange membrane fuel cells (PEMFCs) consuming hydrogen as the fuel have been employed in various applications including electric vehicles. Ammonia itself is not a proper fuel for PEMFC applications since ammonia may poison anode catalyst. However, ammonia can be used as hydrogen production feedstock, and produced hydrogen can be fed into PEMFC for useful work generation (Boggs et al., 2009). Moreover, ammonia fueled alkaline membrane fuel cells (AFMCs), using nickel anode and $\mathrm{MnO}_{2}$ cathode, are under development. AMFCs' operation happens in the same manner as traditional AFCs- via the transfer of hydroxide ions through the electrolyte. The overall reaction occurs in the fuel cell is as follow:

$$
4 \mathrm{NH}_{3}+3 \mathrm{O}_{2} \rightarrow 2 \mathrm{~N}_{2}+6 \mathrm{H}_{2} \mathrm{O}
$$

However, the idea of ammonia fuel cells based on alkaline membrane electrolytes have some drawbacks that are needed to be addressed. First of all, it is difficult to identify a proper anode and cathode catalyst; second, the cross-over of ammonia through the 
polymeric membrane electrolyte may decrease the efficiency; and third, oxidation of diffused ammonia at cathode may generate toxic NO (Suzuki et al., 2012).

\section{Ammonia as a Refrigerant}

Ammonia is an alkaline, colorless chemical compound which is well recognized as the basis for many agricultural, industrial and commercial purposes. Today, ammonia is also widely investigated as an alternative refrigerant to conventional ones since it has a low boiling point $\quad\left(-33.3{ }^{\circ} \mathrm{C}\right.$ at $\left.0 \mathrm{~atm}\right)$ and high latent heat of vaporization (ASHRAE, 2017). Furthermore, ammonia has an ozone depletion potential (ODP) of zero, and it does not directly contribute to global warming due to not containing carbon atom; therefore, ammonia may be considered as an environmentally benign refrigerant. Due to the short lifetime (a few days) of ammonia in the atmosphere, it is considered to be biodegradable. Applications for ammonia-based refrigeration systems include thermal storage systems, HVAC chillers, process cooling, air conditioning, and so on.

As indicated earlier, ammonia has unique characteristics to compete with conventional fuels on onboard storage applications. This concept brings one more advantage that should be pointed out. Zamfirescu and Dincer (2008) proposed a novel system that utilizes the refrigerant effect of the onboard stored liquid ammonia. They presented two ways to exploit the refrigerant effect of the ammonia; first, fuel tank with refrigeration coil, and second, work and refrigeration from $\mathrm{N}_{2}$ expansion. They concluded that exploiting the refrigerant effect of ammonia on $70 \mathrm{~kW}$ engine fuelled with ammonia delivers $5 \mathrm{~kW}$ of cooling, while this figure is $0.84 \mathrm{~kW}$ with similar power propane fuelled engine. In other words, the system allows saving $2.5 \mathrm{~kW}$ from the shaft torque if ammonia refrigerant effect is employed instead of a mechanical air conditioner. Furthermore, the simplicity of this system decreases both the initial, and operation and maintenance cost remarkably by replacing the conventional mechanical air-conditioning system.

\section{Concerns related to Ammonia}

While the benefits of ammonia are emphasized (high energy efficiency, environmentally benign, broad economic uses, and so on), toxicity and corrosion effect of ammonia in potential applications, and the barriers these drawbacks brings in should be addressed as well. These barriers generally relate to human health and ammonia system installation cost. 
Ammonia reacts with copper in the presence of air or water. Therefore, ammonia systems are designed using aluminum, carbon steel, and stainless steel components.

Ammonia's sharp, irritating smell helps reduce exposure to potentially dangerous concentrations. The average smell threshold is $5 \mathrm{ppm}$, well below concentrations that may cause harmful effects to human health. Table 3 which is retrieved from ASHRAE report upon evaluation of ammonia as a refrigerant, shows the effects of various concentrations of ammonia.

Table 1. 3: The effects of various concentration of ammonia (Modified from ASHRAE, 2017).

\begin{tabular}{|l|l|}
\hline Concentration & Effect \\
\hline $5 \mathrm{ppm}$ & Average smell threshold (well below harmful health effect) \\
\hline $100-200 \mathrm{ppm}$ & Irritated eyes \\
\hline $300 \mathrm{ppm}$ & Respiratory protection required above this level \\
\hline $400 \mathrm{ppm}$ & Immediate throat irriatation \\
\hline $500 \mathrm{ppm}$ and below & No permanent eye damage to even chronic exposure \\
\hline $1700 \mathrm{ppm}$ & Cough \\
\hline $2400 \mathrm{ppm}$ & Threat to life after 30 minutes \\
\hline $5000+$ ppm (vapor) & Full body chemical suit required \\
\hline $5000+$ ppm (pure liquid) & Second degree burns \\
\hline $7388 \mathrm{ppm}$ & One hour LC 50 , lethal concentration \\
\hline
\end{tabular}

The characteristic odor brings ammonia to an alarming effect which is recognizable by virtually everything that regularly deals with and works on ammonia systems. Thus, small leaks can be detected and repaired quickly.

The toxicity drawbacks regarding ammonia uses have been addressed by many researchers and these downsides have been largely eliminated by innovative experiences. To compensate for the toxicity problem of ammonia-fed applications, ammonia adsorption in porous metal amine complexes is adressed, e.g., hexaaminemagnesium chloride, $\left(\mathrm{Mg}\left(\mathrm{NH}_{3}\right)_{6} \mathrm{Cl}_{2}\right)$. In this technique, ammonia passes over an anhydrous magnesium chloride $\left(\mathrm{MgCl}_{2}\right)$ powder at room temperature. The absorption and desorption of ammonia from $\mathrm{MgCl}_{2}$ are entirely reversible reactions. However, within this approach, energetic cost to 
release the ammonia stored in the form of hexaaminemagnesium chloride $\left(\mathrm{Mg}\left(\mathrm{NH}_{3}\right)_{6} \mathrm{Cl}_{2}\right)$ must be considered (Zamfirescu and Dincer, 2008).

\subsection{Motivation}

Today, feedstocks used for global ammonia production consist mainly 72 percent natural gas (NG), 22 percent coal and 4 percent fuel oil, which contribute about 420 million tons of $\mathrm{CO}_{2}$ emissions per anum, representing more than 1 percent of global energy-related emissions (Bicer et al., 2017). The most optimistic energy consumption values of ammonia synthesis via NG, coal, and fuel oil are 7.8, 10.6, and 11.7 MWh per ton of ammonia, respectively, and the corresponding $\mathrm{CO}_{2}$ emissions are 1.6, 3.0, and 3.8 tons per ton of ammonia (IFA, 2009). On the other hand, research and development of environmentally benign alternatives for the production of ammonia are vital for the realization of ammoniafed energy applications within the framework of the new global carbon-free energy concept. The term green ammonia is discussed today among global energy authorities in this regard.

Global consumption of ammonia is expected to increase by $\sim 50$ percent by 2050 due to the growing global population and food demand and global efforts to decarbonize its economy. Furthermore, as already mentioned, the interest in ammonia for energy applications is snowballing, which will further increase the demand for ammonia. Therefore, there will be a growing room for emissions-free ammonia. Wind and solar energy are commonly mentioned for the production of carbon-neutral ammonia. However, nuclear energy seems to be wiser for large-scale ammonia production, as it can supply both thermal and electric power to the production chain, making it possible to employ various production processes such as thermochemical and thermoelectrical processes rather than adhering to electrolysis. Nuclear carbon-free ammonia is, therefore, a promising concept for the future-oriented growing global demand for ammonia.

Although its toxicity, ammonia as energy carrier appears as one of the most attractive alternative to fossil fuels due to the following facts;

- It is a carbon-free, entirely recyclable fuel because its oxidation only exhausts water and nitrogen. 
- It can readily be synthesized from common substances water and nitrogen available everywhere.

- It has an existing distribution infrastructure, thus it can be delivered in large amounts without extra investments.

- It has a high volumetric energy density which is comparable the one that of conventional fuels.

- It has a narrow flammability range and therefore, it can be stored onboard safely.

- It is already a vital substance, used currently as a refrigerant, fertilizer, chemical feedstock, and nowadays sustainable energy carrier.

- Innovative storage alternatives can easily eliminate its toxicity and corrosive drawbacks.

- Because of its high octane rate, ammonia can be used in ICEs with small modifications, and directly in fuel cells.

\subsection{Scope and Objectives of the Study}

In this study, nuclear-based hydrogen and ammonia production is investigated by means of environmental impacts. Required thermal and electrical energy for production processes is supplied from NPPs. For hydrogen supply, thermochemical 3-, -4, and -5 step $\mathrm{Cu}-\mathrm{Cl}$ cycles, conventional electrolysis, and high-temperature electrolysis will be comparatively assessed to describe the most convenient option by means of environmental impacts. A cryogenic air separation unit is adopted in this study to provide nitrogen for ammonia synthesis. A Haber-Bosch unit is employed for efficient ammonia synthesis. All process will be investigated by means of life cycle impact assessment (LCIA) via LCA tools. Different variations will be demonstrated for a comparative assessment.

Even though hydrogen and ammonia are considered as clean fuel during their use phase within direct combustion or fuel cells, the production processes of hydrogen and ammonia should be investigated carefully as well. For a comprehensive analysis of the selected production processes of hydrogen and ammonia regarding environmental impacts, life cycle assessment (LCA) is a useful technique that helps to investigate a process from the cradle to the grave. The purpose of the use of the LCA technique is to analyze the environmental impact of a product or process over its lifetime. There are many different 
assessment methods performed so far to categorize and characterize the environmental impacts of systems. CML 2001 method, which was developed by a group of scientists under the principal of CML (Center of Environmental Science of Leiden University) in 2001, proposes a group of impact classes for the impact assessment phase. In this study, the proposed hydrogen and ammonia synthesis techniques are analyzed through LCA method by considering the CML 2001 assessment method to investigate the environmental impacts of the process. SimaPro software is utilized to perform a life cycle impact assessment in this study.

The primary objective of this study is to investigate the nuclear-based hydrogen and ammonia synthesis by means of environmental impacts via life cycle assessment technique. Moreover, the cost analysis of various hydrogen production scenarios regarding hydrogen production method, hydrogen storage, transportation, and nuclear power plant are comparatively evaluated with the Hydrogen Economy Evaluation Program (HEEP). The specific objectives can be summarized as follows:

1. To conduct an LCA study of nuclear based hydrogen and ammonia production methods namely, conventional water electrolysis, high temperature water electrolysis, 3-,4-, and 5 step $\mathrm{Cu}-\mathrm{Cl}$ cycles.

2. To obtain the results of the conducted LCA study in terms of selected CML 2001 impact categories namely, abiotic depletion potential (ADP), acidification potential (AP), global warming potential (GWP), ozone depletion potential (ODP), and human toxicity potential (HTP), and discuss the obtained results to identify the most environmentally benign path for nuclear-based hydrogen and ammonia production.

3. To compare the LCA results with conventional hydrogen and ammonia production methods via steam methane reforming (SMR).

4. To determine the major sub-processes contributing the selected impact categories most.

5. To investigate the impact of nuclear power plant selection on environmental impacts of nuclear based hydrogen production, and compare the LCA results of production processes fed by different types of reactors. 
6. To perform a cost analysis of various nuclear hydrogen production methods by using the HEEP software. 


\section{CHAPTER 2: LITERATURE REVIEW}

In this chapter, a comprehensive review of the literature regarding the systems and technologies utilized in this study is presented. Furthermore, the LCA studies carried out on hydrogen and ammonia production methods are described and reviewed. This thesis is based on life cycle assessment of nuclear-based hydrogen and ammonia production via five different ways namely, conventional water electrolysis, high-temperature water electrolysis, 3-,4-, and 5 step copper-chlorine $(\mathrm{Cu}-\mathrm{Cl})$ cycle. Nowadays, hydrogen is pointed as one of the most promising energy carriers for the future since it is an energyefficient and carbon-free fuel. Combustion of hydrogen with air or utilization of hydrogen in a fuel cell are environmentally benign processes that exhaust only water and a small amount of NOx. Furthermore, many compounds, such as water, fossil fuels, and biomass can be utilized as feedstocks for hydrogen production. However, the issues regarding the storage and transportation of hydrogen need to be addressed when hydrogen is discussed as an energy carrier.

Ammonia is another popular compound discussed among energy authorities recently. Combustion of ammonia or using ammonia in a fuel cell is also a carbon-free environmental benign process. Since ammonia is already produced massively, today's industry has enough experience to handle ammonia safely. Therefore, ammonia, which can be utilized as a medium for hydrogen storage, may accelerate the transition to hydrogenbased energy applications by eliminating the safety and energy efficiency concerns relating the storage and transportation of hydrogen.

\subsection{Hydrogen Production}

Hydrogen can be synthesized utilizing many different techniques such as water electrolysis, thermochemical water splitting and steam methane reforming (SMR), all of which can be powered by a different type of energy sources including nuclear energy, fossil

fuels, and renewables. Today, almost nine out of ten of global hydrogen production is achieved via fossil fuels. Natural gas-fed SMR is the most common method. Therefore, conventional ways of hydrogen production emit a significant amount of GHG emissions. Thus, new techniques for hydrogen production have been investigated. 
Dincer and Acar (2015) examined and comparatively assessed various potential hydrogen production methods from renewable and non-renewable sources for the environmental impact, costs, energy efficiency and exergy efficiency. The study also included social carbon costs in order to show the relationship between environmental and economic factors. The results of the study show that photonic energy based hydrogen production was more environmentally benign than the other selected methods in terms of emissions. Dincer and Acar note that increasing both energy and exergy efficiencies and decreasing the costs of hydrogen production from solar based hydrogen production had a potential to bring them forefront as potential options.

Dincer (2012) conducted a study discussing environmentally friendly and sustainable techniques for hydrogen production and categorizing them according to the driving sources and applications. Renewable sources, nuclear energy, and energy recovery processes are pointed as energy driven sources for electrical, thermal, biochemical and so on. The study presents various case studies to highlight the importance of green hydrogen production methods and systems for practical applications.

Christopher et al. (2012) compared hydrogen production processes utilizing various renewable energy sources. The comparison is based on the exergy and efficiency of the employed methods. Utilized renewable energy sources in the study are wind power, solar energy, hydroelectric power, and biomass. Electricity received from these renewable energy sources is used for the electrolysis process of water to produce hydrogen. The liquefaction process of hydrogen is also taken into account. The study reveals that the hydrogen production process with the highest exergy efficiency is the electrolysis with the value of $5.6 \%$ using the electricity from hydrogen power, whereas solar energy photovoltaics based hydrogen production process yields the lowest exergy efficiency with the value of $1.0 \%$.

Pilavachi et al. (2009) conducted a study comparing seven hydrogen production methods namely, steam methane reforming (SMR), partial oxidation of hydrocarbons (POX), coal gasification (CG), biomass gasification (BG), the combination of photovoltaics and electrolysis (PV-EL), the combination of wind power and electrolysis (W-EL) and the combination of hydropower and electrolysis (H-EL). The systems are compared in terms 
of $\mathrm{CO}_{2}$ emissions, operation and maintenance costs, capital cost, feedstock cost and hydrogen production cost. The study reveals that renewable based hydrogen production (PV-EL, W-EL and H-EL) rank higher in classification than conventional methods.

Ozbilen et al. (2013) evaluated and compared varios hydrogen production processes by considering different energy sources and using life cycle analysis. The study shows that hydrogen production via thermochemical water decomposition cycles are more environmentally friendly methods compared to conventional SMR of natural gas. The results also indicate that the nuclear-based four-step $\mathrm{Cu}-\mathrm{Cl}$ cycle yields the lowest global warming potential since it reuqires the lowest quantity of energy among considered methods. In terms of acidification potential, biomass gasification has the highest enviromental impact. The study also investigates the relation between efficiency and environmental impacts.

There are many studies regarding SMR method in open literature since this is the most common method for hydrogen production. Simpson et al. (2007) investigated the performance of hydrogen production via steam methane reforming (SMR) using exergy analysis, with emphasis on exergy flows, destruction, waste, and efficiencies. Exergy and energy efficiencies of the system are determined as $67 \%$ and $63 \%$, respectively. Exergy waste is calculated as $37.3 \%$ of the total exergy. It is observed that the majority of exergy destruction occurs because of high irreversibility of chemical reactions and heat transfer. Furthermore, it is highlighted that a significant amount of exergy, which consists the 19\% of total exergy, is wasted in the exhaust system. The results of this study offer guidance for where researches in hydrogen production via SMR should be focused. The following sections briefly review hydrogen production methods via water electrolysis and thermochemical water splitting, respectively, both of which are the main focus of this study.

\subsubsection{Conventional and High Temperature Water Electrolysis}

Water electrolysis is the traditional method to produce hydrogen by water splitting which is done by passing an electric current through water. Honnery et al. (2009) conducted a study presenting an estimation of global hydrogen and electricity generation from onshore wind. Global wind energy was assumed by replacing one $2 \mathrm{MW}$ turbine $/ \mathrm{km}^{2}$ over the 
surface of the earth. The study considers hydrogen production via low-pressure electrolysis and hydrogen transmission via high-pressure gas pipelines. The system provides both hydrogen and energy for electricity consumption at the local generation site. The study results that the total annual supply reduces to 229 EJ by constraining turbine placement and wind speed.

Ursua et al. (2012) studied water electrolysis techniques for hydrogen production. The study also surveys the state of the art of water electrolysis operated with renewable energies. Thermodynamic and thermochemical processes are investigated first to understand how electrolysis cells operate. Then, a discussion is led regarding the electrolysis and properties, benefits, disadvantages, and challenges of the three main existing technology of electrolysis namely, alkaline, polymer electrolytes, and solid oxide electrolytes. The study finally presents the possible configurations for integrating water electrolyses in autonomous and grid-connected systems with renewable energies.

Perez-Herranz et al. (2010) investigated a system to control and monitor the operating parameters of an alkaline electrolyser and a metal hydride storage system that allow for continuous hydrogen production. The study suggests the seasonal storage of solar or wind energy in the form of hydrogen. To do so, water electrolysis is pointed as a convenient method for converting electrical energy into a chemical form. The required power is supplied through a photovoltaic array. Hydrogen storage as a metal hydrides is pointed as a reversible process to produce electricity from hydrogen via fuel cells when electricity is needed. Using the system ended up with a decrease in the specific power consumption, and increase in energy efficiency from $57.8 \%$ to $70 \%$.

Hydrogen production via high-temperature electrolysis is a promising method since it requires less electrical energy compared to conventional low-temperature water electrolysis, which leads to more favorable thermodynamic and electrochemical kinetic conditions for the reaction. Brisse et al. (2008) studied high-temperature steam electrolysis. The study reports on solid oxide cells performance as a function of the operating parameters temperature, humidity, and current density. A current density of $-1.4 \mathrm{~A} \mathrm{~cm}-2$ was achieved with $1.1 \mathrm{~V}$ cell voltage at an absolute humidity value below $70 \%$ and 900 ${ }^{\circ} \mathrm{C}$ corresponding $100 \%$ electrical cell efficiency. 
Shin et al. (2007) conducted a study focusing specifically on the calculation of the electrochemical thermodynamic properties and the overall thermal efficiency of the very high-temperature gas-cooled reactor (VHTR) assisted hydrogen production system by employing the high-temperature electrolysis of steam (HTES) technique. The study anticipated an overall feasible thermal efficiency of about $45 \%$ in the VHTR-assisted HTES system. Finally, the study defines the dominant factors the efficiency of the solid oxide cell and the thermal recuperating fraction in the case of the balance of the electricity.

\subsubsection{Thermochemical Water Splitting}

There are many different thermochemical cycles investigated in the literature, a few of which is feasible to progress beyond theoretical calculations to working experimental demonstrations due to economic reasons (Ozbilen et al., 2011). Among all thermochemical cycles, sulfur iodine (S-I) and copper-chlorine $(\mathrm{Cu}-\mathrm{Cl})$ cycles are pointed as the most feasible thermochemical cycles after considering several factors such as availability and abundance of materials, simplicity, chemical viability, thermodynamic feasibility and safety issues (Naterer et al., 2008).

The three-step S-I cycle is the most common one, although there are other types of S-I cycles available. Steps of the three-step S-I cycle are as followings:

- Step 1: Hydrolysis step (exothermic), at $393 \mathrm{~K}$,

$$
\mathrm{I}_{2}(\mathrm{l}+\mathrm{g})+\mathrm{SO}_{2}(\mathrm{~g})+2 \mathrm{H}_{2} \mathrm{O}(\mathrm{g}) \rightarrow 2 \mathrm{HI}(\mathrm{g})+\mathrm{H}_{2} \mathrm{SO}_{4}(\mathrm{l})
$$

- Step 2: Oxygen production step (endothermic), at $1123 \mathrm{~K}$,

$$
\mathrm{H}_{2} \mathrm{SO}_{4}(\mathrm{~g}) \rightarrow \mathrm{SO}_{2}(\mathrm{~g})+0.5 \mathrm{O}_{2}(\mathrm{~g})+\mathrm{H}_{2} \mathrm{O}(\mathrm{g})
$$

- Step 3: Hydrogen production step (endothermic), $723 \mathrm{~K}$,

$$
2 \mathrm{HI}(\mathrm{g}) \rightarrow \mathrm{I}_{2}(\mathrm{~g})+\mathrm{H}_{2}(\mathrm{~g})
$$

The first step occurs at $393 \mathrm{~K}$ as an exothermic reaction, which is called hydrolysis step. The second step is endothermic oxygen production step occured at $1123 \mathrm{~K}$. Lastly, the third step is hydrogen production step which is an endothermic reaction occuring at $723 \mathrm{~K}$ (Ozbilen et al., 2011). 
Prossini et al. (2009) proposed a thermochemical water-splitting cycle representing a modification of the classical sulphur-iodine cycle. Energy demand is decreased by replacing the distillation of the iodine phase with the evaporation of the excess of water and iodine. The distillation was achieved by neutralizing the hydrogen iodide in the iodine phase with nickel oxide. The results of the study indicates that thermal efficiency of the system was $20 \%$ without heat recovery.

The $\mathrm{Cu}-\mathrm{Cl}$ cycle performs a series of reactions to divide the water into hydrogen and oxygen. The cycle decomposes water into hydrogen and oxygen by the use of intermediate copper chloride compounds in a closed internal loop, which continually recycles all chemicals (Naterer et al., 2010). The three-, four-, and five-step $\mathrm{Cu}-\mathrm{Cl}$ cycles are the key variations of $\mathrm{Cu}-\mathrm{Cl}$ cycle. Detailed information about these variations will be given in the system description chapter.

Naterer et al. (2009) conducted a study presenting recent Canadian advance in nuclearbased hydrogen production by electrolysis and thermochemical $\mathrm{Cu}-\mathrm{Cl}$ cycle. The study contains individual process and reactor developments within the $\mathrm{Cu}-\mathrm{Cl}$ cycle, thermochemical properties, advanced materials, controls, safety, reliability, economic analysis of electrolysis at off-peak hours, and integrating hydrogen plants with Canada's nuclear power plants. The presented technologies in the study are still under investigation by a Canadian consortium, as part of the Generation IV International Forum (GIF) for hydrogen production from advanced nuclear reactors.

Orhan et al. (2008) assessed the hydrogen production step of the $\mathrm{Cu}-\mathrm{Cl}$ cycle by means of thermodynamic using energy and exergy methods and considering critical chemical reactions. The study also evaluates energy and exergy efficiencies of the $\mathrm{H} 2$ synthesis step and carries out parametric studies on energetic and exergetic aspects considering variable reaction and reference-environment temperatures. The study shows that the exergy destruction drops with increasing reaction temperature. The exergy efficiency of $\mathrm{H}_{2}$ production step is determined as $99 \%$ at a reaction temperature of $450{ }^{\circ} \mathrm{C}$ and a referenceenvironment temperature of $25{ }^{\circ} \mathrm{C}$. It is also highlighted that assuming hydrogen production is driven by nuclear-based heat yields an environmentally benign overall process. 
Wang et al. (2009) conducted a study comparing different types of $\mathrm{Cu}-\mathrm{Cl}$ cycles. The study analyzes the factors determining the number and useful grouping of steps. The study also analyzes and discusses the main engineering pros and cons of $\mathrm{Cu}-\mathrm{Cl}$ cycles with different amount of steps. It is revealed that the wateer requirement in the hydrolysis step is affected by a combination of drying and hydrolysis steps. Furthermore, the study points out that hydrogen can be produced either from electrolysis of cuprous chloride or from chlorination of copper by hydrogen chloride.

Rosen et al. (2010) studied the challenges and design issues of hydrogen production via $\mathrm{Cu}-\mathrm{Cl}$ cycles coupled with Canada's nuclear reactors. The study also describes the issues related to equipment scale-up and process simulation for $\mathrm{Cu}-\mathrm{Cl}$ cycles. Aspen Plus, process simulation code, is used to simulate the processes, which allowed the cycle efficiency and possible efficiency improvements to be examined. It is highlighted that the results were useful to assist in the development of a lab-scale cycle demonstration.

Ratlamwala et al. (2012) studied energy and exergy analyses of a $\mathrm{Cu}-\mathrm{Cl}$ cycle based hydrogen production system. The study analyzes an integrated $\mathrm{Cu}-\mathrm{Cl}$ cycle, Kalina cycle and electrolyzer for hydrogen production. The results of the study indicate that the performance of the cycle results in a negative trend after $328.6 \mathrm{~K}$. The maximum exergy destruction in the $\mathrm{Cu}-\mathrm{Cl}$ cycle occurred in the first separator and the heat exchanger of the Kalina cycle. Therefore, these two components are pointed to consider for performance improvement of the system.

Daggupati et al. (2010) conducted a study examining the cupric chloride solid conversion during hydrolysis in the $\mathrm{Cu}-\mathrm{Cl}$ cycle for hydrogen production. This step is pointed as a challenging step due to the excess steam requirement and decomposition of cupric chloride into cuprous chloride and chlorine. The study analyzes the hydrolysis and decomposition reactions concerning chemical equilibrium conversion and reaction kinetics. The examined operating parameter on equilibrium conversion is the temperature, pressure and excess steam. The hydrolysis reaction was found to be dependent on the pressure, temperature, the steam mole ratio and the composition of inert gas for higher solid conversion. In addition, the decomposition of solid and chlorine formation will increase with higher temperatures. 


\subsection{Ammonia Production}

Ammonia is already produced as one of the main industrial chemicals in the world. Today, more than $70 \%$ of global ammonia production is achieved by steam reforming of natural gas (SMR), which contributes around 1\% of global GHG emissions. Although there many different approaches to ammonia production in the literature, today, two main methods are operating for ammonia production in the world namely, Haber-Bosch process and solid state ammonia synthesis process. In both processes, nitrogen is supplied from the cryogenic air separation process. Since ammonia synthesis is a very energy and capital intensive process, cryogenic air separation technique, which is known to be economic and mature technique to produce high-purity nitrogen, is preferred as nitrogen supplier in the ammonia production processes to mitigate costs.

\subsubsection{Electrochemical Ammonia Production}

In the literature, there are many studies in search for more efficient and economic ammonia production processes. The electrochemical route is considered as having the potential to substantially reduce the energy input and the complexity of the production process compared to the conventional ammonia production route. There are four different types of electrolytes used for ammonia production via electrochemical process (Yusuf Bicer, 2017):

- Liquid electrolytes (operation at room temperatures)

- Molten salt electrolytes (operation at $300-500{ }^{\circ} \mathrm{C}$ )

- Composite electrolytes (operation at $300-700{ }^{\circ} \mathrm{C}$ )

- Solid electrolytes (operation at $700-800{ }^{\circ} \mathrm{C}$ )

Research and advances on materials used at the anode, cathode, and electrolyte allow for the electrochemical synthesis of ammonia. Giddey et al. (2013) reviewed several electrochemical methods of ammonia production based on liquid, molten salt, solid or composite electrolytes consisting of a molten salt and a solid phase. The study also conducts a discussion regarding materials of construction, operating temperature and pressure regimes, major technical challenges and material issues.

Kyriakou et al. (2017) reported the progress made for electrochemical ammonia production method in both solid and liquid electrolyte cells. The experimental studies were categorized 
according to high $\left(\mathrm{T}>500^{\circ} \mathrm{C}\right)$, intermediate $\left(500{ }^{\circ} \mathrm{C}>\mathrm{T}>100^{\circ} \mathrm{C}\right)$ and low $\left(\mathrm{T}<100^{\circ} \mathrm{C}\right)$ temperatures. Also, an analysis was made of the techno-economic advantages and disadvantages of the electrochemical approach and the demands for practical application. Compared with theoretical predictions based on DFT calculations, the experimental observations were discussed. The study concludes that in order to promote electrical synthesis on an industrial basis, intensive collaboration will be necessary between researchers working in the areas of material sciences, solid state ionics and heterogeneous catalysis.

$\mathrm{Xu}$ et al. (2009) conducted a study investigating ammonia production via electrochemical process at atmospheric pressure and low temperature. The process uses the SFCN materials as the cathode, a Nafion membrane as the electrolyte, nickel-depod SDC (Ni-SDC) as the anode and silver-platinum paste as the current collector. To get the maximum rates of ammonia formation, the production process of ammonia was between 25 and $100{ }^{\circ} \mathrm{C}$ temperature levels when the SFCN materials were utilized as cathode, with

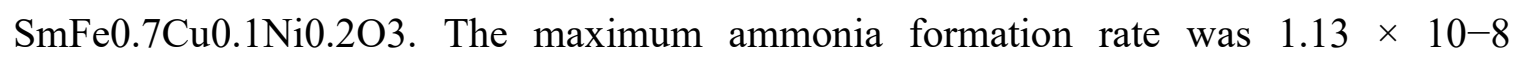
$\mathrm{mol} \cdot \mathrm{cm}^{-2} \cdot \mathrm{s}^{-1}$ at $80{ }^{\circ} \mathrm{C}$, and current efficiency reached $90.4 \%$.

\subsubsection{Conventional Methods of Ammonia Synthesis}

Despite of all progresses in electrochemical process, at present, ammonia is produced through the well known Haber-Bosch process invented at the beginning of the twentieth century, which is main interest of this thesis for ammonia production. The Haber-Bosch procces occurs as an exothermic procces ending up with ammonia combining hydrogen and nitrogen in 3:1 ratio. Catalyst is used to aid the reaction with an optimal temperature of $450-600{ }^{\circ} \mathrm{C}$. Further information about the Haber-Bosch technique will be given in the system description chapter. Vojvodic et al. (2014) examined the catalyst requirements for a new low-pressure, low-temperature synthesis process. The study showed that low pressure, low-temperature Haber-Bosch process is theoretically possible by defining the ideal scaling relation characterizing the most active catalyst possible. The primary challenge is identified as finding new classes of catalyst materials with approaching the ideal. 
Another important ammonia production method is solid state ammonia synthesis (SSAS). In an SSAS system, a solid state electrochemical is employed to produce ammonia from nitrogen, water, and electricity. The proton-conducting membrane is heated to about $550^{\circ} \mathrm{C}$ in SSAS. Nitrogen and water vapor on each side of the membrane are supplied under the same pressure in order to cause the reaction. The protons are transferred by an external voltage through the membrane, and $\mathrm{NH}_{3}$ is formed as a consequence of the nitrogen and protons reaction on the nitrogen side of the membrane. Since power consumption is lower in the SSAS process, it is assessed that ammonia is produced at a lower cost than the Haber-Bosch process (Ganley et al., 2007).

Amar et al. (2011) reviewed solid-state electrolytes and placed a particular emphasis on their application to produce ammonia. The study also discusses the factors affecting the rate of ammonia formation. The highest rate of ammonia formation based on utilized electrolyte type were in the following order; solid polymers $>\mathrm{Ce} 0.8 \mathrm{Gd} 0.2 \mathrm{O} 2-\delta$ $(\mathrm{Ca} 3(\mathrm{PO} 4) 2-\mathrm{K} 3 \mathrm{PO} 4)$ composites $>$ fluorites $>$ perovskites $>$ pyrochlores. It is emphasized that ammonia production from steam and $\mathrm{N}_{2}$, by-passing $\mathrm{H}_{2}$ stage provides advantages like reducing device numbers and costs.

Marnellos et al. (2000) studied synthesizing ammonia from nitrogen and hydrogen at atmospheric pressure in a solid state proton-conducting cell reactor. The study uses two types of reactors; one double-chamber and one single-chamber cell. In the cell of the double chamber, hydrogen flowed through the anode and was converted into protons transported through the solid electrolyte, reaching the cathode (Pd). Almost 80 percent of the hydrogen supplied by the electrochemical process was converted to ammonia at $570^{\circ} \mathrm{C}$. Hydrogen and nitrogen were fed into a single chamber cell together, and the solid electrolyte cell hung into the gaseous flux. A NEMCA effect was observed at $750^{\circ} \mathrm{C}$, but there was a very low enhancement. This new process eliminates thermodynamic requirements for conventional catalytic reactors' temperature and operating pressure.

\subsection{Life Cycle Assessment of Hydrogen and Ammonia Production}

Life cycle assessment of several hydrogen and ammonia production methods have been reported in the literature. Ozbilen et al. (2013) conducted a study evaluating and comparing

the environmental impacts of various hydrogen production processes by considering 
different energy sources and using life cycle analysis. The results show that hydrogen production via thermochemical water decomposition cycles has lower environmental impacts compared to conventional steam reforming of natural gas. Specifically, nuclear based four-step $\mathrm{Cu}-\mathrm{Cl}$ cycle was reported as the one having the lowest global warming potential with the value of $0.559 \mathrm{~kg} \mathrm{CO}_{2}$ eq per $\mathrm{kg}$ of hydrogen production.

Bicer et al. (2016) investigated the environmental impacts of four different ammonia production methods by using life cycle assessment. The system includes an electrolyzer for hydrogen synthesis and a Haber-Bosch plant for ammonia production. The required energy for the system was supplied from different sources for a comparative assessment namely, hydropower, nuclear, biomass and municipal waste. The selected environmental impact categories were global warming potential (GWP), human toxicity potential (HTP) and abiotic depletion potential (ADP). The results of the LCA study showed that municipal waste based ammonia production method yields the lowest GHG emission with the value of $0.34 \mathrm{~kg} \mathrm{CO}_{2}$-eq per $\mathrm{kg}$ of ammonia that was followed by hydropower based ammonia production with the value of $0.38 \mathrm{~kg} \mathrm{CO}_{2}$-eq per $\mathrm{kg}$ of ammonia. The energy efficiencies of the selected ammonia production methods were reported to be $42.7 \%, 23.8 \%, 15.4 \%$, and $11.7 \%$. The corresponding exergy efficiencies for hydropower, nuclear, biomass and municipal waste options were reported as $46.4 \%, 20.4 \%, 15.5 \%$, and $10.3 \%$, respectively.

One of the most appealing advantages of hydrogen and ammonia synthesis that they can utilize from any energy sources during production processes. In regards to environmental impacts, LCA tools may help to define the most benign way of ammonia and hydrogen synthesis. Cetinkaya et al. (2012) performed a comprehensive life cycle assessment for various hydrogen production methods consisting coal gasification, steam reforming of natural gas, water cracking via wind and solar, and thermochemical water splitting via $\mathrm{Cu}$ $\mathrm{Cl}$ cycle. They concluded that the most environmentally friendly methods are wind-based hydrogen production via electrolysis, then followed by solar-based electrolysis. The high entropy of these energy sources might be questionable to utilize in hydrogen and ammonia synthesis, but both of them can be used in appropriate locations for low production capacities. Bicer et al. (2017) studied conventional resource-based ammonia production methods by means of life cycle assessment. The energy input for ammonia production 
methods was supplied by traditional resources including coal, nuclear, natural gas and heavy oil. The performed life cycle assessment deduced that nuclear electrolysis-based ammonia generation method yields the lowest global warming and climate change impacts compared to other conventional resources defined in the study.

As indicated earlier, most of the proposed thermochemical cycles in open literature demands high thermal energies. Due to lower operational temperature requirements, $\mathrm{Cu}$ $\mathrm{Cl}$ thermochemical cycles are preferred in the content of hydrogen and eventually ammonia productions. Hacatoglu et al. (2012) studied the LCA of a nuclear-based $\mathrm{Cu}-\mathrm{Cl}$ hydrogen production method, including the fossil fuel energy use and GHG emissions. The study considers GEN-4 supercritical water reactors as power supplier to the promoted system which is still under development. GEN-4 nuclear reactor assisted thermochemical water splitting cycle is a promising method for a large-scale hydrogen production due to the high thermal output of GEN-4 reactors. Utgikar and Theisen (2006) conducted an LCA of nuclear-based hydrogen production via high-temperature electrolysis method. They evaluated the results by means of Global Warming Potential (GWP) and Acidification Potential (AP). They indicated that increasing the electrolysis temperature from 375 to $1050 \mathrm{~K}$ decreased the combined electrical and thermal energy need for the process by $35 \%$.

Bicer and Dincer (2017) evaluated nuclear energy based ammonia and hydrogen production options through the life cycle assessment (LCA) method. The study compares the nuclear-based thermochemical and electrolysis methods with natural gas based conventional steam methane reforming (SMR) method to reveal the advantages of nuclear power by means of environmental impacts. The supplied nuclear power for ammonia and hydrogen production was a mixture of $66.5 \%$ from a pressurized water reactor (PWR) and $33.5 \%$ from a boiling water reactor (BWR). They came up with the result that nuclearbased thermochemical and electrolysis ammonia production systems had significantly lower global warming potential than that of SMR method. Ozbilen et al. (2011) performed a comparative LCA study of hydrogen production via Copper-Chlorine $(\mathrm{Cu}-\mathrm{Cl})$ cycle. The research indicates that the thermochemical cycles have a lower impact on the environment while steam reforming of the natural gas has the highest. In another study, Ozbilen et al. (2012) conducted a comparative LCA study of nuclear based thermochemical hydrogen 
production cycles. They performed different scenarios in which various sources supplied the required energy. They resulted that the four-step $\mathrm{Cu}-\mathrm{Cl}$ cycle has lower environmental impacts than the three and five-step $\mathrm{Cu}-\mathrm{Cl}$ cycles due to lower thermal energy requirements.

\subsection{Cost Assessment of Nuclear Based Hydrogen Production}

El-Emam et al. (2015) conducted a cost assessmet study of different nuclear hydrogen production methods using the Hydrogen Economy Evaluation Program (HEEP) developed by IAEA. The study investigates and compares various storage and transportation scenarios for nuclear hydrogen production. In addition to the thermal energy and electricity cost details, the cost estimations for capital, fuel, decommissioning, and consumables are evaluated. Moreover, the study calculates and assesses both pipeline and vehicle transportation costs for hydrogen transportation to end users.

Khamis and Malshe presented a paper including information presented at IAEA technical meetings on status of nuclear hydrogen production regarding ongoing R\&D acitivities in Member States. The study reviews the IAEA hydrogen evaluation program (HEEP) which was developed by IAEA under agreement and in collaboration with the BHABHA Atomic Research Centre (BARC). The study also includes information about the HEEP structure and formulation, important features of HEEP, and execution module of HEEP.

The HEEP software is also used in the present study for cost assessment of various hydrogen production methods. More detailed information about HEEP will be presented in the system description chapter. 


\section{CHAPTER 3: LIFE CYCLE ASSESSMENT}

This chapter details the methodology for the life cycle assessment (LCA). In line with ISO standards, the different phases of the life cycle assessment will be fully explained. The definition and significance of different environmental impact categories are presented.

\subsection{Definition and History of Life Cycle Assessment Technique}

The LCA methodology is accepted as a useful technique for industrial decision-making and public policy formulation. LCA can be used to examine the impact of a product or process on the environment. LCA is a useful technique since it assesses the environmental impact of a product or process from the extraction of resources to disposal, which gives decision-makers the opportunity to see the total environmental impact of a process from the cradle to the grave. The LCA technique shows critical sub-processes in which possible changes can mitigate the environmental effects of a system drastically, which is described as the primary purpose of conducting an LCA study (Curran, 2012).

The history of LCA began with concerns over raw material and energy sources ' limitations, which generated interest in the cumulative energy use finding of the 1960s. At the World Energy Conference in 1963, Harold Smith presented a study on increasing energy needs for the production of chemical intermediates and products. In 1969, researchers conducted the Coco-Cola Company's first life cycle inventory analysis, in which raw materials, fuel consumption and environmental loads from different beverage container manufacturing processes were quantified.

In the 1970s, a resource and energy usage quantification process and product environmental discharges have been referred to as the U.S. Resource and Environmental Profile Analysis (REPA). This was in Europe known as EcoBalance. In the early 1970s, the oil shortage forced the industry to look for energy and environmental emissions. Consequently, between 1970 and 1975, about 15 REPAs have been reported. During the early 1980s, the problems of householders regarding hazardous waste management shifted environmental concerns. However, the inventory of life cycles, mainly on energy needs, has been conducted at a slower rate all this time. 
In 1988, solid waste became a worldwide issue, LCA again emerged as a tool for analyzing environmental issues. The LCA methodology was constantly improved, and the LCA methodology evolved from an inventory to an impact assessment. In 1991 worries arose about the misuse of LCAs. Pressure on the standardization of LCA methodology from environmental organizations lead to LCA standards in the 14000 series of ISOs (Curran, 2006):

- ISO 14040, Life Cycle Assessment - Principles and Framework (ISO 14040, 1997)

- ISO 14041, Life Cycle Assessment - Goal and Scope Definition and Inventory Analysis (ISO 14041, 1998)

- ISO 14042, Life Cycle Assessment - Life Cycle Impact Assessment (ISO 14042, 2000)

- ISO 14043, Life Cycle Assessment - Life Cycle Interpretation (ISO 14043, 2000)

- ISO 14044, Life Cycle Assessment - Requirements and Guidelines (ISO 14044, 2006)

\subsection{Objectives of LCA}

The critical requirement for the establishment of LCA studies was a need to measure releases of products to classify potential rooms of improvement through lower resources consumption and lower environmental impacts throughout the life cycle. LCA can be used for a variety of purposes, and a separate set of data collection information may be required for each derivative purpose. The data depends significantly on the application and use of the LCA tool and data is very simplified or detailed (Schenck, 2005). In the following sections, some important LCA objectives are explained.

\subsubsection{Product Development}

In the design phase of any product, there are generally numerous options for choosing resources and materials. The use of LCA during product development is essential, and any resource and material choice affects the life cycle phases (Tillman, 2000). However, it can be useful to make LCA easier, so that the focus, analysis, and research would be on the resources and materials which have a high environmental impact and then try to find alternative solutions before moving towards developing processes (Finnveden et al., 2009). 


\subsubsection{Product Upgrading}

Data collection can be significant for the improvement of an existing process or product. The focus on resources and materials is significant, which can remarkably affect the product when LCA is used as a tool to improve the product. Thus, several products can be compared to each other through an environmental perspective, which calculates the environmental impact of each specified product and compares it to some other cases of the same classification. Alternative solutions are then combined for the reassessment of the whole solution for resources or materials that create more significant effects on the surroundings during life cycle phases (production, operations, and disposal) (McAloone, 2017).

\subsubsection{Marketing}

Marketing is the method for collaborating with customers ' requirements for individual quality requirements on the specific characteristics of the product. With an increase in environmental awareness, the consumer pays more attention to specific environmental characteristics of services and goods. Environmental labeling (Eco-labeling) is known as the most suitable type for the use of LCA for environmental marketing purposes (European Environmental Agency, 2006).

Environmental labeling is taken as evidence to confirm whether the product is environmentally friendly. If a product is appropriate for eco-labeling standards, it receives an Eco-label, which is the reason why it is more attractive for the consumer when it comes to marketing intensity and ecologically friendly products. Following the EU ecological label regulation, LCA is the primary requirement for the promotion of eco-label criteria. In terms of criteria for definite product classifications such as paint and varnish, washing machines, washing detergents, soil improvers, toilet papers, towels, copying papers, water heaters, t-shirts and bed linens, light bulbs, dishwashers, kettles and freezers, air conditioning, cars, and televisions, the EU Ecolabelling Structure has been established in the past (Jimenez-Guerrero et al., (2015), and Sto, (2005)).

Another type of marketing tool similar to the Ecolabel is the Environmental Product Declaration (EPD). EPD contains some information concerning the environmental characteristics and components of a product defined according to the ISO 14025 standards 
and based on LCA (Fyrendal et al., 2017, and Del Borghi, 2013). The overall intent of EPD is that a product of an existing environmental impact number is presented graphically, as is the case with a bar diagram. Although graphically aware consumers and professional purchasers can easily understand the presentation, it may not be clear enough for broadranging consumers. It appears that the level of details required to establish EPD is higher compared to eco-labeling, which is challenging to implement and operate (Firth, 2012).

\subsection{LCA Framework}

This section discusses some general terminologies and definitions of the LCA process. The defined framework for using in an LCA process is specified by ISO 14040. The scope, considered limits and the level of detail of an LCA study depends entirely on the subject and the purpose of the study. LCA studies can be complicated and extensive depending on the objective of a particular LCA study. To produce accurate results for direct applications, all LCA studies should follow four main steps defined in ISO standards. These four essential steps can be defined as follows and followed up with all standards and recommendations;

- Goal and scope definition

- Inventory analysis

- Impact assessment, and

- İmprovement of analysis (interpretation of results).

These are all essential steps in Figure 3.1. The arrows in the Figure show the iterative and cooperative character of LCA. A scenario during an impact assessment can result in vague or absent specific information, which shows that the analysis needs improvement. If the interpreted results are unclear or insufficient during the entire interpretation phase to overcome the application requirements, this indicates that the definitions of scope and aim may have to be improved and changed (European Environmental Agency, 2006).

The most crucial phase of the LCA study is a life cycle impact assessment (LCIA) which alters the life cycle inventory (LCI) results for the particular substances involved in the system study to include comprehensible environmental effects classifications. Many LCIA methods were developed to deal with the modeling of ecological emission effects. In this 
study, CML-2001 method, which is developed at Leiden Uninversity, is utilized for LCIA of the production processes.

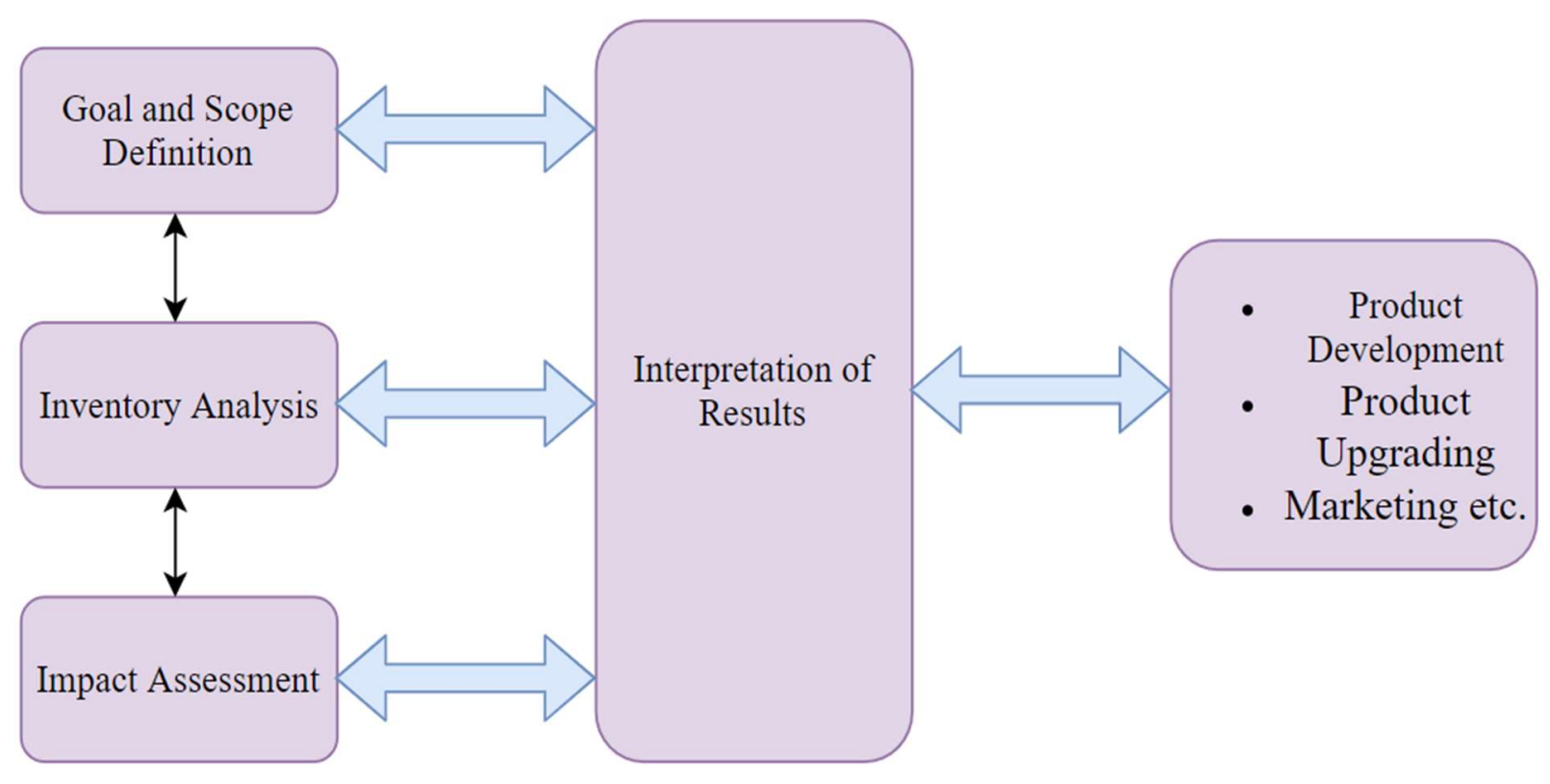

Figure 3.1: ISO 14040 standard LCA framework.

\subsubsection{Goal and Scope Definition}

Definition of purpose and scope is the first phase of an LCA analysis to specify the product and to establish the valuation framework. In an LCA study, this step is crucial. The impact assessment phase influences the identification of many parameters: the purpose of the study, time, resources, the application intended, the methodology of assessment, system boundaries, and broad limitations and assumptions. The definition of goal and scope will lead to the entire LCA process, ensuring the best possible results (ISO, 2006).

\subsubsection{Inventory Analysis}

The results of the inventory analysis are organized as a list containing the amount of material and energy consumed during a particular product's various life-cycle phases. Thus, the associated materials and energy flow based on the product and total inputs and outputs 
from and to the corresponding natural environment is indicated during the inventory analyzes stage (Baumann, 2004). The LCI analysis depends heavily on the quantity and types of numerous natural resources such as water, power, etc., the methods of transportation, production materials, use of the defined product for its life and disposal. The deliberation and individual effects of the factors described may vary between regions. Various scenarios, such as a region that does not have enough resources to produce specific products or a region which contains different technologies for certain materials or which may further depend on fossil fuels or renewable energy resources, can alter the suppositions and limitations of LCAs (Karasu, 2018).

\subsubsection{Impact Assessment}

All process steps must be identified as LCI's first stage as inputs / outputs of all the flows in the system boundary. LCI analysis then includes data collection and processes for calculating the relevant system inputs and outputs. These inputs can consist of material consumption, energy consumption and air, water, and soil releases of the system (ISO 14040, 1997). Crucial steps include defining and classifying impact categories and characterizing them, while standardization and weighting optional steps are included.

\subsubsection{Interpretation of Results}

The results of this evaluation are illustrated and conclusions for guidance in the decisionmaking process are drawn in this step. The considered environmental issues and the significance of the relative environmental load contributions of the specific processes and product components are documented. The results can be prepared by means of data control in three positions; completeness check, sensitivity check, and consistency check (Curran, 2012).

\subsection{ISO Standards}

\subsubsection{ISO 14040:2006}

The framework and principles for LCA counting are defined in ISO 14040:2006: target and scope definition in LCA; the stage for LCIA analysis; the phase for LCI analysis, the stage of LCA life cycle interpretation, the LCA limitations, the reporting and key review of the LCA; the link between the LCA stages and the optional conditions. LCA and LCI 
are covered by ISO 14040:2006. The LCA technique is not stressed and the phase methods for LCA are not specified. Throughout the definition of purpose and scope of application of LCA or LCI findings, the application itself is not included within the scope of that International Standard.

\subsubsection{ISO 14044:2006}

The guidelines for LCA are provided by ISO 14044:2006. LCA comprising: LCA target definition and scope definition; LCI analysis (LCI) stage; reporting and key review for LCA; LCIA stage; stage of life cycle interpretation; LCA interaction; LCA boundaries and optional elements utilization situations.

\subsection{Life Cycle Impact Assessment (LCIA) Method}

LCIA is considered to be the most important step of an LCA study, and the reason is that it treats the full data quantity shown in the results obtained through inventory analysis. These results for the inventory analysis will then be transformed into easily comprehensible impact indicators coinciding with the environmental compound modeling which focuses on the standardization and characterization of environmental and natural science and recognizes the social, political, and ethical issues. Because of this difficulty, approaches to simplifying and improving the LCIA process have been developed in the LCIA stage.

LCIA approaches are recognized as the instruments for linking LCI findings to accompanying environmental effects in which LCI results are categorized within 28 category-individual impact classifications. This enhances the trade-off and disparities between different alternative products with the development of LCIA methodologies, simplifies the process for LCA practitioners and facilitates benchmarking. In the LCIA stage, two characterization approaches can exist next to the path of the impact indicator. An indicator located somewhere, apart from the methodology mechanism, but before the endpoint classifiers, is used to categorize midpoint level models; endpoint quality requires modeling in all categories of endpoint defined by the protection regions (The key protection

areas used are: quality of ecosystems, human health, and resources). Thus, between the LCI results and the categories endpoints of the cause of the effect chain, it is possible to locate these category indicators. 


\subsubsection{2001 Method}

The Institute of the Environmental Research at Leiden University, which contained a group of impact categories and methods for characterizing the stage of impact assessment in 2001, proposed an intermediate - point approach called CML (Frischknecht, 2007). Normalization is provided, but there is no weighting or addition. The legitimacy of the CML approach by the provincial impact categories is universal without acidification and the formation of photo-oxidant. The method CML 2001 is most commonly used in LCA studies as this is a problem-focused approach. Because of its suitability for this study, the results are defined in the CML 2001 method. In the following subsections, the categories of impact selected are explained. The impact categories, units, and definitions were chosen for this study are shown in Table 3.1.

Table 3. 1: Selected CML 2001 environmental impact categories and their units.

\begin{tabular}{|l|l|l|}
\hline Impact Category & Unit Definition \\
\hline $\begin{array}{l}\text { Abiotic depletion potential (ADP) } \\
\text { (kg Sb-eq) }\end{array}$ & Kilogram of Antimony equivalent \\
\hline $\begin{array}{l}\text { Acidification potential (AP) } \\
\text { (kg SO} 2 \text {-eq) }\end{array}$ & Kilogram of Sulphur dioxide equivalent \\
\hline $\begin{array}{l}\text { Global warming potential (GWP) } \\
\text { (kg CO} 2 \text {-eq) }\end{array}$ & Kilogram of Carbon dioxide equivalent \\
\hline $\begin{array}{l}\text { Ozone layer depletion potential (ODP) } \\
\text { (kg CFC-11-eq) }\end{array}$ & $\begin{array}{l}\text { Kilogram of Trichlorofluoromethane } \\
\text { equivalent }\end{array}$ \\
\hline $\begin{array}{l}\text { Human toxicity potential (HTP) } \\
\text { (kg 1,4-DB-eq) }\end{array}$ & $\begin{array}{l}\text { Kilogram of 1,4-dichlorobenzene } \\
\text { equivalent }\end{array}$ \\
\hline
\end{tabular}

\subsubsection{Abiotic Depletion Potential (ADP)}

Abiotic resources are natural, non-living substances such as crude oil, copper mineral, and may include energy resources such as fossil fuels. The ADP is one of the most popular impact category and there are a wide variety of processes to describe contributions for this category. In this category, the depletion of non-renewable materials is considered. The unit indicator used for this category of impact is the $\mathrm{kg}$ antimony equivalent $(\mathrm{Sb})$. The ecosystem and human health, which are affected by minerals and fossil fuels as system inputs, is at the forefront of the described category. For every mineral and fossil fuel extraction, the abiotic depletion factor (ADF) is evaluated. The indicator used globally and 
was based on the rate of decumulation and concentrator reserves described (SimaPro, 2014).

\subsubsection{Acidification Potential (AP)}

The acid deposition of acidifying contamination in groundwater, soil, surface water, ecosystems, biological organisms, and substances is associated with the Acidifying Potential (AP). $\mathrm{SO}_{2}, \mathrm{NO}_{\mathrm{x}}$, and $\mathrm{NH}_{\mathrm{x}}$ are the key acidifying pollutants. Protected areas are the natural environment, human health, the social environment, and natural resources. Acidification constituents motivate an extensive collection of influence on groundwater, soils, surface water, ecosystems, organisms, and components. To determine the AP for air discharges and to describe deposition of acidifying elements, the RAINS model uses local air pollution information and simulation 10 (RAINS). The AP is expressed by using equivalents/kg of emission $\mathrm{SO}_{2}$ (kg Sb-eq) (SimaPro, 2014).

\subsubsection{Global Warming Potential (GWP)}

GWP represents the effect of emissions on some of the atmospheric radiation forcing, such as thermal radiation absorption. Global warming affects the environment and human health, ultimately bringing about climate change. Most such releases increase radiational force, which raises the temperatures on the surface of the earth, which is generally referred to as the 'greenhouse effect'. The airborne GHGs are climate change related. Climate change can harm the ecosystem, human health, and welfare. The IPCC has defined the categorization model, carefully chosen for the advancement of the characterizing factors. The GWP is characterized by a 500 year time horizon (GWP500) with a $\mathrm{kg}$ of emission of $\mathrm{CO}_{2}$ (Ecoinvent, 2013).

\subsubsection{Ozone Layer Depletion Potential (ODP)}

Due to previously described releases, the stratospheric ozone layer is getting thinner, and these phenomena can be labeled as stratospheric ozone depletion. Thinning of stratospheric ozone layer ends up with the absorption of the significant portion of solar UV-B radiation to the surface of the earth, which potentially damages the environment, human health, aquatic and terrestrial ecology, animals, materials and biochemical cycles. The unit of this impact category is defined as $\mathrm{kg}$ CFC-11-eq. A description model has been developed by 
the World Meteorological Organization (WMO) to express different gases through their potential ozone depletion. The geographical scope of the indicator described is presented worldwide over an infinite time period (SimaPro, 2014).

\subsubsection{Human Toxicity Potential (HTP)}

The core focus of this category is toxic ecological components that harm human health and the environment. The risk to human health in the operational environment is not included in the category discussed. The HTP and categorization factors are assessed for an unlimited time by USES-LCA exposure, fate and toxic effects of substances. The unit of this impact category is 1,4-dichlorobenzene equivalents (SimaPro, 2014). 


\section{CHAPTER 4: SYSTEM DESCRIPTIONS}

In this chapter, the sub-systems employed in this study for nuclear-based hydrogen and ammonia production are described. In the present study, five different hydrogen production methods are selected for comparative assessment purposes. Sythesized hydrogen via selected tecniques is sent to a Haber-Bosch unit to be used for ammonia synthesis. Required nitrogen for ammonia synthesis is supplied by a cryogenic air seperation unit. Thermal and electrical enegy need for the hydrogen and Haber-Bosch ammonia production units are provided from a nuclear power plant. Required material and energy inputs for production processes are defined in the following sections, which are recieved from open literature (Bicer and Dincer, 2016). Figure 4.1 shows a simplified potential sample of a nuclear-based hydrogen and ammonia production system. All sub-systems shown in Figure 4.1 are described in the upcoming sections.

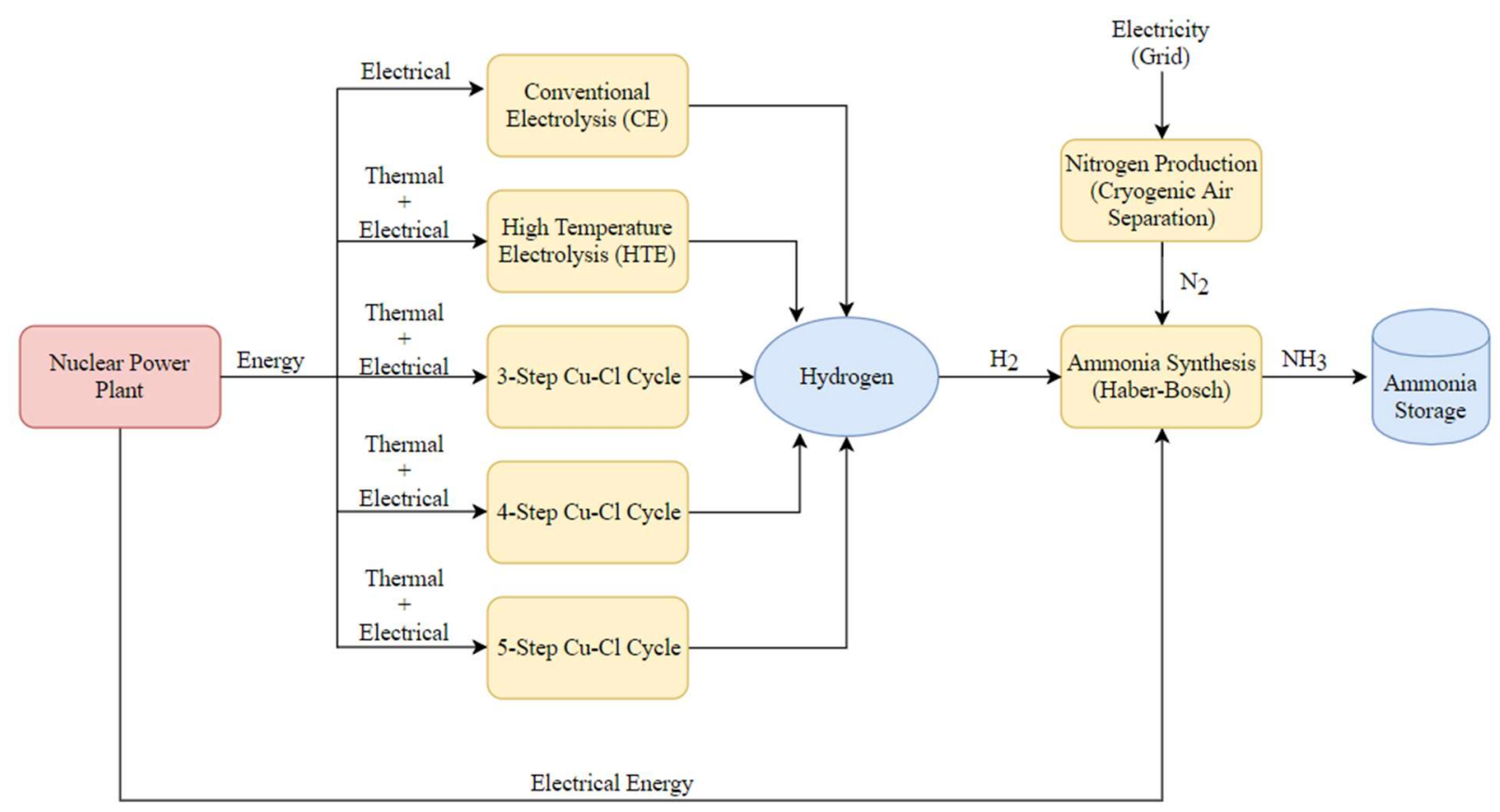

Figure 4. 1: Simplified overwiev of hydrogen and ammonia production methods.

Nuclear based hydrogen and ammonia production via water splitting and thermochemical cycle is a promising a alternative to conventional techniques such as natural gas fed steam methane reforming (SMR). Figure 4.2 displays the simplified overwiev of the system used 
for the life cycle assessment (LCA). The fuel process, which consists of mining, milling, conversion, enrichment and fuel production, is the first process of the system. The manufactured uranium is transferred to the nuclear plant after fuel processing. The output thermal and electrical energy are employed in the production processes of hydrogen and ammonia. Construction and use are also taken into account as well in the LCA study. The reactions occuring in the hydrogen and ammonia production cycle forms a closed internal loop recycling all chemicals on a continuos basis, without emitting any greenhouse gases. Thus, water, thermal energy, and electrical energy are the only inputs to the system.

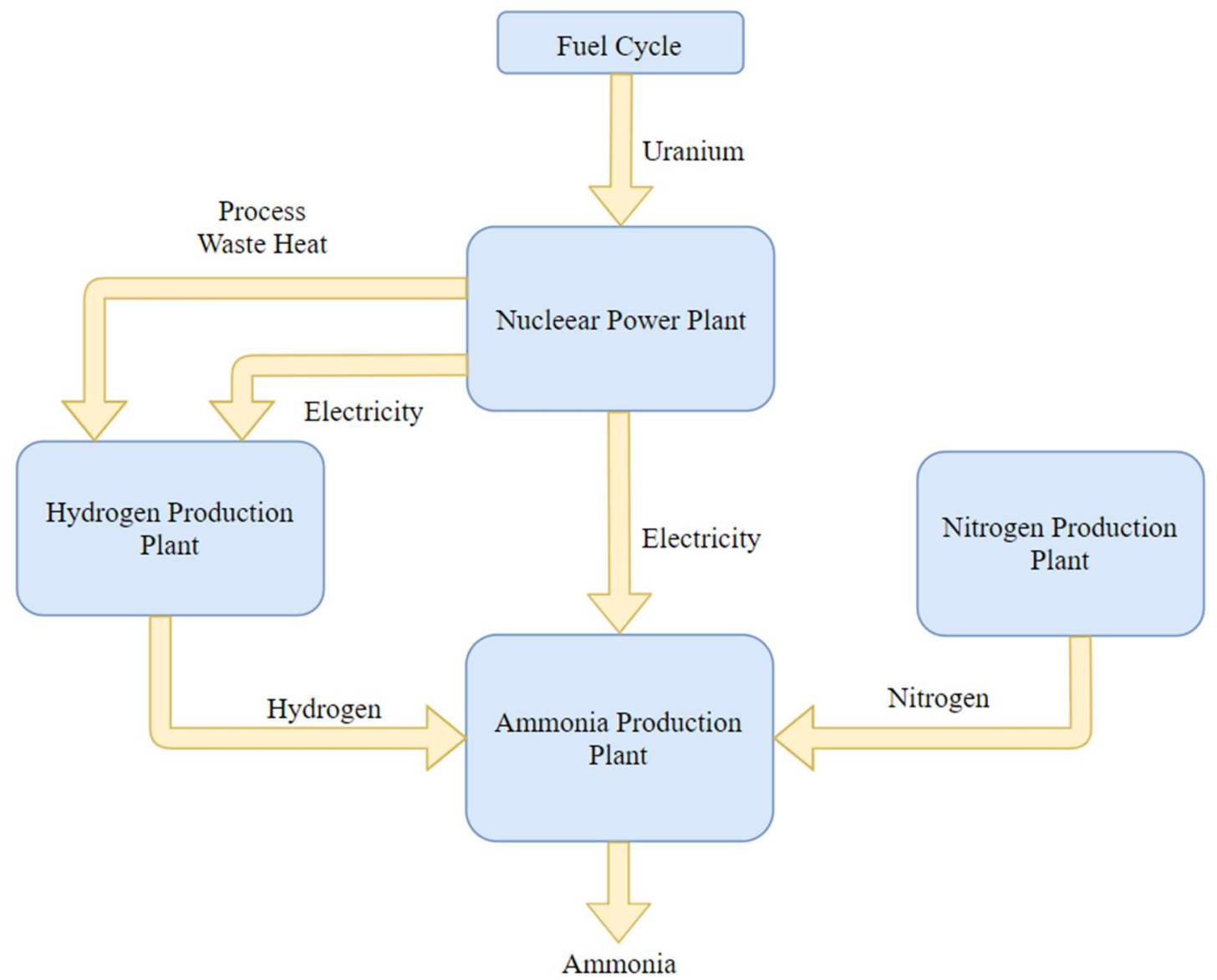

Figure 4. 2: Simplified overwiev of the system used for the LCA.

\subsection{Hydrogen Production}

Five different nuclear-based hydrogen production methods are employed in this study, namely, conventional electrolysis, high temperature electrolysis, 3-, 4-, and five step $\mathrm{Cu}-$ 
$\mathrm{Cl}$ cycles. Required material and energy inputs for one $\mathrm{kg}$ of nuclear hydrogen production via selected methods are received from open literature (Bicer and Dincer, 2017).

\subsubsection{Conventional Water Electrolysis}

Electrolysis of water is a conventional method of producing hydrogen by splitting water into hydrogen and oxygen, which is accomplished by passing an electric current through water. A basic electrolysis unit consists of an anode, a cathode, power supply, and an electrolyte. A direct current (DC) is used to maintain the balance of electricity. Electrons then flow from the DC source's negative terminal to the cathode in which hydrogen ions consume the electrons to form hydrogen. Figure 4.3 shows the schematic of a conventional water electroylsis unit. Required power for the electrolysis is supplied by a nuclear power plant. Table 4.1 illustrates the main material and energy inputs and outputs for nuclear hydrogen production via conventional electrolysis. Energy and material need for hydrogen production methods are received from open literature (Bicer and Dincer, 2017).

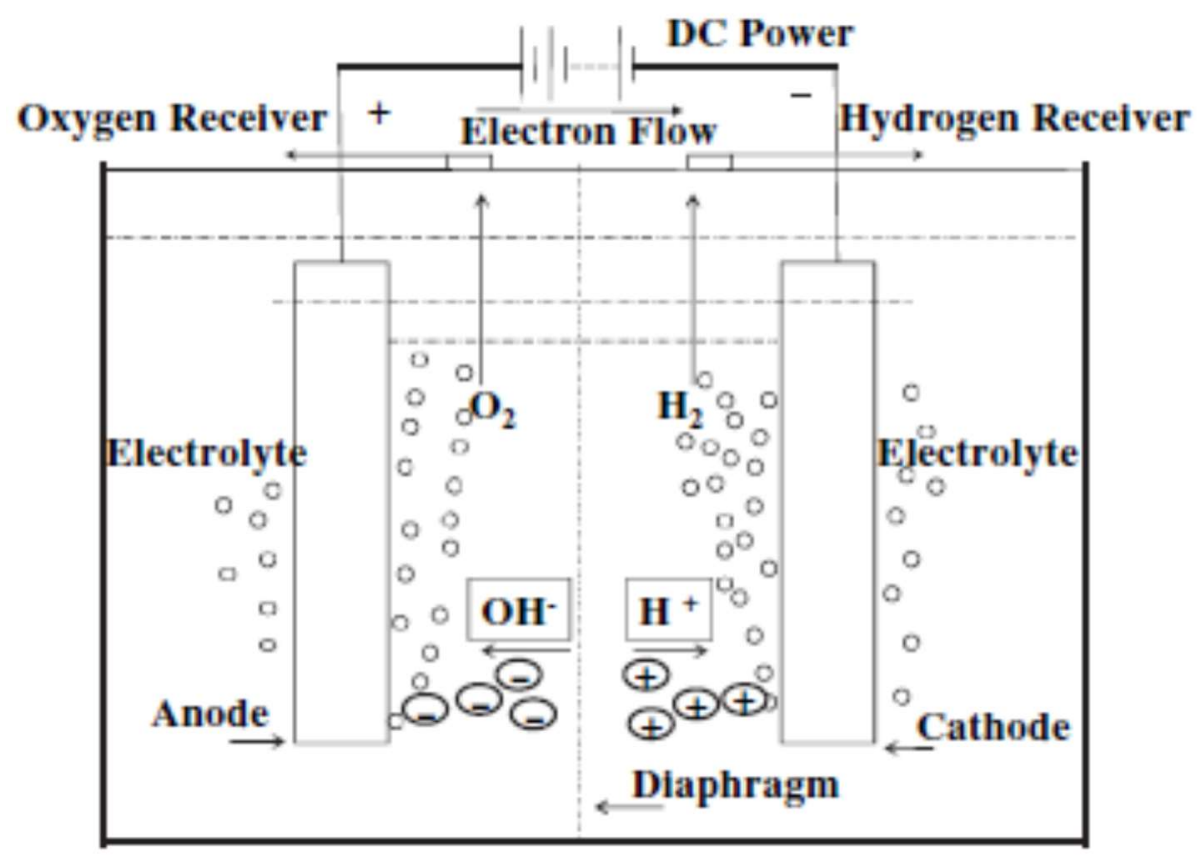

Figure 4. 3: The schematic of a conventional water electrolysis unit. (Adapted from Zeng et al, 2010). 
Table 4. 1: Main inputs and outputs for nuclear based hydrogen production via conventional electrolysis.

\begin{tabular}{|l|l|l|l|}
\hline \multicolumn{2}{|l|}{ Input } & \multicolumn{2}{l|}{ Output } \\
\hline $\begin{array}{l}\text { Electricity, nuclear } \\
(\mathrm{kWh})\end{array}$ & $\begin{array}{l}\text { Water used } \\
(\mathrm{kg})\end{array}$ & $\begin{array}{l}\text { Hydrogen } \\
(\mathrm{kg})\end{array}$ & $\begin{array}{l}\text { Oxygen } \\
(\mathrm{kg})\end{array}$ \\
\hline 53.5 & 9 & 1 & 8 \\
\hline
\end{tabular}

\subsubsection{High Temperature Water Electrolysis (HTE)}

Different than conventional electrolysis method, nuclear high temperature electrolysis (HTE) utilizes the excess heat from the nuclear plant to mitigate consumed electricity for electrolysis. Operating temperatures, electrolyte properties, and operating pressures creates the differences between the electrolysis methods. Electrolysis of water via HTE occurs at $1100-1250 \mathrm{~K}$, and in general, a yttria-stabilized zirconia is utilized as an electrolyte for this process. (Dutta et al, 1997).

Water splitting in a HTE process occurs as following reaction (Utgikar and Thiesen, 2005)

$$
\begin{gathered}
\text { Cathode: } \mathrm{H}_{2} \mathrm{O}+2 \mathrm{e}^{-} \rightarrow \mathrm{H}_{2}+\mathrm{O}^{2-}(1) \\
\text { Anode: } \mathrm{O}^{2-} \rightarrow 1 / 2 \mathrm{O}_{2}+2 \mathrm{e}^{-}(2)
\end{gathered}
$$

The main components of a high temperature electrolsis unit are the anode, cathode, electrolyte, and interconnect material. Table 4.2 shows the main inputs and outputs for nuclear-based hydrogen production via high temperature water electrolysis.

Table 4. 2: Main inputs and outputs for nuclear-based hydrogen production via high temperature electrolysis.

\begin{tabular}{|l|l|l|l|l|}
\hline \multicolumn{3}{|l|}{ Input } & Output \\
\hline $\begin{array}{l}\text { Electricity, nuclear } \\
(\mathrm{kWh})\end{array}$ & $\begin{array}{l}\text { Heat, nuclear } \\
(\mathrm{kWh})\end{array}$ & $\begin{array}{l}\text { Water used } \\
(\mathrm{kg})\end{array}$ & $\begin{array}{l}\text { Hydrogen } \\
(\mathrm{kg})\end{array}$ & $\begin{array}{l}\text { Oxygen } \\
(\mathrm{kg})\end{array}$ \\
\hline 28.9 & 6.67 & 9 & 1 & 8 \\
\hline
\end{tabular}




\subsubsection{Step Cu-Cl Cycle}

The copper-chlorine $(\mathrm{Cu}-\mathrm{Cl})$ cycle operates a sequence of reactions to splitt water into hydrogen and oxygen. The cycle decomposes water into hydrogen and oxygen by using intermediate copper chloride compuonds. In the 5 step cycle, copper is produced electrolytically, moved to an exothermic thermochemical hydrogen reactor and then reacted with $\mathrm{HCl}$ gas to produce hydrogen gas and molten $\mathrm{Cu}-\mathrm{Cl}$. All reactions are performed in a closed loop that recycles all chemicals in a continuous basis. Table 4.3 shows the five steps of this $\mathrm{Cu}-\mathrm{Cl}$ cycle with chemical reactions.

Table 4. 3: Steps and reactions in the five $\mathrm{Cu}-\mathrm{Cl}$ cycle for water decomposition.

\begin{tabular}{|l|l|l|}
\hline Step & Chemical reaction & $\begin{array}{l}\text { Temperature } \\
\left({ }^{\circ} \mathrm{C}\right)\end{array}$ \\
\hline $\begin{array}{l}\text { 1. Hydrogen } \\
\text { production }\end{array}$ & $2 \mathrm{Cu}(\mathrm{s})+2 \mathrm{HCl}(\mathrm{g}) \rightarrow 2 \mathrm{CuCl}(\mathrm{l})+\mathrm{H}_{2}(\mathrm{~g})$ & 450 \\
\hline 2. $\mathrm{Cu}$ production & $4 \mathrm{CuCl}(\mathrm{aq}) \rightarrow 2 \mathrm{CuCl}_{2}(\mathrm{aq})+2 \mathrm{Cu}(\mathrm{s})$ & 25 \\
\hline 3. Drying & $2 \mathrm{CuCl}_{2}(\mathrm{aq}) \rightarrow 2 \mathrm{CuCl}_{2}(\mathrm{~s})$ & 90 \\
\hline 4. $\mathrm{HCl}$ production & $2 \mathrm{CuCl}_{2}(\mathrm{~s})+\mathrm{H}_{2} \mathrm{O}(\mathrm{g}) \rightarrow \mathrm{CuO}^{*} \mathrm{CuCl}_{2}(\mathrm{~s})+2 \mathrm{HCl}(\mathrm{g})$ & 450 \\
\hline 5. $\mathrm{O}_{2}$ production & $\mathrm{CuOCuCl}_{2}(\mathrm{~s}) \rightarrow 2 \mathrm{CuCl}(\mathrm{l})+1 / 2 \mathrm{O}_{2}(\mathrm{~g})$ & 500 \\
\hline
\end{tabular}

Source: Ozbilen et al., (2011).

Hydrogen is produced in the first step of the cycle which occurs at $450{ }^{\circ} \mathrm{C}$ as an exothermic reaction. In the second step, the reaction occurs around $25{ }^{\circ} \mathrm{C}$ to produce copper from molten $\mathrm{CuCl}$. Product copper moves to the production stage of hydrogen, while the other product $\mathrm{CuCl}_{2}$ is transferred to the third step. In the third step, the molten $\mathrm{CuCl}_{2}$ is dried to solid $\mathrm{CuCl}_{2}$ to be used in the fourth step. $\mathrm{CuCl}_{2}$ reacts with water in this step to produce $\mathrm{HCl}$ and $\mathrm{CuOCuCl}_{2}$. $\mathrm{HCl}$ production step (4. step) occurs at a temperature of around 450 ${ }^{\circ} \mathrm{C}$. The $\mathrm{O}_{2}$ production is the final step of the cycle which happens at a temperature of approximately $500{ }^{\circ} \mathrm{C}$. Heat exchangers are utilized before each step to obtain the required temperature since the reaction temperatures of each stage are different.

The net reaction of the $\mathrm{Cu}-\mathrm{Cl}$ cycle decomposes water into hydrogen and oxygen. $\mathrm{Cu}-\mathrm{Cl}$ cycles requires both thermal and electrical energy which are provided from a nuclear power plant in this study. Table 4.4 shows the main inputs and outputs for nuclear hydrogen production via 5 step $\mathrm{Cu}-\mathrm{Cl}$ cycle. 
Table 4. 4: Main inputs and outputs of nuclear-based hydrogen production via 5 step CuCl cycle.

\begin{tabular}{|l|l|l|l|l|}
\hline \multicolumn{2}{|l|}{ Input } & Output \\
\hline $\begin{array}{l}\text { Electricity, nuclear } \\
(\mathrm{MJ})\end{array}$ & $\begin{array}{l}\text { Heat, nuclear } \\
(\mathrm{MJ})\end{array}$ & $\begin{array}{l}\text { Water used } \\
(\mathrm{kg})\end{array}$ & $\begin{array}{l}\text { Hydrogen } \\
(\mathrm{kg})\end{array}$ & $\begin{array}{l}\text { Oxygen } \\
(\mathrm{kg})\end{array}$ \\
\hline 50.3 & 352.26 & 9 & 1 & 8 \\
\hline
\end{tabular}

\subsubsection{Step Cu-Cl Cycle}

4 step copper-chlorine cycle combines step 2 (Cu production) and step 3 (drying) in the Table 4.3 to eliminate the intermediate production and handling of copper solids (Naterer et al, 2010). Due to combining these two steps, 4 step $\mathrm{Cu}-\mathrm{Cl}$ cyle is requires lower thermal energy input, but higher electrical energy input than 5 step $\mathrm{Cu}-\mathrm{Cl}$ cycle since production of hydrogen and aqueous $\mathrm{Cu}$ chloride is achieved through a $\mathrm{CuCl} \backslash \mathrm{HCl}$ eletrolyzer electrolytically. Table 4.5 displays the steps and reaction occuring in the 4 step $\mathrm{Cu}-\mathrm{Cl}$ cycle.

Table 4. 5: Steps and reactions occuring in the 4 step $\mathrm{Cu}-\mathrm{Cl}$ cycle for water decompostion.

\begin{tabular}{|l|l|l|}
\hline Step & Chemical reaction & $\begin{array}{l}\text { Temperature } \\
\left({ }^{\circ} \mathrm{C}\right)\end{array}$ \\
\hline 1. Hydrogen production & $2 \mathrm{Cu}(\mathrm{s})+2 \mathrm{HCl}(\mathrm{g}) \rightarrow 2 \mathrm{CuCl}(\mathrm{l})+\mathrm{H}_{2}(\mathrm{~g})$ & 450 \\
\hline 2. Combined step & $4 \mathrm{CuCl}(\mathrm{aq}) \rightarrow 2 \mathrm{CuCl}_{2}(\mathrm{aq})+2 \mathrm{Cu}(\mathrm{s})$ & $25-90$ \\
\hline 3. $\mathrm{HCl}$ production & $2 \mathrm{CuCl}_{2}(\mathrm{~s})+\mathrm{H}_{2} \mathrm{O}(\mathrm{g}) \rightarrow \mathrm{CuO}^{2} \mathrm{CuCl}_{2}(\mathrm{~s})+2 \mathrm{HCl}(\mathrm{g})$ & 450 \\
\hline 4. $\mathrm{O}_{2}$ production & $\mathrm{CuO}^{2} \mathrm{CuCl}_{2}(\mathrm{~s}) \rightarrow 2 \mathrm{CuCl}(\mathrm{l})+1 / 2 \mathrm{O}_{2}(\mathrm{~g})$ & 500 \\
\hline
\end{tabular}

Source: Ozbilen et al., (2010).

Hydrogen production via 4 step $\mathrm{Cu}-\mathrm{Cl}$ cycle is pointed as the most feasible production process among thermochemical copper-chlorine cycle in the literature. It is to be highlighted that due to combining $\mathrm{Cu}$ production step and drying step, 4 step $\mathrm{Cu}-\mathrm{Cl}$ cycle has higher thermal efficiency than 3 and 5 step $\mathrm{Cu}-\mathrm{Cl}$ cycles. Required thermal and electrical energy inputs for nuclear hydrogen production via 4 step $\mathrm{Cu}-\mathrm{Cl}$ cycle are illustrated in Table 4.6.

As shown in Table 4.6, the inputs of the hydrogen plant are $67.15 \mathrm{MJ}$ electrical and 289.89 MJ thermal energy supplied from a nuclear power plant, and nine kg of water whreas the 
outputs of the plant one $\mathrm{kg}$ of hydrogen, which is intended production, and eight $\mathrm{kg}$ of oxygen.

Table 4. 6: Main inputs ad outputs of nuclear-based hydrogen production via 4 step $\mathrm{Cu}$ $\mathrm{Cl}$ cycle.

\begin{tabular}{|l|l|l|l|l|}
\hline \multicolumn{3}{|l|}{ Input } & Output \\
\hline $\begin{array}{l}\text { Electricity, nuclear } \\
(\mathrm{MJ})\end{array}$ & $\begin{array}{l}\text { Heat, nuclear } \\
(\mathrm{MJ})\end{array}$ & $\begin{array}{l}\text { Water used } \\
(\mathrm{kg})\end{array}$ & $\begin{array}{l}\text { Hydrogen } \\
(\mathrm{kg})\end{array}$ & $\begin{array}{l}\text { Oxygen } \\
(\mathrm{kg})\end{array}$ \\
\hline 67.15 & 289.89 & 9 & 1 & 8 \\
\hline
\end{tabular}

\subsubsection{Step Cu-Cl Cycle}

3 step copper-chlorine $(\mathrm{Cu}-\mathrm{Cl})$ cycle combines the step 1 ( hydrogen production) and the step 2 (combined step) in Table 4.5 by supplying aqueous $\mathrm{Cu}$ chloride to hydrolysis chamber directly. Hence, steps and reactions occuring in the 3 step $\mathrm{Cu}-\mathrm{Cl}$ cycle becomes as shown in Table 4.7.

Table 4. 7: Steps and reactions occuring in the 3 step $\mathrm{Cu}-\mathrm{Cl}$ cycle for water decompostion.

\begin{tabular}{|l|l|l|}
\hline Step & Chemical reaction & $\begin{array}{l}\text { Temperature } \\
\left({ }^{\circ} \mathrm{C}\right)\end{array}$ \\
\hline 1. Combined step & $2 \mathrm{Cu}(\mathrm{s})+2 \mathrm{HCl}(\mathrm{g}) \rightarrow 2 \mathrm{CuCl}(\mathrm{l})+\mathrm{H}_{2}(\mathrm{~g})$ & 100 \\
\hline 3. $\mathrm{HCl}$ production & $2 \mathrm{CuCl}_{2}(\mathrm{~s})+\mathrm{H}_{2} \mathrm{O}(\mathrm{g}) \rightarrow \mathrm{CuO}^{*} \mathrm{CuCl}_{2}(\mathrm{~s})+2 \mathrm{HCl}(\mathrm{g})$ & 430 \\
\hline 4. $\mathrm{O}_{2}$ production & $\mathrm{CuO}^{*} \mathrm{CuCl}_{2}(\mathrm{~s}) \rightarrow 2 \mathrm{CuCl}(\mathrm{l})+1 / 2 \mathrm{O}_{2}(\mathrm{~g})$ & 550 \\
\hline
\end{tabular}

Source: Ozbilen et al., (2010).

Main material and energy input for nuclear hydrogen production via 3 step $\mathrm{Cu}-\mathrm{Cl}$ cycle are shown in Table 4.8. The inputs of the hydrogen production via 3 step $\mathrm{Cu}-\mathrm{Cl}$ cycle are 67.15 MJ electrical and $325 \mathrm{MJ}$ thermal energy from hydrogen plant, and nine $\mathrm{kg}$ of water, whereas the system outputs one $\mathrm{kg}$ of hydrogen and eight $\mathrm{kg}$ of oxygen as shown in Table 4.8 . 
Table 4. 8: Main inputs and outputs of nuclear hydrogen production via 3 step $\mathrm{Cu}-\mathrm{Cl}$ cycle.

\begin{tabular}{|l|l|l|l|l|}
\hline \multicolumn{3}{|l|}{ Input } & Output \\
\hline $\begin{array}{l}\text { Electricity, nuclear } \\
(\mathrm{MJ})\end{array}$ & $\begin{array}{l}\text { Heat, nuclear } \\
(\mathrm{MJ})\end{array}$ & $\begin{array}{l}\text { Water used } \\
(\mathrm{kg})\end{array}$ & $\begin{array}{l}\text { Hydrogen } \\
(\mathrm{kg})\end{array}$ & $\begin{array}{l}\text { Oxygen } \\
(\mathrm{kg})\end{array}$ \\
\hline 67.15 & 325 & 9 & 1 & 8 \\
\hline
\end{tabular}

\subsection{Ammonia Production}

In this study, nuclear ammonia production is achieved by a conventional Haber-Bosch technique. Requried hydrogen for ammonia synthesis is supplied from selected methods described previously. A cryogenic air seperation unit is also attached to the system as nitrogen supplier for ammonia production. Additional energy need for ammonia synthesis is provided by a nuclear power plant. Figure 4.4 represents the schematic of a potential nuclear ammonia production process. Hydrogen production processes are already presented in previous sections. Remaining processes shown in Figure 4.4 is described in the following section in detail.

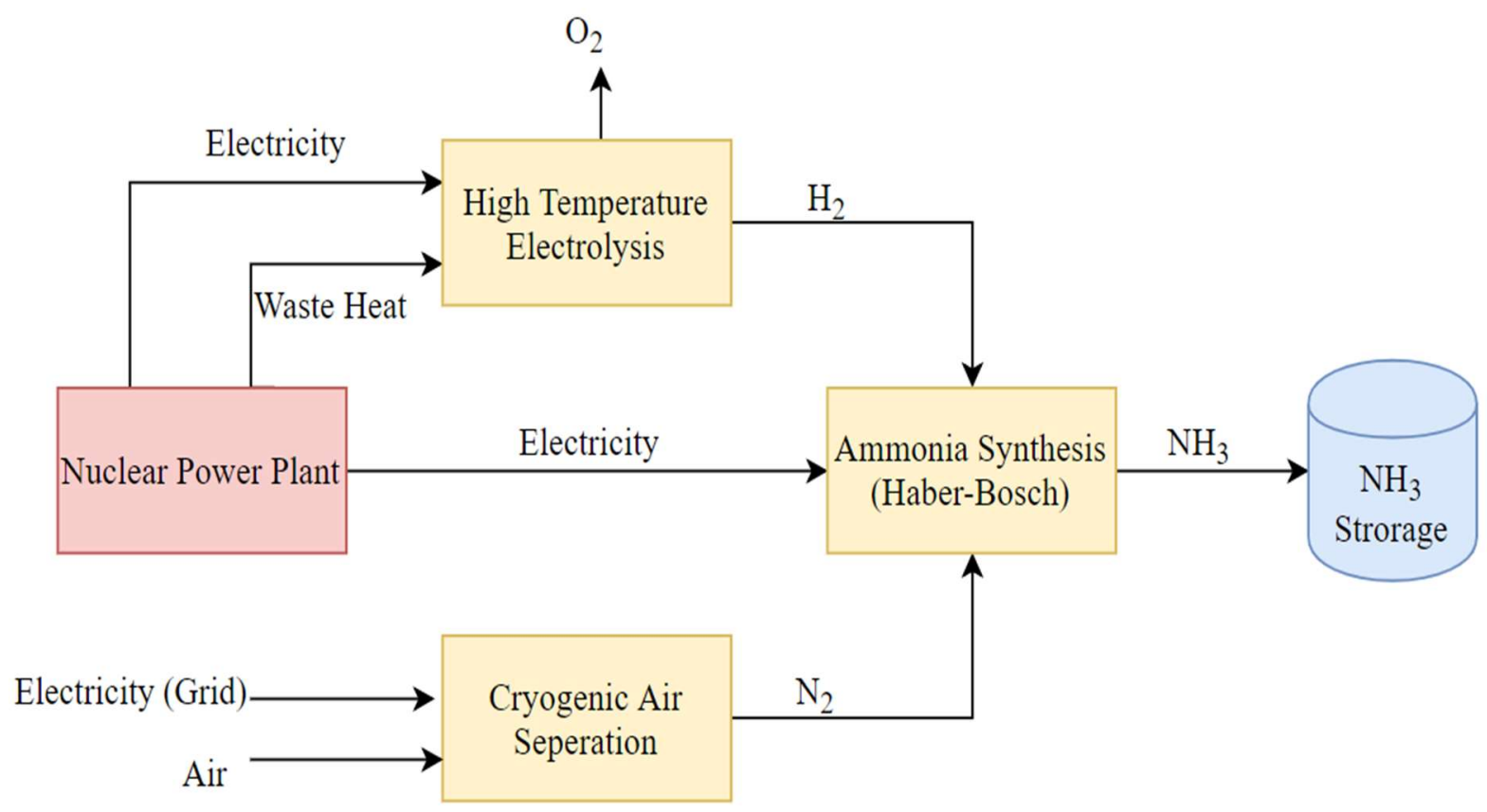

Figure 4. 4: Simple layout of nuclear-based ammonia production via HTE. 


\subsubsection{Nitrogen Production}

Nitrogen is also needed for ammonia productoin. Conventionally, cryogenic air seperation is employed for a massive nitrogen production since it is a mature technology. The Linde process, which is developed by William Hampson and Carl von Linde in 1895 (Timmerhouse and Reed, 2007), is the dominant process for cryogenic air worldwide which is utilized in this study since the technology is already available in SimaPro database. In the Linde cycle, air is first liquefied by cooling and compression, then fractionated by distillation. Nitrogen, oxygen and argon are produced both in their gaseous and liquid form for industrial uses (Simapro Database, 2007). Required electricity for the process is supplied from the national grid. In the life cycle assessment of nitrogen production, electricity for the process, cooling water, waste heat and infrastructure for air fractionation plant are considered. The utilized software for LCA study, SimaPro, has the values for nitrogen production from cryogenic air fractination process in the database.

\subsubsection{Haber-Bosch Ammonia Synthesis}

The Haber-Bosch is a mature technology which is used for production of ammonia worldwide. The reaction is assisted by catalyst and the optimal temperature range is 450$600{ }^{\circ} \mathrm{C}$. The process occurs as following reaction to combine hydrogen and nitrogen thermo-catalytically:

$$
3 / 2 \mathrm{H}_{2}+1 / 2 \mathrm{~N}_{2} \rightarrow \mathrm{NH}_{3}+45.2 \mathrm{~kJ} / \mathrm{mol}
$$

The ammonia production process in a Haber-Bosch plant, as shown in Figure 4.5, occurs as follows. Make-up gas consisting of hydrogen and nitrogen is supplied as input and compressed to medium pressure. The make-up gas is combined with unreacted gasses returned from the loop and further compressed to the conversion pressure. The feed is sent to the catalytic converter, which mainly covers catalysts based on iron. The resulting gasses, which comprise the converted ammonia product, arrive at the intermediate pressure ammonia separator. Ammonia is separated from the bottom of the separator by condensation and collected as a liquid. To cool, condense and separate the product, an ammonia-based refrigeration plant is used. The residual gasses, which contain mainly unreacted nitrogen and hydrogen, are partly recycled by recompression together with the make-up gas (Yusuf Bicer, 2017). 


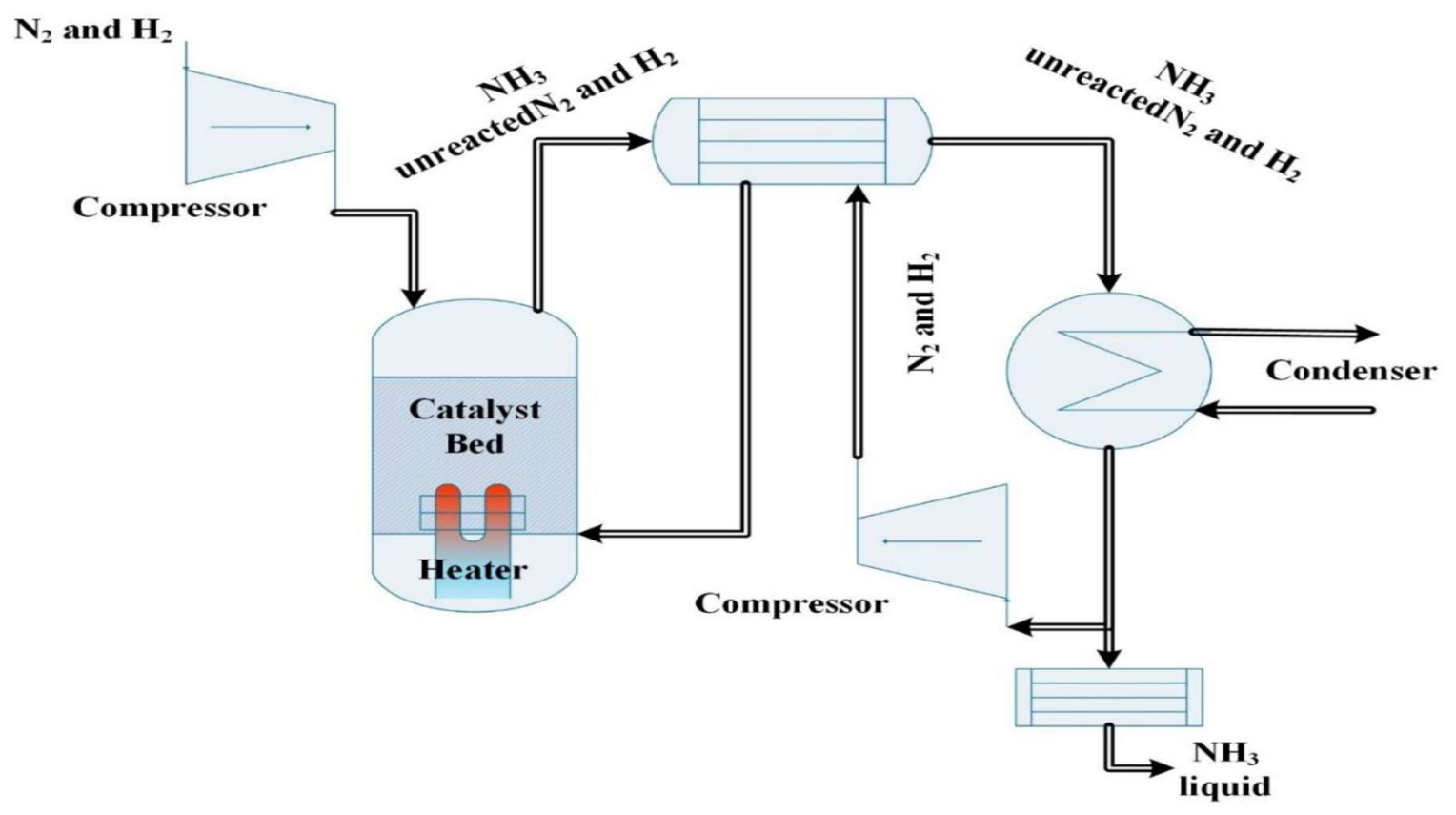

Figure 4. 5: Simple schematic of Haber-Bosch ammonia production process ( Adapted from Yusuf Bicer, 2017).

Haber-Bosch ammonia production process occurs as an exothermic reaction which combines hydrogen and nitrogen in 3:1 ratio to yield ammonia. Table 4.9 shows the main input and output for nuclear-based ammonia production. Ammonia production process consumes $2 \mathrm{kWh}$ additional electricity for Haber-Bosch production unit.

Table 4. 9: Main inputs and outputs for nuclear-based ammonia production via HaberBosch process.

\begin{tabular}{|l|l|l|l|}
\hline Input & Nitrogen & $\begin{array}{l}\text { Electricity, nuclear } \\
(\text { additional }\end{array}$ & Output \\
\hline Hydrogen & $(\mathrm{kg})$ & $(\mathrm{kg})$ & $(\mathrm{kg})$ \\
\hline$(\mathrm{kg})$ & 0.823 & 2 & 1 \\
\hline 0.177 & & & \\
\hline
\end{tabular}

\subsubsection{Nuclear Power Plant}

The electrical and thermal energy requirements of all used processes and sub-components are supplied from a pressurized water reactor in this study. In some scenarios, the boiling 
water reactor is also used to show the impact of reactor selection on the results of LCA. On the basis of the operation of the average US PWR with an average burnup of $37.5 \mathrm{MWd} /$ $\mathrm{kg}$ heavy metal, all data set was developed for the PWR reactor used. The average burn corresponds to an average enrichment of 3.8 percent U235 for fresh uranium fuel elements in the PWR reactor, all of which use fresh uranium.

Based on the operation of the average US BWR with an average burnup of $32.4 \mathrm{MWd}$-th / kg heavy metal, the data set was developed for the used BWR type rector. The average burnup corresponds to an average enrichment of 3.0 percent U235 for fuel elements, all of which use fresh uranium because reprocessing is not allowed in the United States. The life cycle assessment includes the requirements for fuel, chemicals, and diesel as well as the relevant transport requirements. The use of cooling water is also taken into consideration. Radioactive waste streams are considered: Used fuel for reprocessing and conditioning; low active operational waste for conditioning in the intermediate repository; and contaminated waste from dismantling. Non-radioactive waste is considered. The excess heat process with an efficiency of 90 percent is assumed. It is important to note that the waste heat used in the analysis does not come from any heat from the chemical plant, but excess heat from the nuclear plant. In this way, the total impact on the environment for the systems used is reduced.

\subsection{Hydrogen Economy Evaluation Program (HEEP)}

In several parts of the world, the hydrogen economy is becoming more visible and more supported politically. In this regard, the International Atomic Energy Agency (IAEA) developed and released the Hydrogen Economy Evaluation Program (HEEP) that can be utilized to assess the economics of large-scale nuclear-based hydrogen production. HEEP includes four different hydrogen production processes namely, high and low-temperature electrolysis, thermochemical cycles including sodium-iodine (S-I) cycle, conventional electrolysis, and steam reforming. The HEEP models are based on economic and technical data, as well as on the cost modeling of hydrogen economies, including storage, transportation, and distribution, with options for removal of specific details if required. (IAEA, 2018). The characterics of all employed production, storage, and transportation systems will be provided in the following sections. 
In this study, The HEEP software is utilized for cost estimation of nuclear-based hydrogen production methods namely, conventional electrolysis (CE), high temperature steam electrolysis (HTSE) and thermochemical S-I cycles. Various configurations of co-located nuclear-based hydrogen productions with different storage methods and different nuclear power plant types will be considered for comparative cost assessment. Table 4.10 shows the characteristics of hydrogen production plants used in the HEEP software for comparative cost analysis.

Table 4. 10: Hydrogen production plants details used in the HEEP software.

\begin{tabular}{|l|c|c|c|}
\hline Hydrogen generation plant & HTSE & CE & S-I \\
\hline $\mathrm{H}_{2}$ generation per unit (kg/year) & $1.26 \mathrm{E}+08$ & $1.26 \mathrm{E}+08$ & $1.26 \mathrm{E}+08$ \\
\hline Heat consumption (MWth/unit) & 1020 & 0 & 1261.4 \\
\hline Electricity required (MWe/unit) & 0 & 719 & 428 \\
\hline Number of units & 1 & 1 & 1 \\
\hline Overnight capital cost (USD/unit) & $4.59 \mathrm{E}+08$ & $4.23 \mathrm{E}+08$ & $6.66 \mathrm{E}+08$ \\
\hline Other O\&M cost (\% of capital cost) & 17.23 & 4 & 6.68 \\
\hline Decommissioning cost (\% of capital cost) & 10 & 10 & 10 \\
\hline
\end{tabular}

The HEEP includes three different hydrogen storage methods namely, compressed gas, liquefaction, and metal hydrides. Moreover, the HEEP provides different hydrogen transportation options for comparative assessment. Since liquefaction and metal hydrides storage options cannot be co-operated with pipelines for transportation, trucks will be considered only as a transportation option in cost analysis. Table 4.11 and Table 4.12 display the details about the hydrogen storage methods used in the HEEP software and the transportation details for hydrogen transportation to end users, respectively.

Table 4. 11: Hydrogen storage details used in the HEEP software.

\begin{tabular}{|l|c|c|c|}
\hline Storage method & $\begin{array}{c}\text { Compressed } \\
\text { gas }\end{array}$ & Liquefaction & $\begin{array}{c}\text { Metal } \\
\text { hydrides }\end{array}$ \\
\hline Storage capacity (kg) & $1.26 \mathrm{E}+08$ & $1.26 \mathrm{E}+08$ & $1.26 \mathrm{E}+08$ \\
\hline Compressor cooling water (Lit/hr) & $7.48 \mathrm{E}+05$ & $1.04 \mathrm{E}+07$ & $9.29 \mathrm{E}+04$ \\
\hline Electricity requirement (kWe) & $3.29 \mathrm{E}+04$ & $1.66 \mathrm{E}+05$ & $3.01 \mathrm{E}+06$ \\
\hline Overnight capital cost (USD) & $2.64 \mathrm{E}+08$ & $2.53 \mathrm{E}+08$ & $5.32 \mathrm{E}+09$ \\
\hline $\begin{array}{l}\text { Other O\&M cost } \% \text { of capital } \\
\text { cost) }\end{array}$ & $5.00 \mathrm{E}+00$ & $5.00 \mathrm{E}+00$ & $0.00 \mathrm{E}+00$ \\
\hline
\end{tabular}


Table 4. 12: Hydrogen transportation details by trucks used in the HEEP software.

\begin{tabular}{|l|c|}
\hline Distance for transport (km) & 200 \\
\hline Overnight capital cost (USD) & $9.58 \mathrm{E}+07$ \\
\hline Fuel cost \& driver's pay (USD) & $9.84 \mathrm{E}+07$ \\
\hline Other O\&M cost $(\%$ of capital cost) & 0.1 \\
\hline Decommissioning cost (\% of capital cost) & 0.5 \\
\hline
\end{tabular}

One of the most important factors to be considered when deciding on nuclear hydrogen production is the size and the type of nuclear reactor.The HEEP includes many different nuclear types that allow users to create various scenarious operating with various different reactor types. In this study, three different reactor types will be employed in the HEEP software utilization namely, advance pressurized water reactor (APWR), high temperature gas-cooled reactor (HTGR), and high temperature reactor (HTR_K). The reason operating with these three reactor is that they have higher thermal capacity than that of other reactor types the HEEP includes. Since hydrogen production methods requires both thermal and electrical energy, co-operation with an NPP with high thermal capacity is more suitable for large-scale hydrogen production. Table 4.13 inludes the characteristics of NPPs selected in the HEEP software for comparative assessment.

Table 4. 13: Nuclear power plants details used in the HEEP software.

\begin{tabular}{|l|c|c|c|}
\hline Reactor type & APWR & HTGR & HTR_K \\
\hline Thermal rating (MWth/unit) & 3385 & 630.7 & 600 \\
\hline Heat for H2 plant (MWth/unit) & 1020 & 630.7 & 540 \\
\hline Electricity rating (MWth/unit) & 1117.5 & 0 & 0 \\
\hline Number of units & 2 & 2 & 4 \\
\hline Initial fuel load (kg/unit) & 75000 & 18000 & 100000 \\
\hline Annual fuel feed (kg/unit) & 25000 & 6000 & 100000 \\
\hline Overnight capital cost (USD/unit) & $5.96 \mathrm{E}+09$ & $6.05 \mathrm{E}+08$ & $6.05 \mathrm{E}+08$ \\
\hline $\begin{array}{l}\text { Capital cost fraction for electricity } \\
\text { generation } \\
\text { infrastructure (\%) }\end{array}$ & 10 & 0 & 0 \\
\hline Fuel cost (USD/kg) & 1260 & 5535 & 250 \\
\hline O\&M cost (\%of capital cost) & 1.7 & 5.75 & 2.07 \\
\hline Decommissioning cost ( \% of capital cost) & 2.8 & 8.35 & 10 \\
\hline
\end{tabular}


The HEEP calculates the levelized hydrogen cost as the present value of the generated hydrogen, storage, and transport to the current value of the generated gross hydrogen (Khamis et al., 2010).

$$
C_{H_{2}}=\frac{E_{N P P}\left(t_{0}\right)+E_{H_{2} G P}\left(t_{0}\right)+E_{H_{2} T}\left(t_{0}\right)}{G_{H_{2}}\left(t_{0}\right)}
$$

In this equation, $\mathrm{E}, \mathrm{C}$ and $\mathrm{G}$ refer to expenditures, whereas subscripts $\mathrm{NPP}, \mathrm{H}_{2} \mathrm{GP}$, and $\mathrm{H}_{2} \mathrm{~T}$ address to the nuclear power plant, hydrogen production and storage, and hydrogen transportation, respectively. The present values of expenditures are calculated with the following equation ( El-Emam et al., 2015):

$$
E\left(t_{0}\right)=\sum_{t_{-} i}^{t_{-} f} \frac{C I_{t}\left(t_{0}\right)}{(1+r)^{t-t_{0}}}+\sum_{t_{-} i}^{t_{-} f} \frac{R_{t}}{(1+r)^{t-t_{0}}}+\sum_{t_{-} i}^{t_{-} f} \frac{D C_{t}}{(1+r)^{t-t_{0}}}
$$

In this equation, $\mathrm{CI}, \mathrm{R}$ and $\mathrm{DC}$ regard to capital investment expenditures, facility running expenditures and decommissioning expenditures for the year $t$, respectively. Subscript 0 is the base year, and $r$ is the actual rate of discount.. Table 4.14 shows the general cost and operational parameters used in the HEEP software for comparative assessment of created nuclear-based hydrogen production configurations.

Table 4. 14: Other cost and operating parameters used in the HEEP software.

\begin{tabular}{|l|c|}
\hline Discount rate (\%) & 5 \\
\hline Inflation rate (\%) & 1.2 \\
\hline Interest rate (\%) & 10 \\
\hline Tax rate (\%) & 10 \\
\hline Equity: debt (\%) & $70 \%: 30 \%$ \\
\hline Deprecation period (year) & 20 \\
\hline Construction period (year) & 5 \\
\hline Operation life time (year) & 60 \\
\hline $\begin{array}{l}\text { Cooling before decommissioning } \\
\text { (month) }\end{array}$ & 12 \\
\hline Decommissioning (year) & 10 \\
\hline Fuel cooling (month) & 24 \\
\hline Waster cooling (month) & 24 \\
\hline Capacity factor $(\%)$ & 90 \\
\hline Availability factor $(\%)$ & 100 \\
\hline Unit cost of grid electricity (\$/kWh) & 5 \\
\hline
\end{tabular}


The present value of the gross production of hydrogen for $t_{0}$ is as follows:

$$
G_{H_{2}}\left(t_{0}\right)=\sum_{t_{-} i}^{t_{-} f} \frac{G_{H_{2}}\left(t_{0}\right)}{(1+r)^{t-t_{0}}}
$$

Where; $\mathrm{G}_{\mathrm{H} 2}$ refers to hydrogen generation in the year $\mathrm{t}$. The HEEP adopts the "Power Credit Method" to estimate the cost of thermal energy and electricity generation (Khamis et al., 2010).

To sum up, the sub-processes of nuclear-based hydrogen and ammonia production have been described. Primary inputs and outputs of production processes have been determined. The inputs for the production processes will be used in the LCA study of nuclear-based hydrogen and ammonia production processes. In the LCA study, uranium fuel process, which consists of mining, milling, conversion, enrichment, and fuel fabrication is taken into account. Construction and utilization have been considered as well. Furthermore, the HEEP software is described and required operating parameters for the cost analysis of various nuclear-based hydrogen production configurations. The results for the LCA study of nuclear-based hydrogen and ammonia production, and results of the performed cost analysis of different hydrogen production methods in the HEEP software are discussed in the next chapter herein. 


\section{CHAPTER 5: RESULTS AND DISCUSSION}

In this chapter, the results are obtained through modeling a comprehensive LCA study of nuclear-based hydrogen and ammonia production methods via SimaPro software. Results of the LCA study are presented and assessed comparatively. Firstly, section 5.1 presents results of LCA carried out in this study. Section 5.1.1 contains the LCA results of the employed hydrogen production methods regarding selected impact categories defined by CML 2001 method. Section 5.1.2 discusses the LCA results of ammonia production methods. Section 5.1.3 compares the LCA results of BWR-based and PWR-based nuclear hydrogen production methods to reveal the impacts of nuclear power plant selection on LCA results. Section 5.2 shows the cost comparison results of nuclear hydrogen production through different configuration using HEEP software.

\subsection{LCA Results in terms of Impact Categories}

SimaPro software's background database the Ecoinvent is utilized to calculate life cycle impact (LCI) data for the hydrogen and ammonia production processes. However, since the SimaPro database does not include the defined hydrogen and ammonia production techniques' data, new processes have been created to analyze the determined production methods via life cycle impact assessment (LCIA) technique.

Environmental impacts for one $\mathrm{kg}$ hydrogen and ammonia production will be shown in following categories in depth:

- Abiotic Resource Depletion Potential (ADP)

- Acidification Potential (AP)

- Global Warming Potential (GWP)

- Ozone Depletion Potential (ODP)

- Human Toxicity Potential (HTP)

Various nuclear-based hydrogen and ammonia production processes are defined, and energy and material requirements for each method are determined. The values are used in SimaPro software for calculations of life cycle assessment. One $\mathrm{kg}$ of hydrogen and 
ammonia is defined as the functional unit of production processes. The environmental impact results are presented herein.

\subsubsection{Hydrogen Production Results}

In this section, the environmental impacts of one kg nuclear-based hydrogen production from employed methods are comparatively given in detail to reveal the contribution of various sub-processes. When reporting the contribution of different processes to selected impact category, applied cut-off vary from 3 to $12 \%$ to reveal the contributors since the contribution of some sub-processes is very small, and high cut-off does not show the contributors in detail in some cases. Table 5.1 displays the LCA results of selected impact categories obtained for hydrogen production processes. Each impact categories in Table 5.1 will be discussed in detail by providing graphs and tables in the following sections.

Table 5. 1: Environmental Impacts of various nuclear-based hydrogen production methods

\begin{tabular}{|l|c|c|c|c|c|}
\hline \multicolumn{1}{|c|}{ Impact Categories } & $\begin{array}{c}\text { Conventional } \\
\text { Water } \\
\text { Electrolysis }\end{array}$ & $\begin{array}{c}\text { Temperature } \\
\text { Water } \\
\text { Electrolysis }\end{array}$ & $\begin{array}{c}3 \text { step Cu-Cl } \\
\text { cycle }\end{array}$ & $\begin{array}{c}\text { 4 step Cu-Cl } \\
\text { cycle }\end{array}$ & $\begin{array}{c}5 \text { step Cu-Cl } \\
\text { cycle }\end{array}$ \\
\hline $\mathrm{ADP}(\mathrm{kg} \mathrm{SB}$ eq) & 0.0048 & 0.0033 & 0.0090 & 0.0082 & 0.0092 \\
\hline $\mathrm{AP}\left(\mathrm{kg} \mathrm{SO} \mathrm{SO}_{2}\right.$ eq & 0.0051 & 0.0034 & 0.0095 & 0.0086 & 0.0096 \\
\hline $\mathrm{GWP}(\mathrm{kg} \mathrm{CO}$ eq $)$ & 0.7071 & 0.4768 & 1.320 & 1.201 & 1.346 \\
\hline ODP $(\mathrm{kg} \mathrm{CFC11} \mathrm{eq)}$ & $4.268 \mathrm{E}-08$ & $2.876 \mathrm{E}-08$ & $7.966 \mathrm{E}-08$ & $7.250 \mathrm{E}-08$ & $8.125 \mathrm{E}-08$ \\
\hline $\mathrm{HTP}(\mathrm{kg} 1,4-\mathrm{DB}$ eq $)$ & 6.458 & 4.345 & 12.07 & 10.98 & 12.31 \\
\hline
\end{tabular}

Hydrogen productions are seen in Figure 5.1 according to the energy supplier and production process. For instance, Hydrogen (PWR 3 step $\mathrm{Cu}-\mathrm{Cl}$ ) means required thermal and electrical energy is provided from pressurized water reactor, hydrogen is produced via thermochemical 3 step $\mathrm{Cu}-\mathrm{Cl}$ cycle. It is observed that the main contributor in all categories is the energy input from a pressurized water reactor (PWR). As it can be seen from Figure 5.1 created on SimaPro software, the high-temperature electrolysis (HTE) method has the lowest environmental impacts in all categories since it requires lower energy input compared to the other employed hydrogen production methods. For instance, GWPs for high-temperature electrolysis and five-step $\mathrm{Cu}-\mathrm{Cl}$ cycle correspond to $0.477 \mathrm{~kg} \mathrm{CO}$ eq. and1.346 $\mathrm{kg} \mathrm{CO}_{2}$ eq., respectively. 


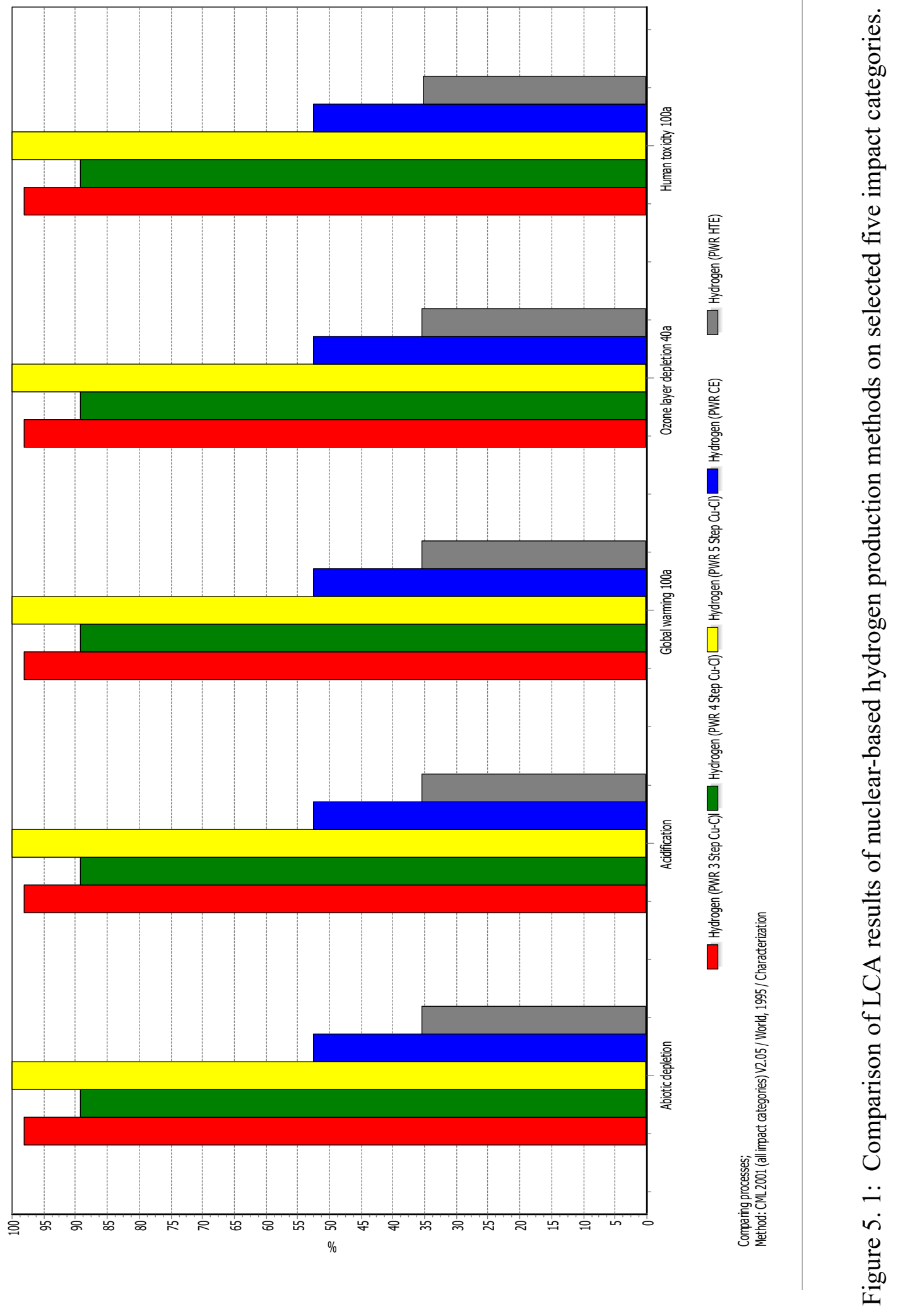




\subsubsection{Abiotic Resource Depletion Potential}

Abiotic resource depletion potential (ADP) deals with the effect on non-living natural resources. Figure 5.2 illustrates the ADP values per $\mathrm{kg}$ of hydrogen produced via five different employed methods powered via nuclear energy. ADP for the five-step $\mathrm{Cu}-\mathrm{Cl}$ cycle has the highest value with $0.009 \mathrm{~kg} \mathrm{Sb}$ eq as expected due to demanding highest thermal and electrical energy. Considering the selected methods, high-temperature water electrolysis corresponds to the lowest ADP value with $0.003 \mathrm{~kg} \mathrm{SB}$ eq per $\mathrm{kg}$ of hydrogen production.

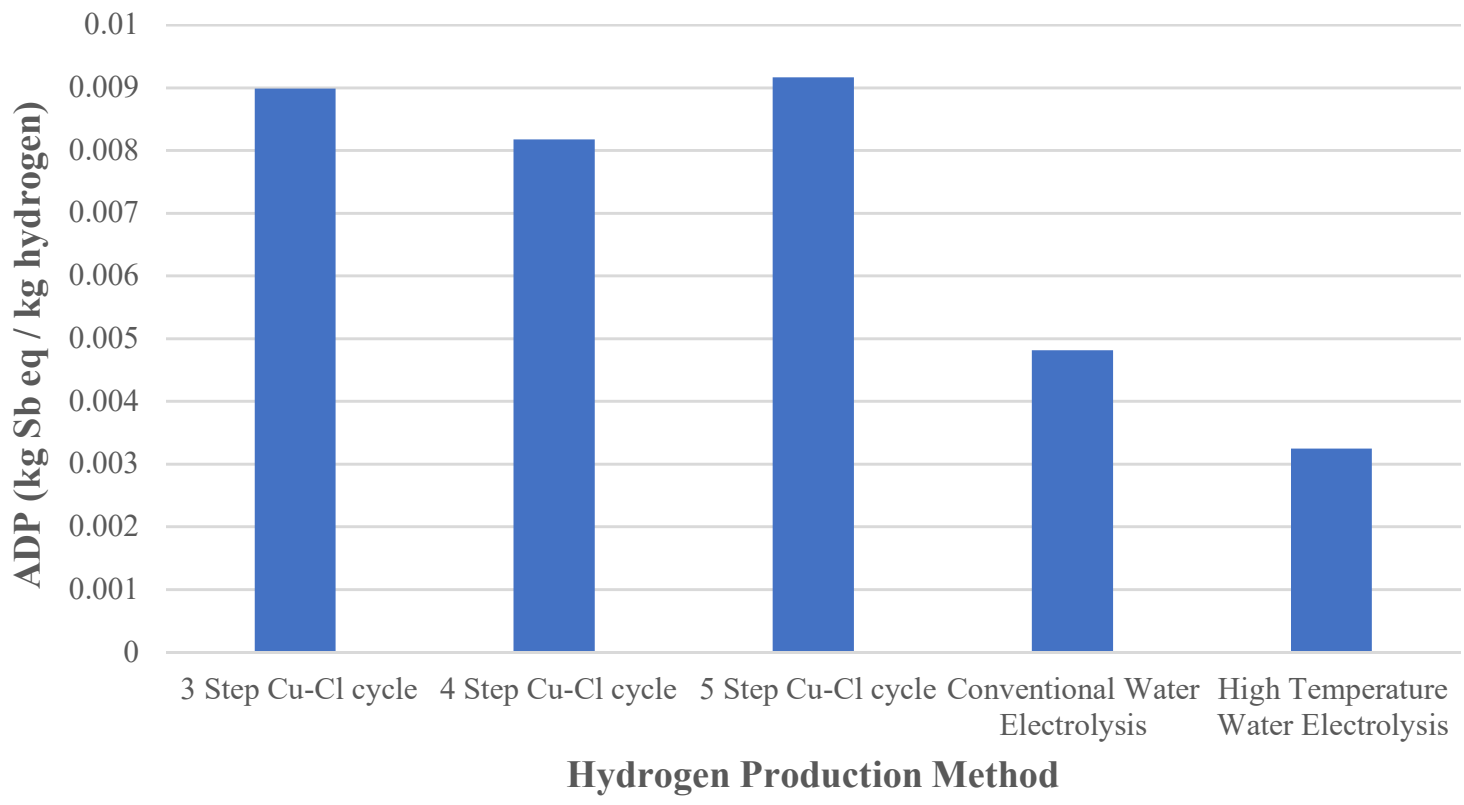

Figure 5. 2: Abiotic depletion potential (ADP) of nuclear-based hydrogen production methods

It is observed that $41 \%$ of abiotic depletion potential of hydrogen production via high temperature electrolysis (HTE) is coming from hard coal mining as shown in Figure 5.3 and Figure 5.4. This coal is used for uranium enrichment process. Since LCA method considers all processes from cradle to grave, it could be too complicated to show all contributors. Instead, $3 \%$ cut off is carried out to see significant contributors to this impact category. Remaining processes consists the $33 \%$ of ADP of hydrogen production via HTE. Figure 5.5 shows the process flowchart of various sub-categories in hydrogen production 
via HTE and highlights the main contributors to ADP of the hydrogen production. When creating Figure 5.5, 7\% cut-off is applied to show a reasonable flowchart.

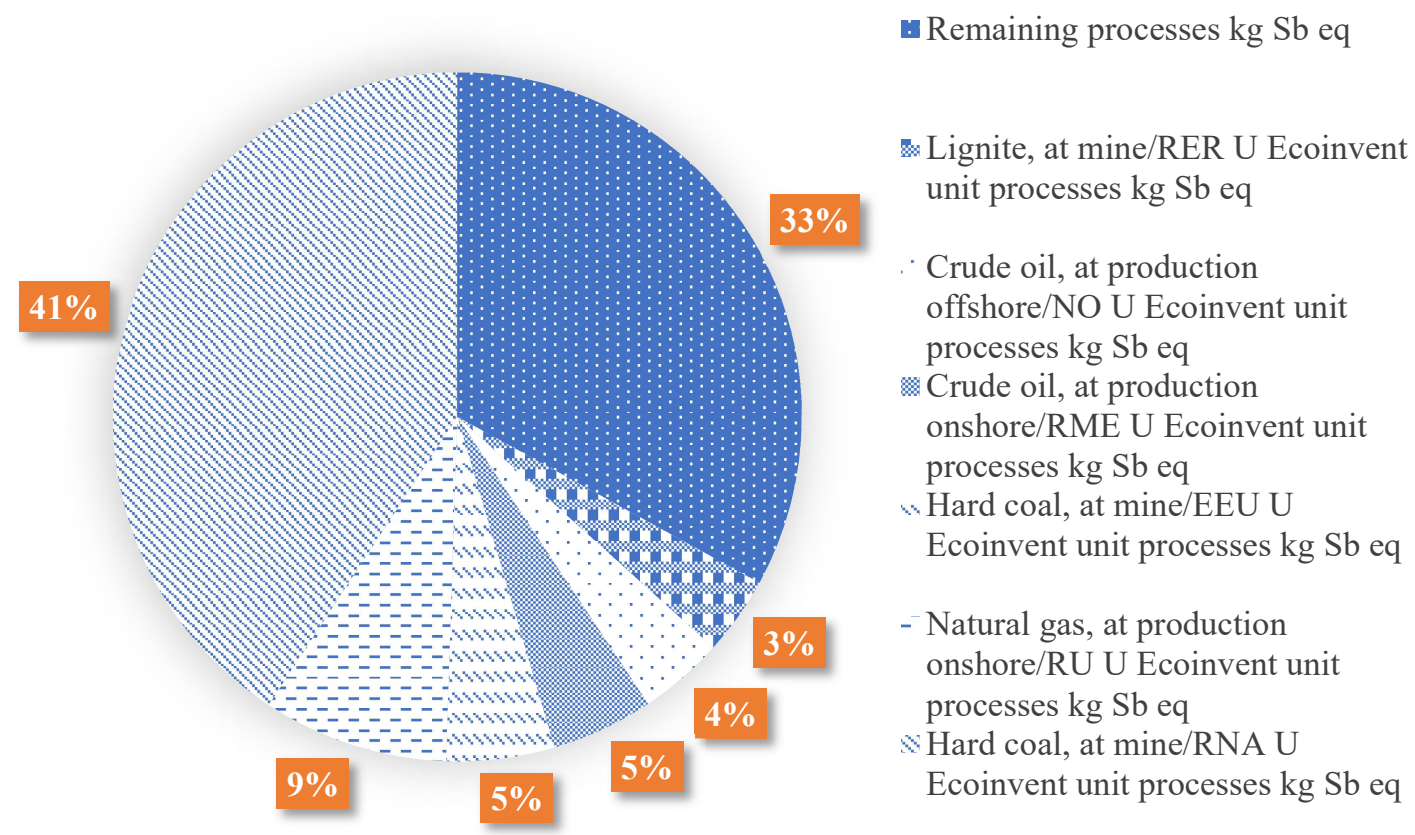

Figure 5. 3: Major contributors of abiotic depletion potential (ADP) of nuclear-based hydrogen production via high temperature electrolysis (HTE).

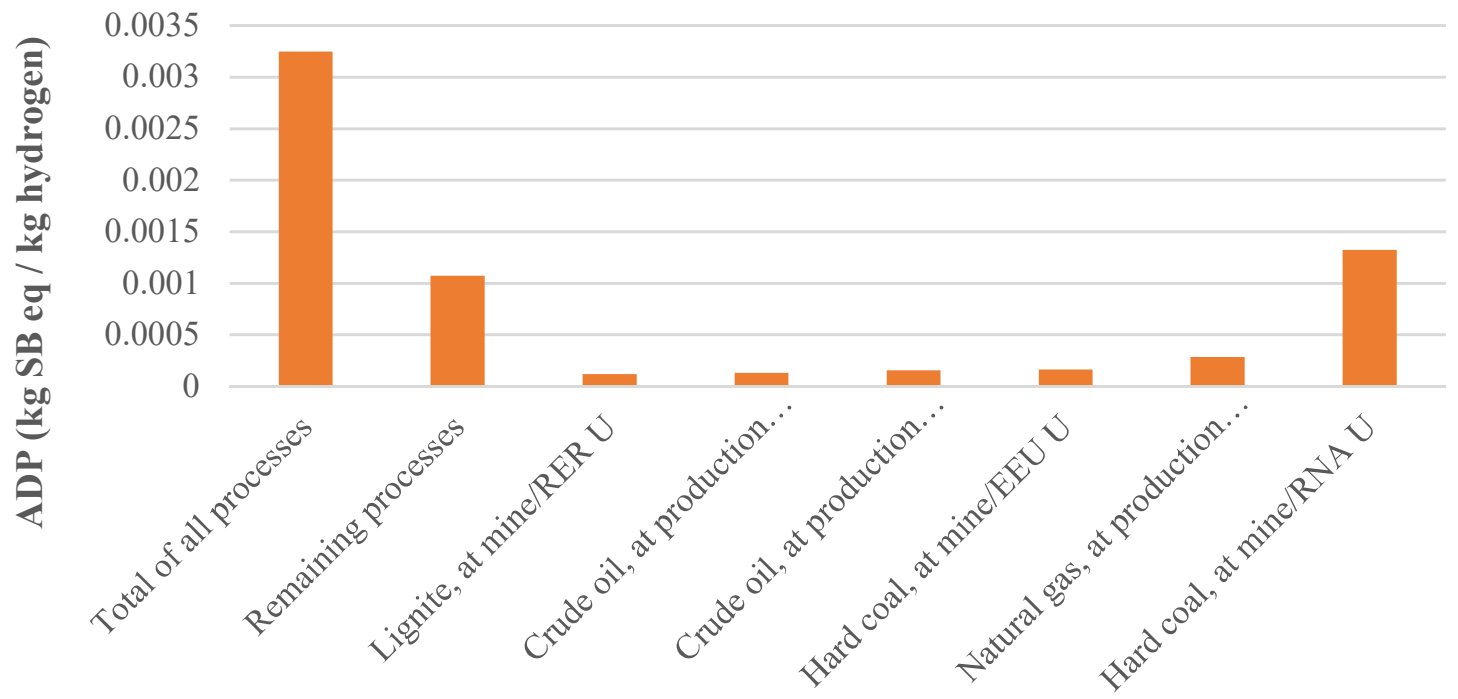

Figure 5. 4: Contribution of various sub-processes to abiotic depletion potential of nuclear-based HTE. 


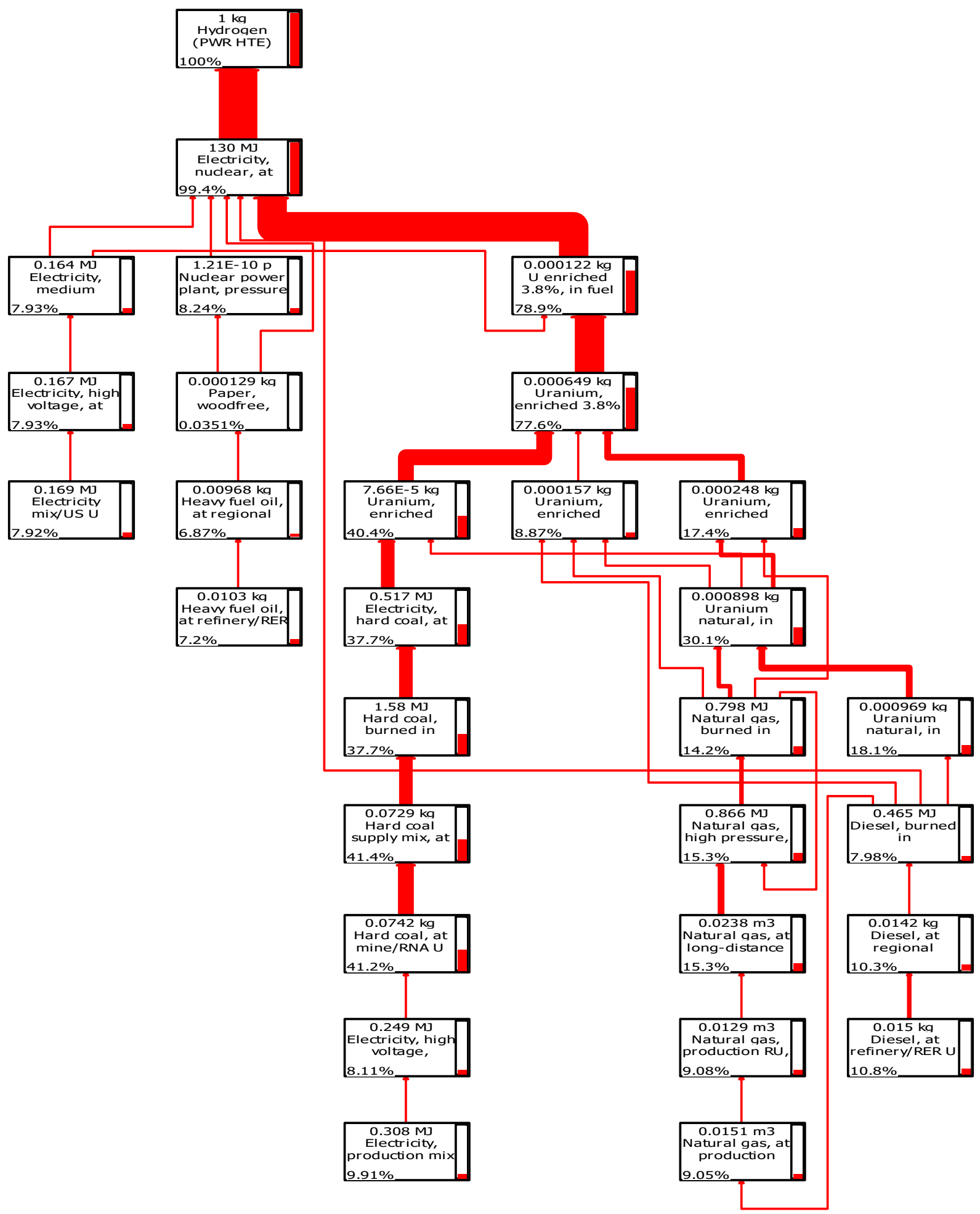

Figure 5. 5: LCA process flowchart for abiotic depletion (ADP) of PWR HTE based hydrogen production (cut-off $7 \%$ ). 


\subsubsection{Acidification Potential (AP)}

The acid deposition of acidifying pollutants in soil, groundwater, surface waters, biological organisms, ecosystems, and materials is related to the acidification potential (AP). Figure 5.6 shows the AP values per $\mathrm{kg}$ of hydrogen production. The minimum AP is achieved as $0.003 \mathrm{~kg} \mathrm{SO}_{2}$ via high-temperature electrolysis whereas AP from five-step $\mathrm{Cu}-\mathrm{Cl}$ cycle has the highest value due to higher energy consumption. Among thermochemical cycles namely, 3-, 4-, and 5-step $\mathrm{Cu}-\mathrm{Cl}$ cycle, it can be observed that the four-step $\mathrm{Cu}-\mathrm{Cl}$ cycle has lower environmental impacts than three and five-step $\mathrm{Cu}-\mathrm{Cl}$ cycles. This is because of that the four-step $\mathrm{Cu}-\mathrm{Cl}$ cycle requires lower thermal energy. Lower thermal energy need also lower the amount of uranium consumed to supply this thermal energy. Since the fuel cycle is the most significant contributor to this impact category, lower uranium consumption decreases the AP. Figure 5.7 and Figure 5.8 show the main contributors to AP of hydrogen production via conventional electrolysis (CE). Hard coal burning for $3.8 \%$ enriched uranium in uranium enrichment plant represents the $32 \%$ of overall life cycle acidification potential of hydrogen production via $\mathrm{CE}$.

0.012

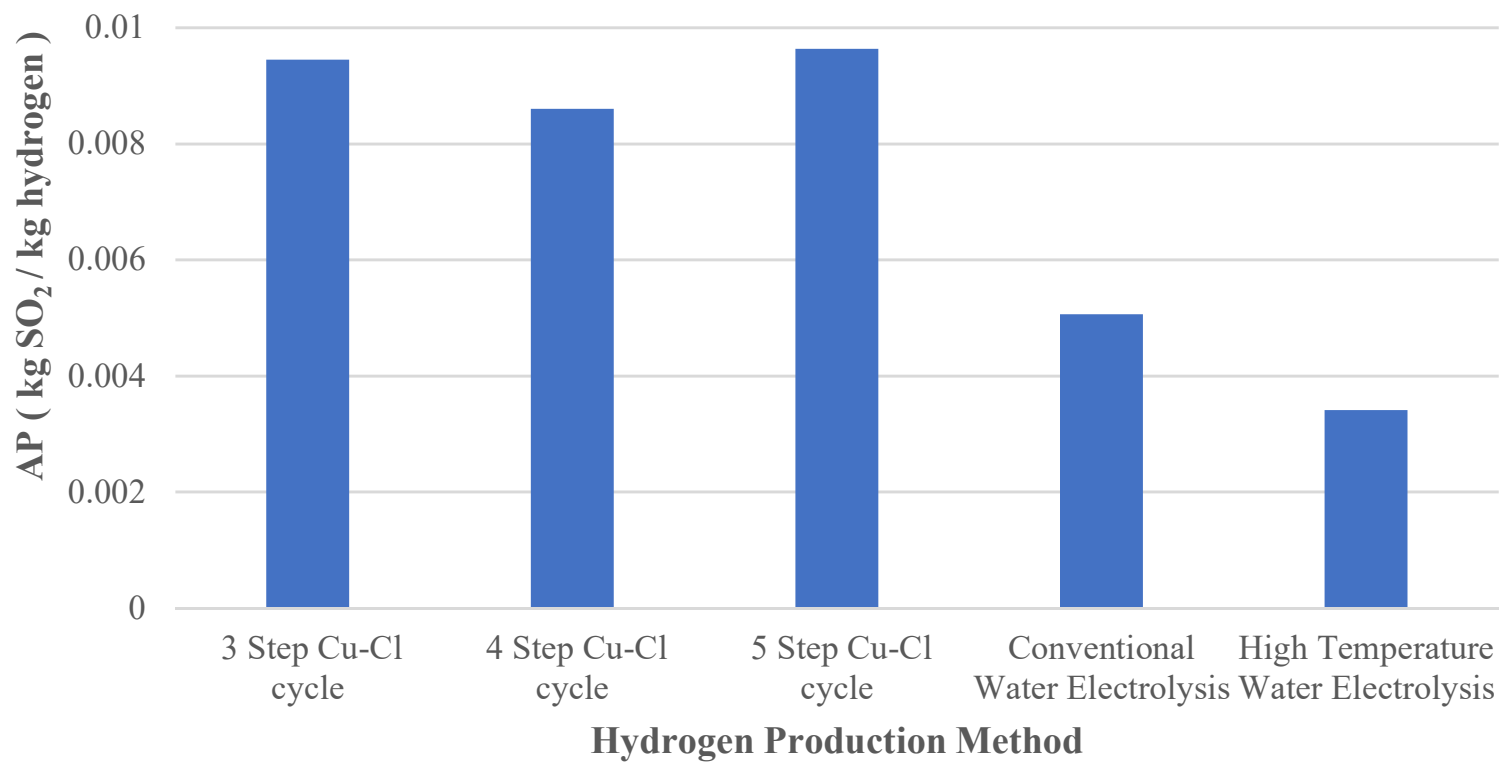

Figure 5. 6: Acidification Potential (AP) of nuclear-based hydrogen production methods. 


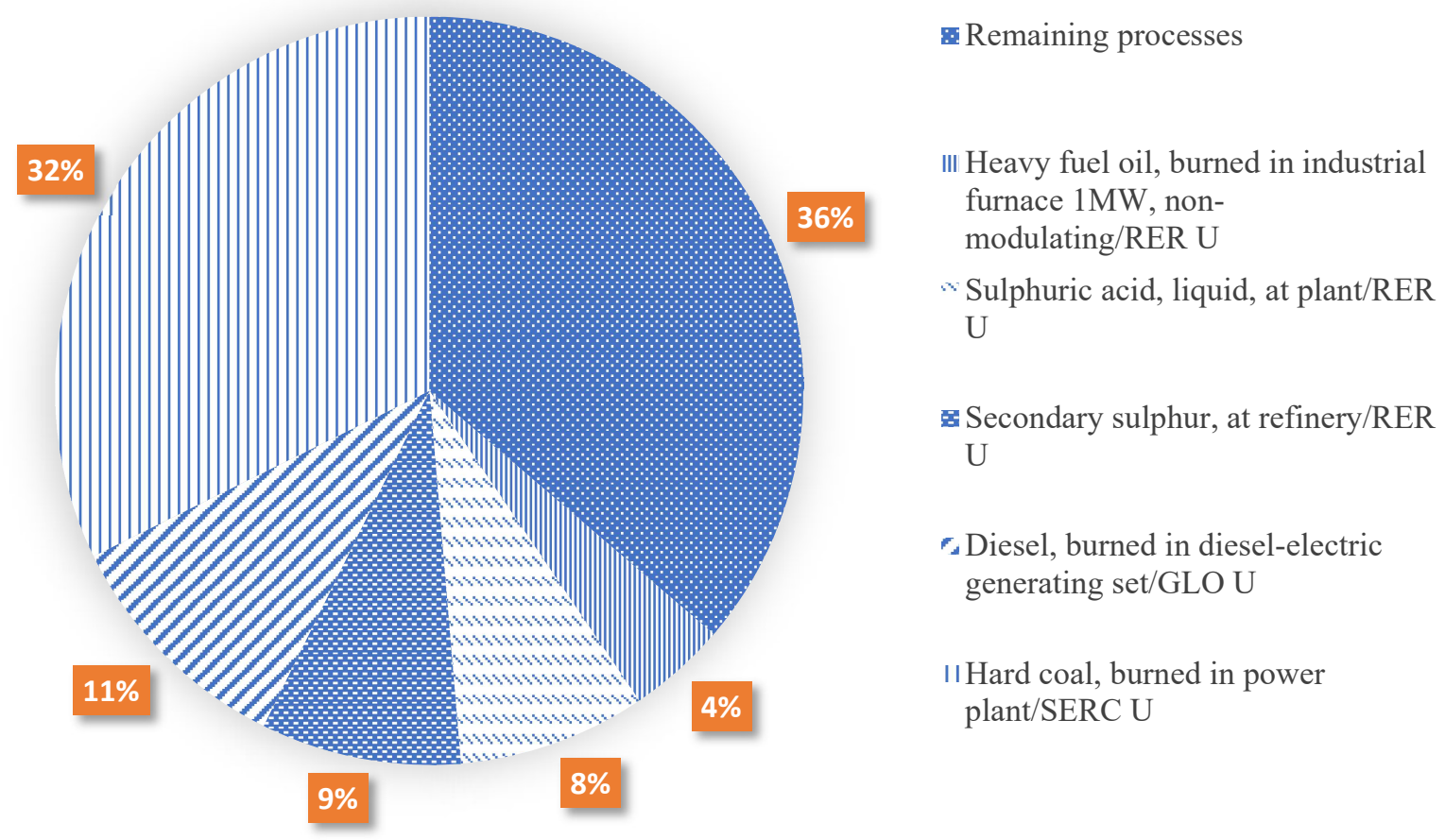

Figure 5. 7: The share of various sub-processes in acidification potential (AP) of nuclearbased hydrogen production via thermoelectrical conventional electrolysis (CE).

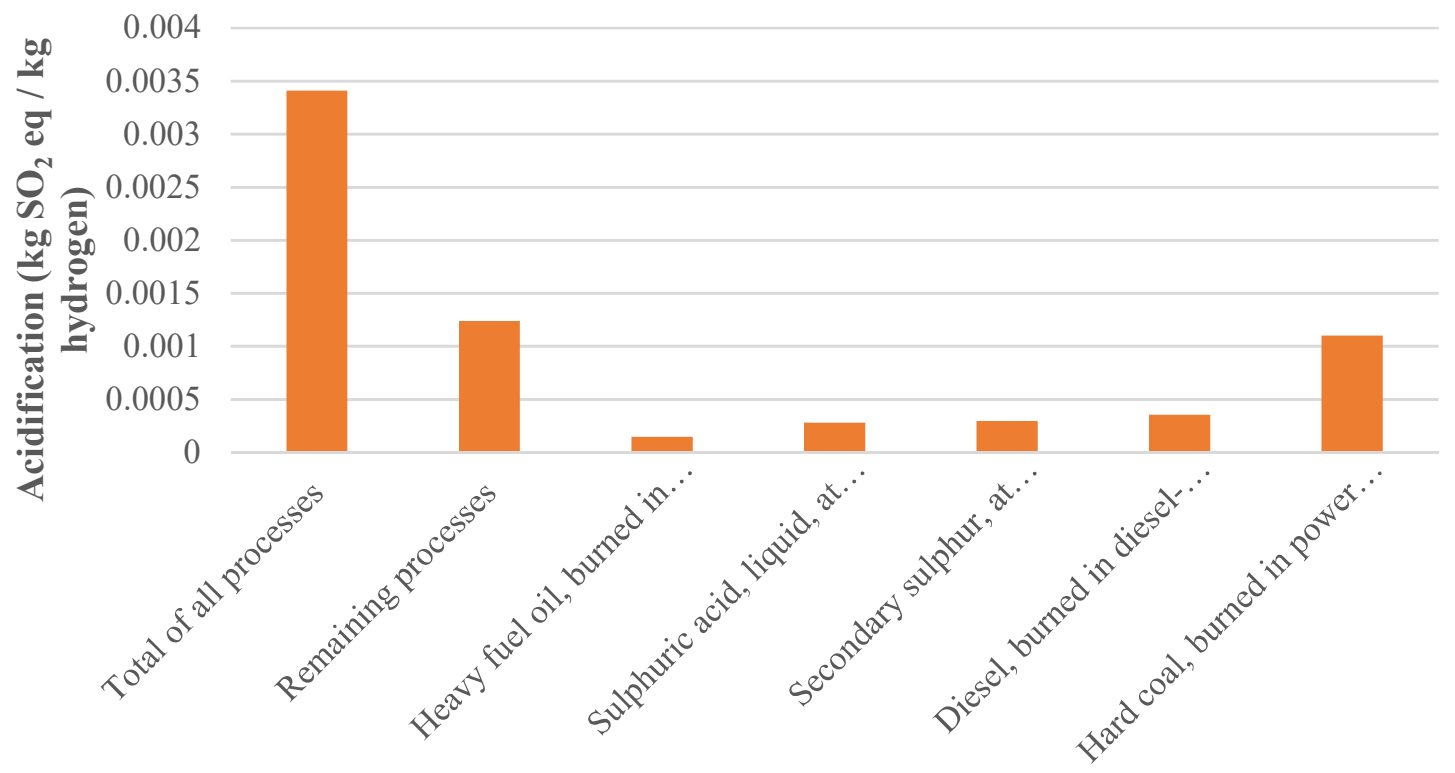

Figure 5. 8: Contribution of various sub-processes to AP of the thermoelectrical conventional electrolysis (CE). 


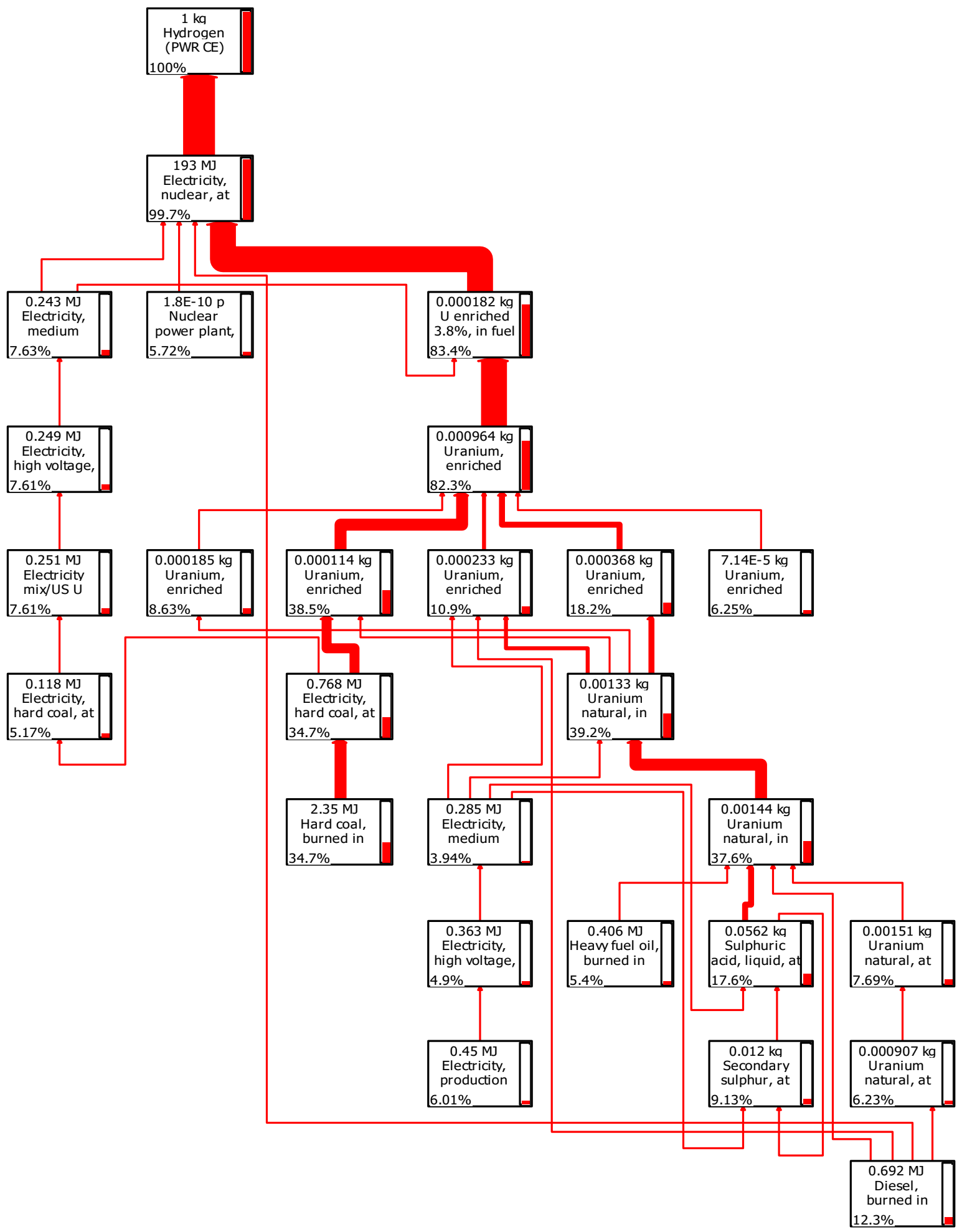

Figure 5. 9: LCA process flow chart for acidification potential (AP) of hydrogen production via CE (cut-off 5\%). 


\subsubsection{Global Warming Potential (GWP)}

Global warming potential (GWP) is related to the temperature rise on the earth due to emissions from human activities which is popularly known as "greenhouse effect". Figure 5.10 shows GWPs from nuclear-based hydrogen production methods. The lowest GWP per $\mathrm{kg}$ of hydrogen production is obtained from high-temperature electrolysis with the value of $0.477 \mathrm{~kg} \mathrm{CO}_{2}$ eq, whereas 3-, 4-, and 5-step $\mathrm{Cu}-\mathrm{Cl}$ cycle and conventional electrolysis correspond to $1.319,1.200,1.346$, and $0.708 \mathrm{~kg} \mathrm{CO}_{2}$ eq per $\mathrm{kg}$ of hydrogen, respectively. Figure 5.11 and Figure 5.12 shows the share and contribution of sub-processes to GWP of 3 step $\mathrm{Cu}-\mathrm{Cl}$ cycle. Contributors for all production processes could be demonstrated, but instead, contributors of each production processes are discussed for each impact categories. The most signifcant contributor of GWP for 3 step $\mathrm{Cu}-\mathrm{Cl}$ cycle is hard coal burned in power plant with the value of $0.427 \mathrm{~kg} \mathrm{CO}_{2}$ eq which is used for enrichment of $3.8 \% \mathrm{U} 235$ for fresh uranium fuel elements in pressurized water reactor (PWR). Figure 5.13 displays the sub-processes contributing to GWP of hydrogen production via HTE. Since total network of all contibutor is too complicated, flow chart is created with $5 \%$ cut off.

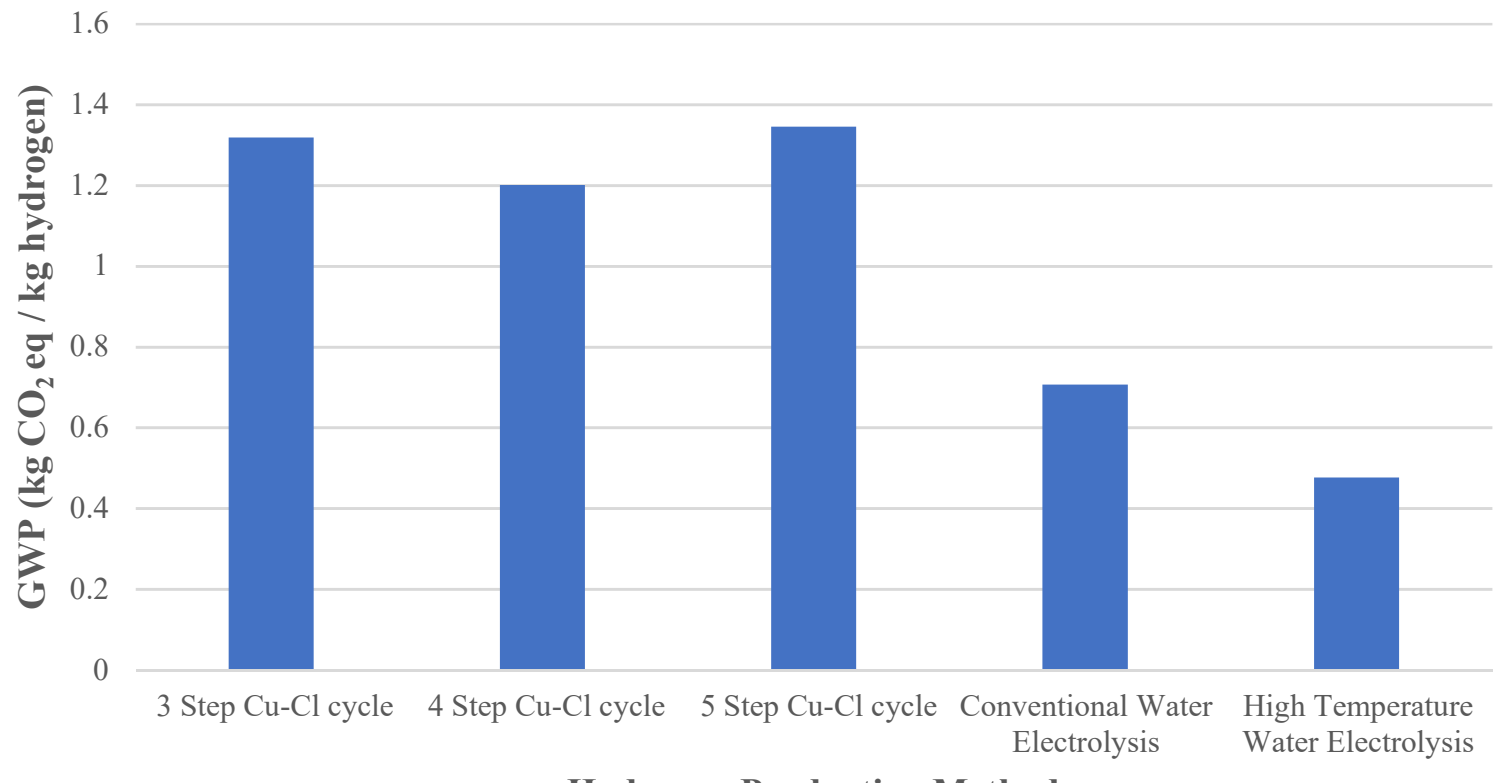

Hydrogen Production Method

Figure 5. 10: Global warming potential (GWP) of nuclear-based hydrogen production methods. 


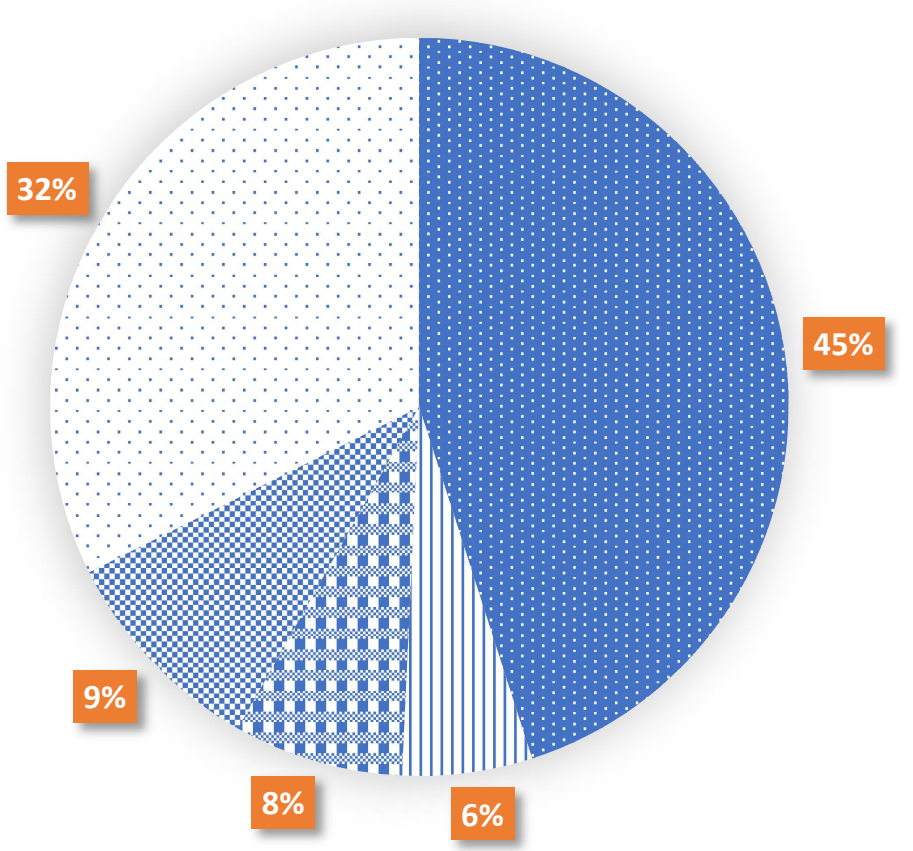

- Remaining processes

I) Uranium, enriched 3.8\%, at USEC enrichment plant/US U

Diesel, burned in diesel-electric generating set/GLO U

Q Natural gas, burned in industrial furnace $>100 \mathrm{~kW} /$ RER U

Hard coal, burned in power plant/SERC U

Figure 5. 11: The share of different sub-processes in greenhouse gas emissions of for nuclear-based hydrogen production via 3 step $\mathrm{Cu}-\mathrm{Cl}$ cycle.

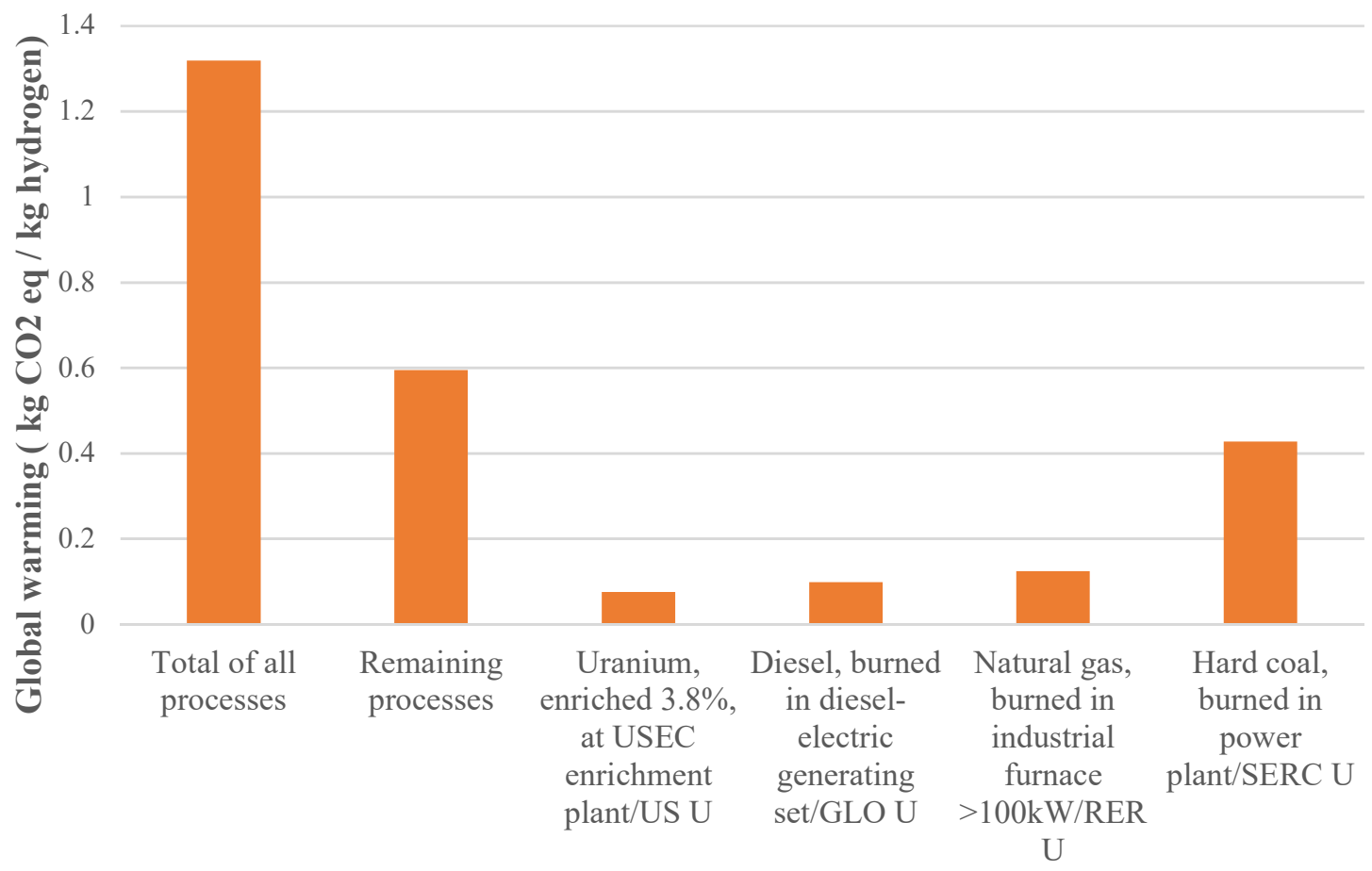

Figure 5. 12: The contribution of sub-processes to GWP of nuclear-based hydrogen production via thermochemical 3 step $\mathrm{Cu}-\mathrm{Cl}$ cycle. 


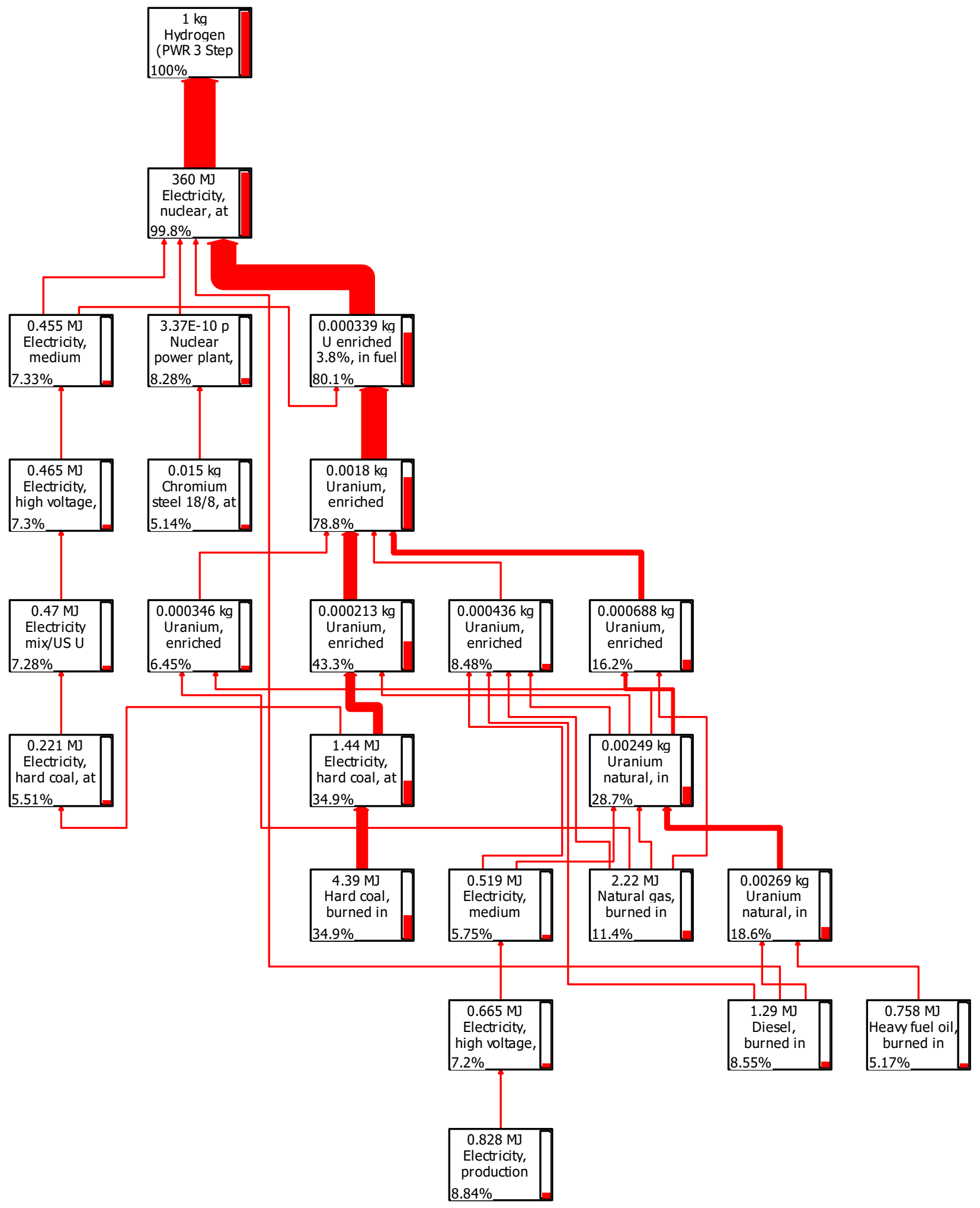

Figure 5. 13: Major contributors to global warming potential (GWP) of nuclear-based hydrogen production via 3 step $\mathrm{Cu}-\mathrm{Cl}$ cycle (cut-off $5 \%$ ). 


\subsubsection{Ozone Layer Depletion (ODP)}

Ozone layer depletion (ODP) is related to the thinning of the stratospheric ozone layer due to emissions leading to a higher proportion of solar UV-B radiation to reach the surface of the earth. Figure 5.14 shows ODP values for selected nuclear-based hydrogen production methods. The primary contributor to ODP is the utilization of nuclear energy for production processes. Since it requires the lowest energy input, it is observed that HTE has the lowest ODP value. Thermochemical 5 step $\mathrm{Cu}-\mathrm{Cl}$ cycle has the highest ozone layer depletive environmental impact with the value of $8.12 \mathrm{E}-08 \mathrm{~kg}$ CFC-11 eq per $\mathrm{kg}$ hydrogen which is followed by the 3 step $\mathrm{Cu}-\mathrm{Cl}$ cycle, 4 step $\mathrm{Cu}-\mathrm{Cl}$ cycle, and conventional electrolysis. Figure 5.15 and Figure 5.16 shows contributors of this impact category for thermochemical 4 step $\mathrm{Cu}-\mathrm{Cl}$ cycle. The most major contributor to this impact category is transportation of natural gas via pipeline to be used in uranium enrichment plant. Remaining processes consist $20 \%$ of total contributors. Figure 5.17 displays other sub-processes for 4 step $\mathrm{Cu}$ $\mathrm{Cl}$ cycle contributing this impact category.

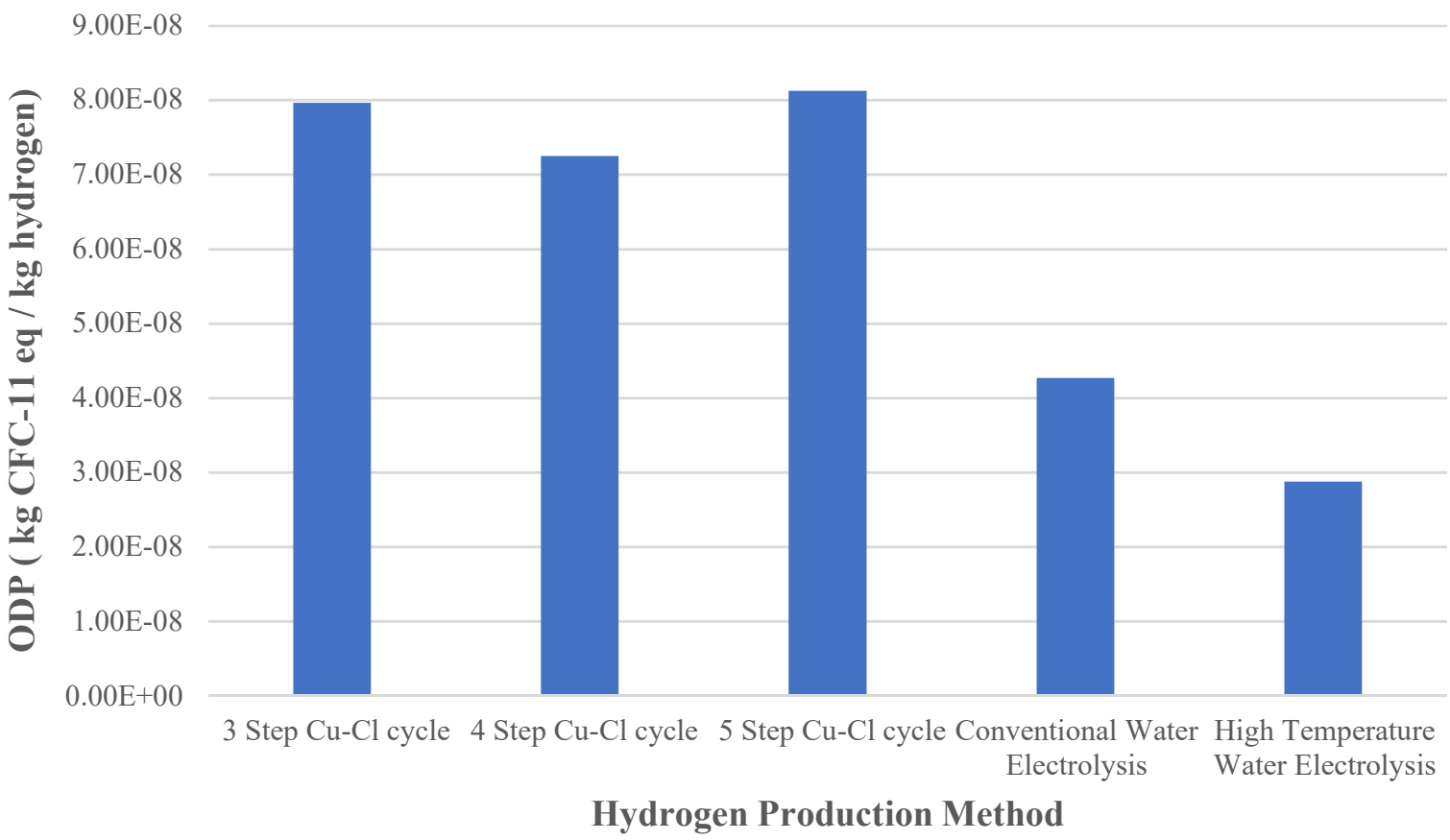

Figure 5. 14: Ozone layer depletion potential (ODP) of nuclear-based hydrogen production methods. 


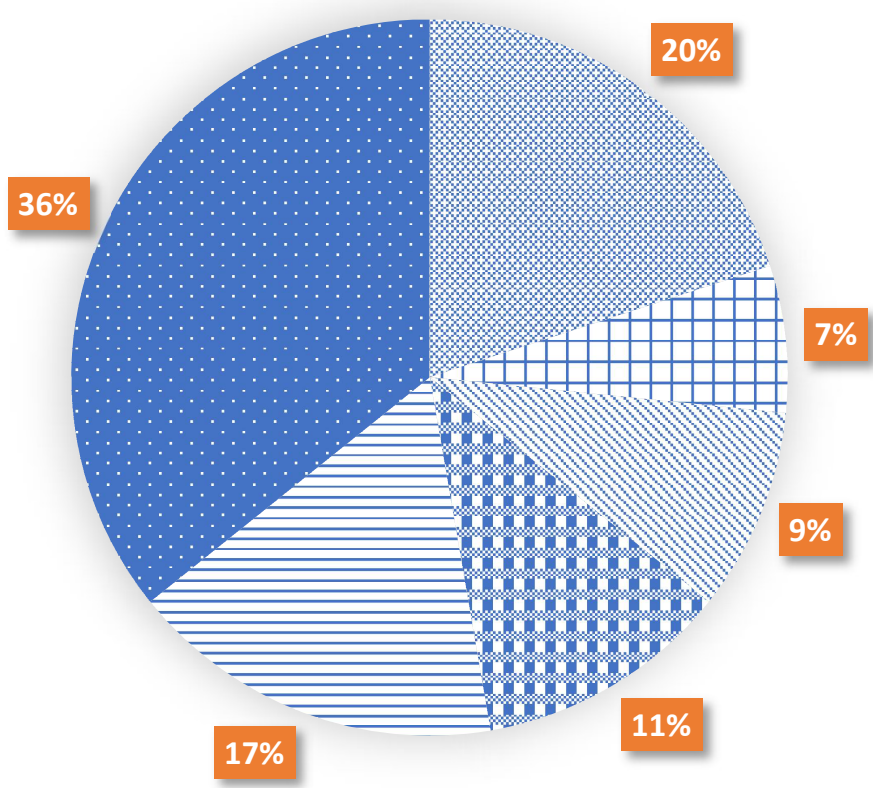

Remaining processes

+ Transport, natural gas, pipeline, long distance/RER U

sCrude oil, at production onshore/RAF U

Crude oil, at production onshore/RU U

= Crude oil, at production onshore/RME U

- Transport, natural gas, pipeline, long distance/RU U

Figure 5. 15: The share of sub-processes for ODP of hydrogen production via thermochmical 4 step $\mathrm{Cu}-\mathrm{Cl}$ cycle.

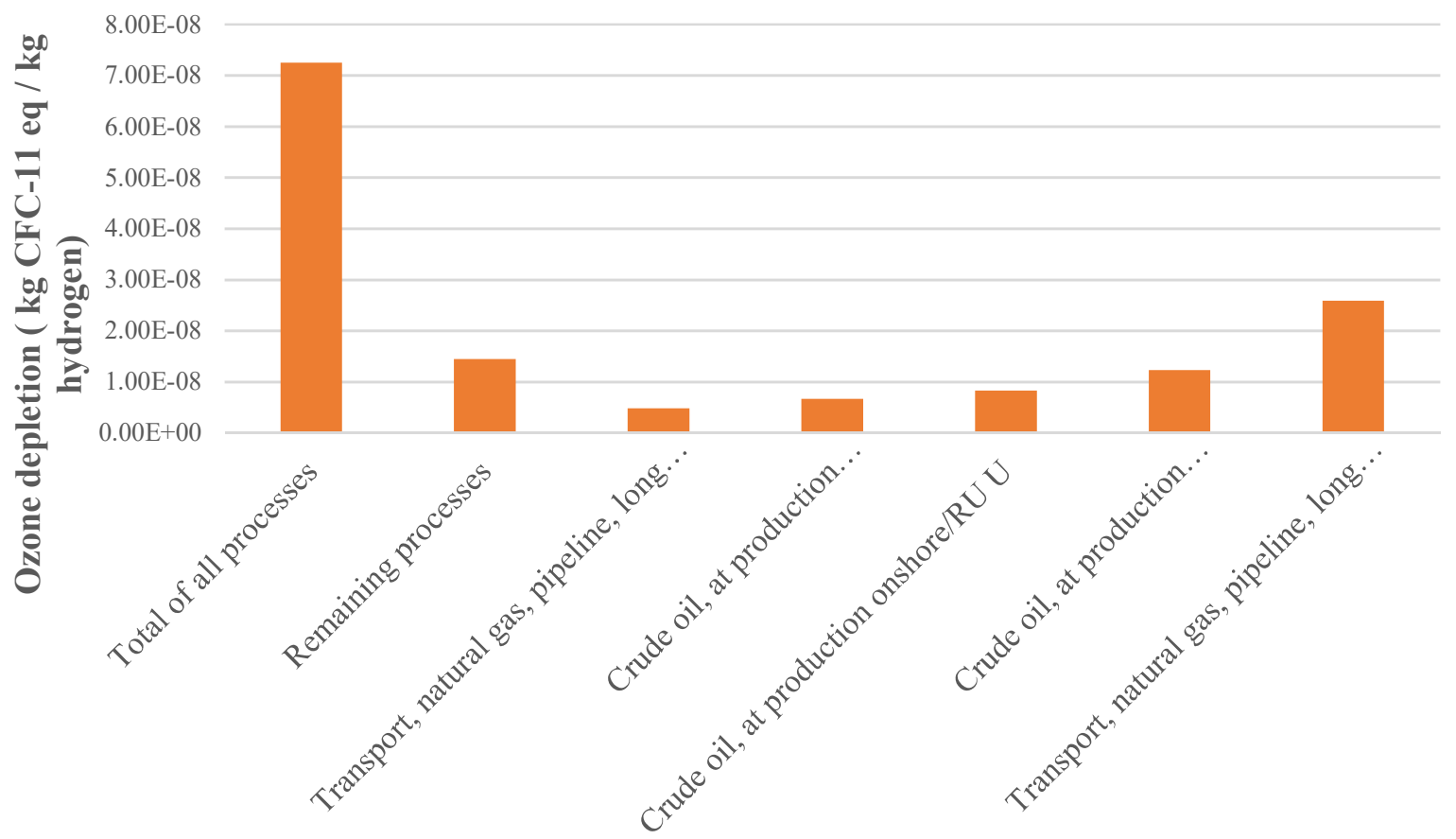

Figure 5. 16: The main contributors of ODP for 4 step $\mathrm{Cu}-\mathrm{Cl}$ cycle and their contribution. 


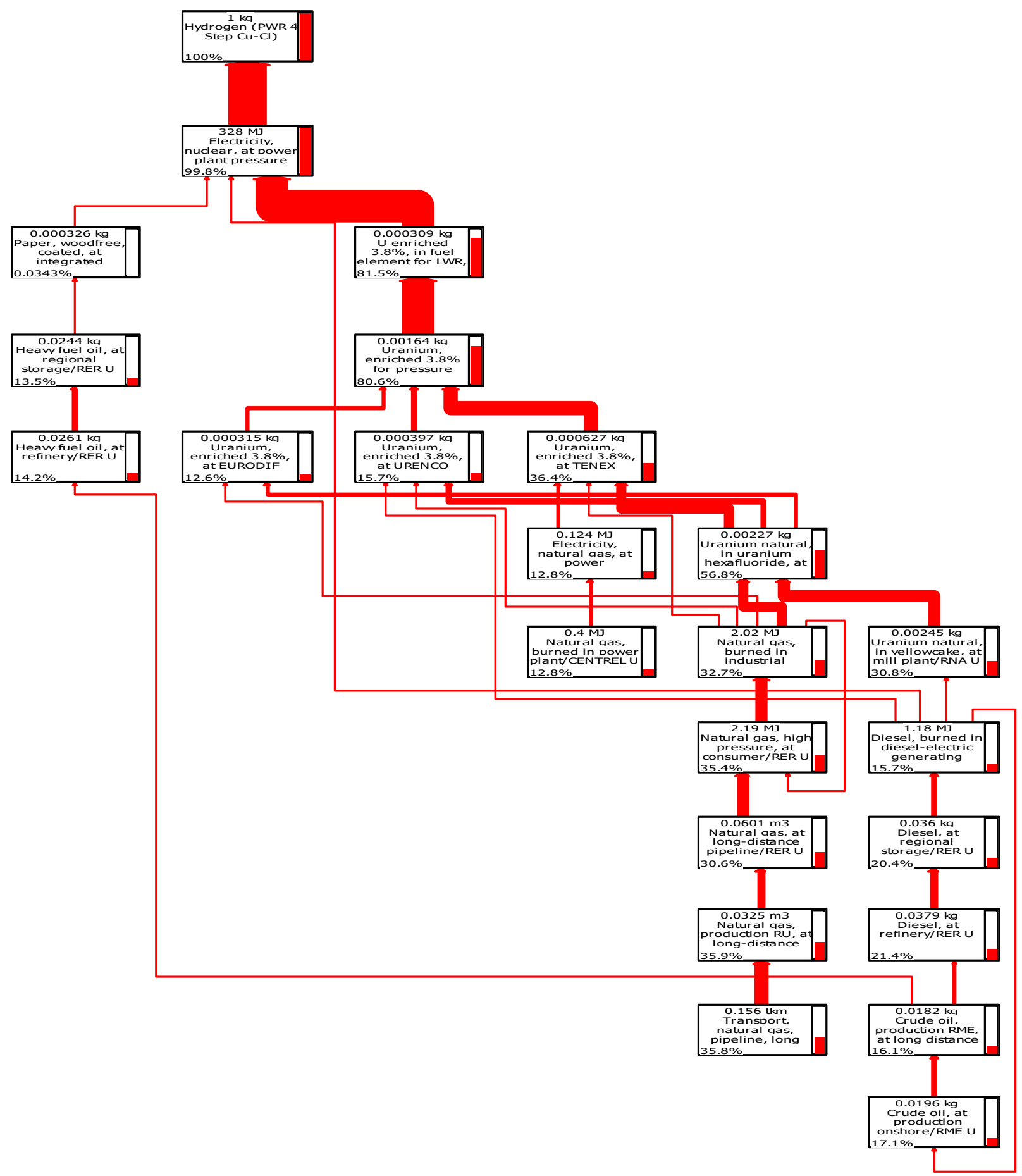

Figure 5. 17: LCA process flow chart for ozone depletion potential (ODP) of hydrogen production via 4 step $\mathrm{Cu}-\mathrm{Cl}$ cycle (cut-off $12 \%$ ). 


\subsubsection{Human Toxicity Potential (HTP)}

Human toxicity is defined as the harmful effects of toxic materials on human health and the environment. Figure 5.18 shows the HTP of the selected hydrogen production processes. Nuclear based hydrogen production via high-temperature electrolysis has the lowest environmental impact on this category with the value of $4.35 \mathrm{~kg} 1,4 \mathrm{DB}$ eq per $\mathrm{kg}$ hydrogen. 3 and 4 step $\mathrm{Cu}-\mathrm{Cl}$ cycle HTP values are $12.1 \mathrm{~kg}$ 1,4 DB eq and $10.98 \mathrm{~kg}$ 1,4 DB eq per kg hydrogen, respectively. 5 step $\mathrm{Cu}-\mathrm{Cl}$ cycle has the highest environmental impact on this category with the value of 12.31 1,4 DB eq per kg hydrogen. The most significant contributor to HTP in nuclear-based hydrogen production cycle is observed as fuel cycle. Figure 5.19 and Figure 5.20 displays the main sub-processes contributing HTP most for 5 step $\mathrm{Cu}-\mathrm{Cl}$ cycle. $87 \%$ of total human toxicity of 5 step $\mathrm{Cu}-\mathrm{Cl}$ cycle comes from uranium tailing and disposal process in the nuclear plant. The contribution of Ferrochromium to this impact category for 5 step $\mathrm{Cu}-\mathrm{Cl}$ cycle is $10 \%$. Ferrochromium is an alloy which is utilized in the production of stainless steel production for the nuclear power plant. Figure 5.21 shows all major sub-processes contributing to this impact category for thermochemical 5 step $\mathrm{Cu}-\mathrm{Cl}$ cycle.

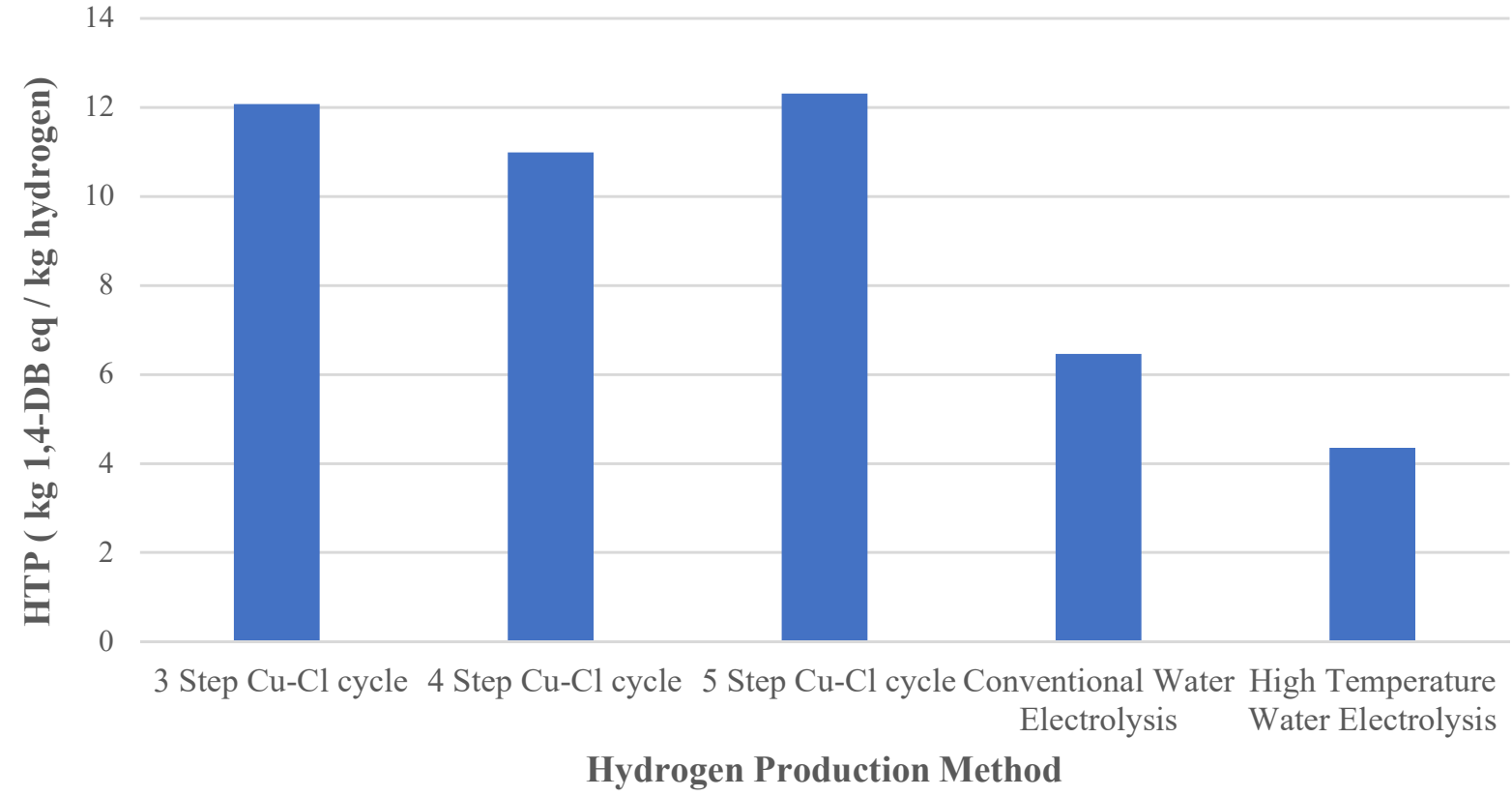

Figure 5. 18: Human toxicity potential (HTP) of nuclear-based hydrogen production mehods. 


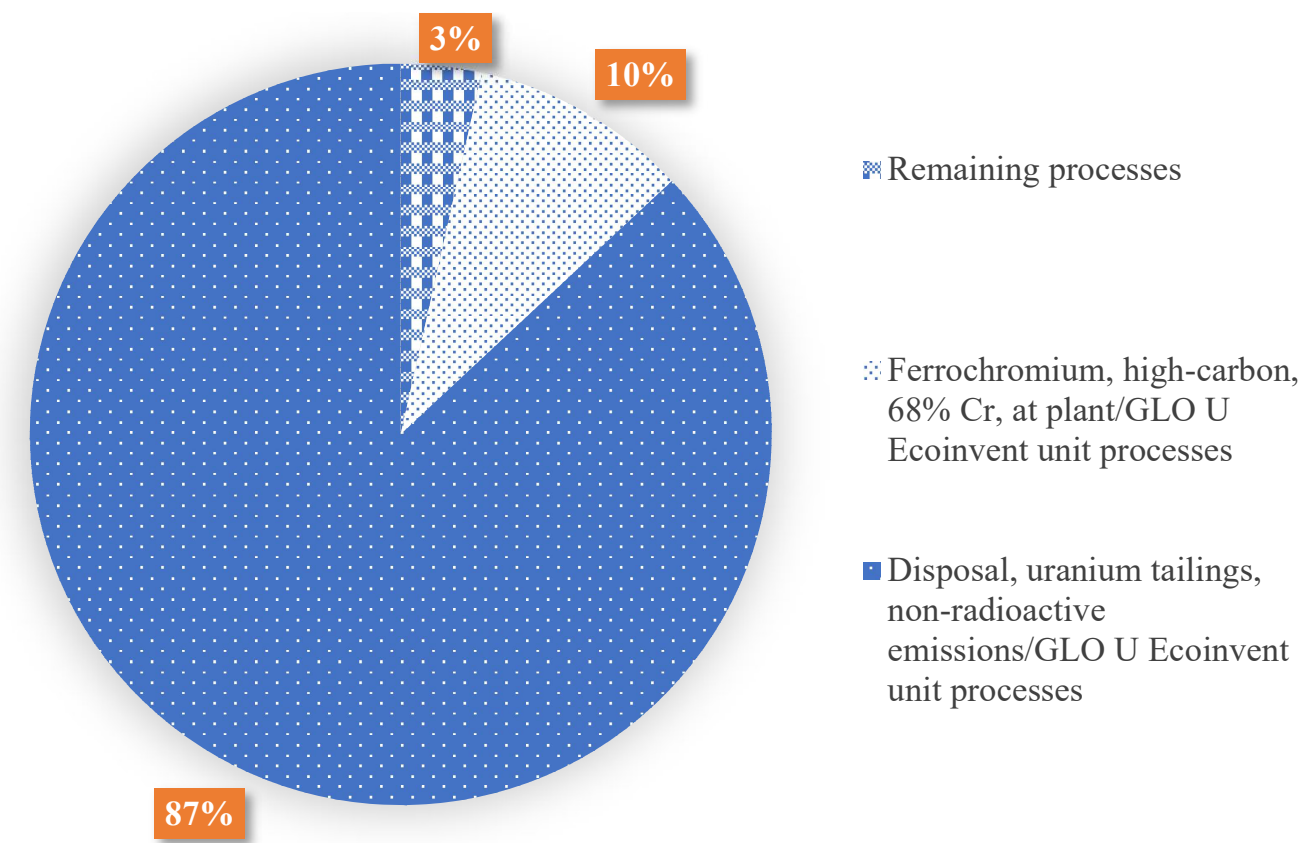

Figure 5. 19: The share of sub-processes for HTP of hydrogen production via thermochemical 5 step $\mathrm{Cu}-\mathrm{Cl}$ cycle.

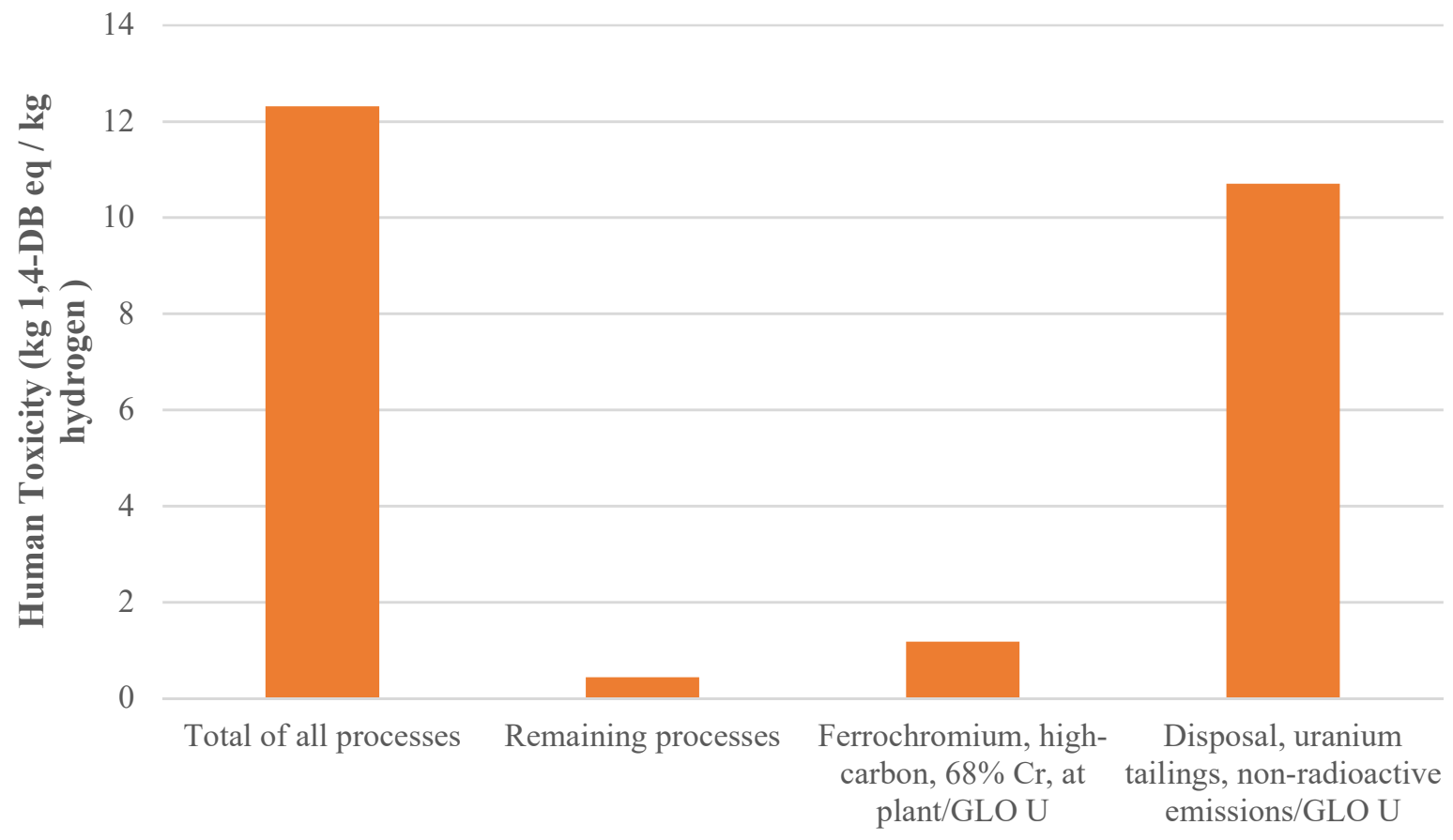

Figure 5. 20: Main contributors of HTP for nuclear-based hydrogen production via thermochemical 5 step $\mathrm{Cu}-\mathrm{Cl}$ cycle. 


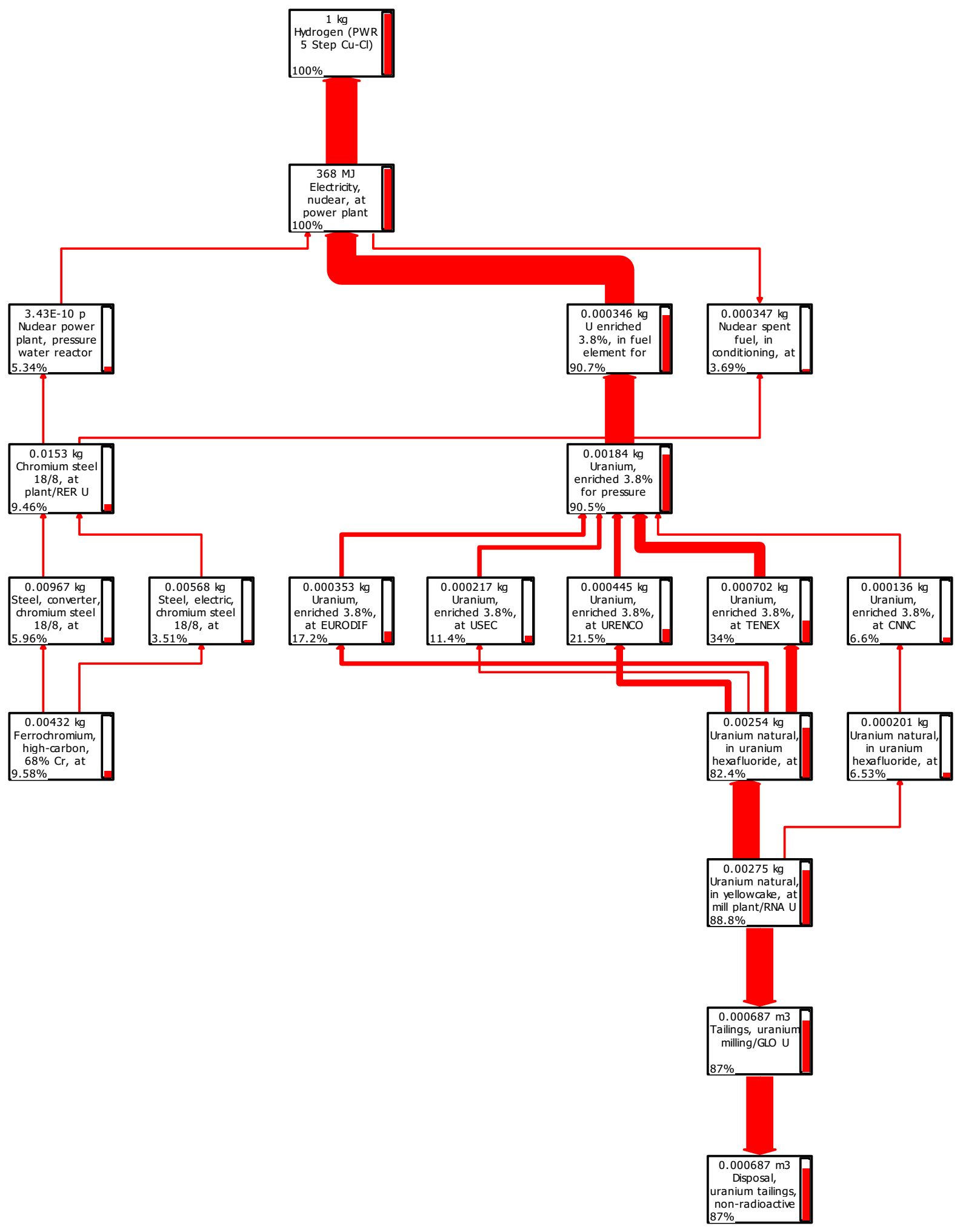

Figure 5. 21: LCA process flow chart for human toxicity potential (HTP) of hydrogen production via 5 step $\mathrm{Cu}-\mathrm{Cl}$ cycle (cut-off $3 \%$ ). 


\subsubsection{Ammonia Production Results}

In this section, the environmental impacts of one $\mathrm{kg}$ ammonia production via conventional Haber-Bosch technique is comparatively shown in Table 5.2 to provide a comparison per unit of ammonia production. Required hydrogen for ammonia synthesis is produced by the employed nuclear hydrogen production methods in this study. Nitrogen is supplied via a cryogenic air separation unit. All required thermal and electrical energy is provided from a pressurized water nuclear reactor (PWR). Table 5.2 displays the life clcyle assessment (LCA) results of ammonia production methods for per $\mathrm{kg}$ ammonia production. Each impact categories in Table 5.2 will be discussed in detail by providing graphs in the following sections. It has to be clarified that although the ammonia production processes are named according to the hydrogen production method, Table 5.2 illustrates emissions values from both hydrogen production and nitrogen production. Nitrogen emission values for cryogenic air separation are received directly from SimaPro software's database since they were already available.

Table 5. 2: Environmental impacts of nuclear-based ammonia production methods.

\begin{tabular}{|l|c|c|c|c|c|}
\hline \multicolumn{1}{|c|}{ Impact category } & $\begin{array}{c}3 \text { Step Cu-Cl } \\
\text { cycle }\end{array}$ & $\begin{array}{c}4 \text { Step Cu-Cl } \\
\text { cycle }\end{array}$ & $\begin{array}{c}5 \text { Step Cu-Cl } \\
\text { cycle }\end{array}$ & $\begin{array}{c}\text { Conventional } \\
\text { Water } \\
\text { Electrolysis }\end{array}$ & $\begin{array}{c}\text { High } \\
\text { Temperature } \\
\text { Water } \\
\text { Electrolysis }\end{array}$ \\
\hline $\mathrm{ADP}(\mathrm{kg} \mathrm{Sb}$ eq) & 0.0022 & 0.0021 & 0.0023 & 0.0015 & 0.0012 \\
\hline $\mathrm{AP}\left(\mathrm{kg} \mathrm{SO} \mathrm{C}_{2}\right.$ eq $)$ & 0.0025 & 0.0023 & 0.0026 & 0.0017 & 0.0014 \\
\hline $\mathrm{GWP}(\mathrm{kg} \mathrm{CO}$ eq) & 0.3323 & 0.3113 & 0.3370 & 0.2240 & 0.1832 \\
\hline ODP $(\mathrm{kg} \mathrm{CFC-11} \mathrm{eq)}$ & $2.40 \mathrm{E}-08$ & $2.27 \mathrm{E}-08$ & $2.42 \mathrm{E}-08$ & $1.74 \mathrm{E}-08$ & $1.50 \mathrm{E}-08$ \\
\hline $\mathrm{HTP}(\mathrm{kg} 1,4-\mathrm{DB}$ eq $)$ & 2.3807 & 2.1885 & 2.4235 & 1.3874 & 1.0136 \\
\hline
\end{tabular}

Environmental impacts of conventional natural gas-based ammonia production via steam methane reforming (SMR) is received from the open literature to provide a comparison. Today the massive share of industrial ammonia production is achieved via natural gasbased SMR method. Therefore, it is wise to compare the selected ammonia production methods with the conventional SMR method to emphasize the environmental benign characteristic of nuclear-based ammonia production. It is observed that nuclear-based ammonia production via thermoelectrical high temperature electrolysis, which is named as Ammonia (PWR HTE) in SimaPro software, has the lowest environmental impacts in all catergories as shown in Figure 5.22. 


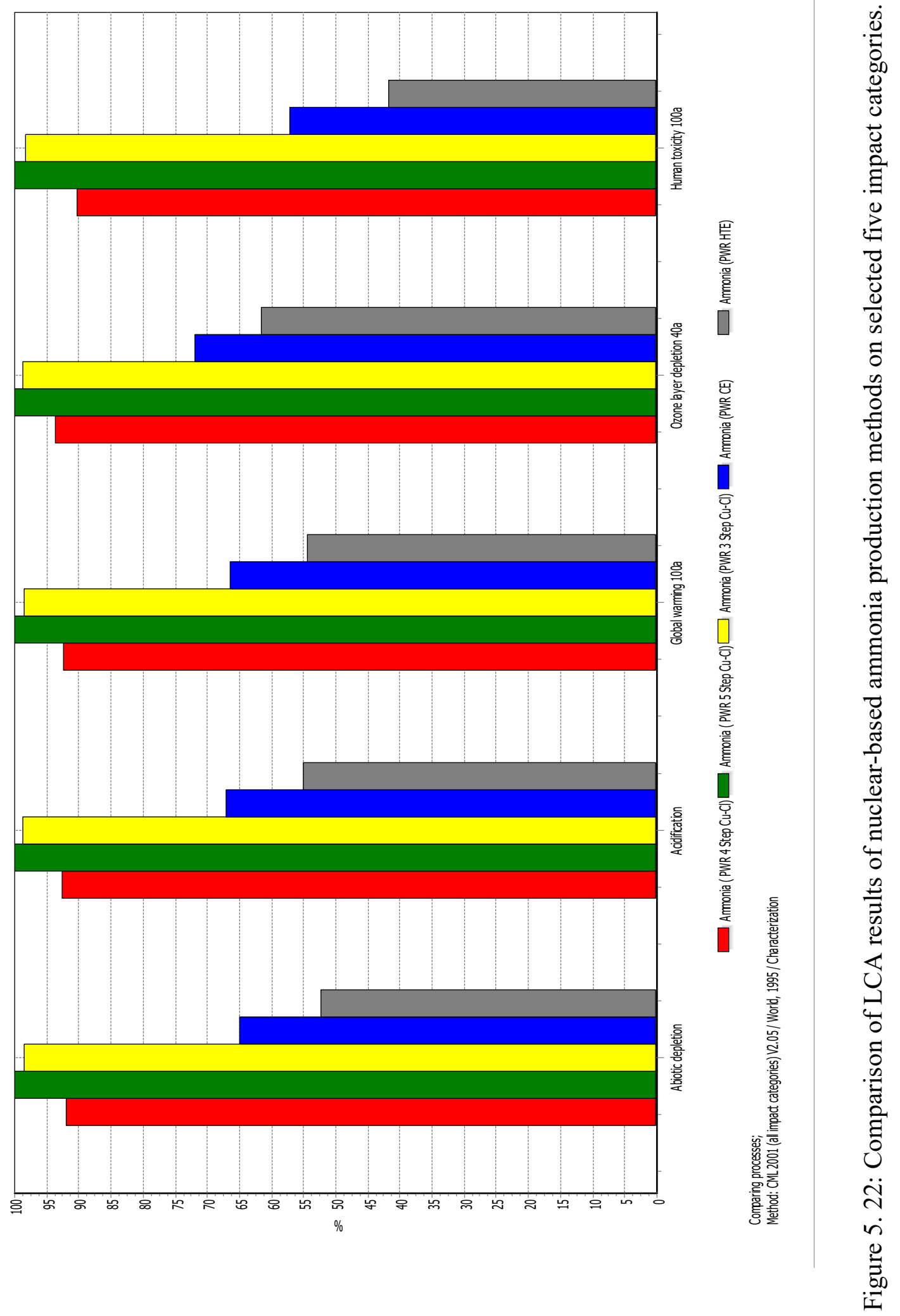


It has to be clarified that, ammonia is not synthesized directly from SMR. Hydrogen produced by SMR is employed in ammonia synthesis. Thus, the ammonia synthesis is named according to the hydrogen production method once again. Abiotic depletion potential (ADP) is maximum for the ammonia production from the nuclear five-step thermochemical cycle where it corresponds to $0.0023 \mathrm{~kg} \mathrm{Sb}$ eq per $\mathrm{kg}$ of ammonia which is, however, much lower than SMR's ADP. Ammonia from nuclear-based electrolysis methods yields lower ADP where the most economical is for high-temperature electrolysis with a value of $0.0012 \mathrm{~kg} \mathrm{Sb}$ eq as seen in Figure 5.23. Abiotic depletion potential of 3 and 4 step thermochemical $\mathrm{Cu}-\mathrm{Cl}$ cycles corresponds to 0.0023 and $0.0022 \mathrm{~kg} \mathrm{SB}$ eq per $\mathrm{kg}$ of ammonia, respectively. Main sub-processes contributing to this impact category are nitrogen synthesis via cryogenic air separation, hard coal mining, onshore natural gas production, and other remaining sub-processes. Figure 5.24 and Figure 5.25 show the share and values of the main contributors of ADP for nuclear-based ammonia production via HTE. Nitrogen production has the highest contribution to this impact category with an amount of $0.004 \mathrm{~kg} \mathrm{Sb}$ eq per kilograms of ammonia. As it can be seen from Figure 5.26, there are three mainline under ammonia production. The third line represents the contribution of additional electricity for ammonia synthesis.

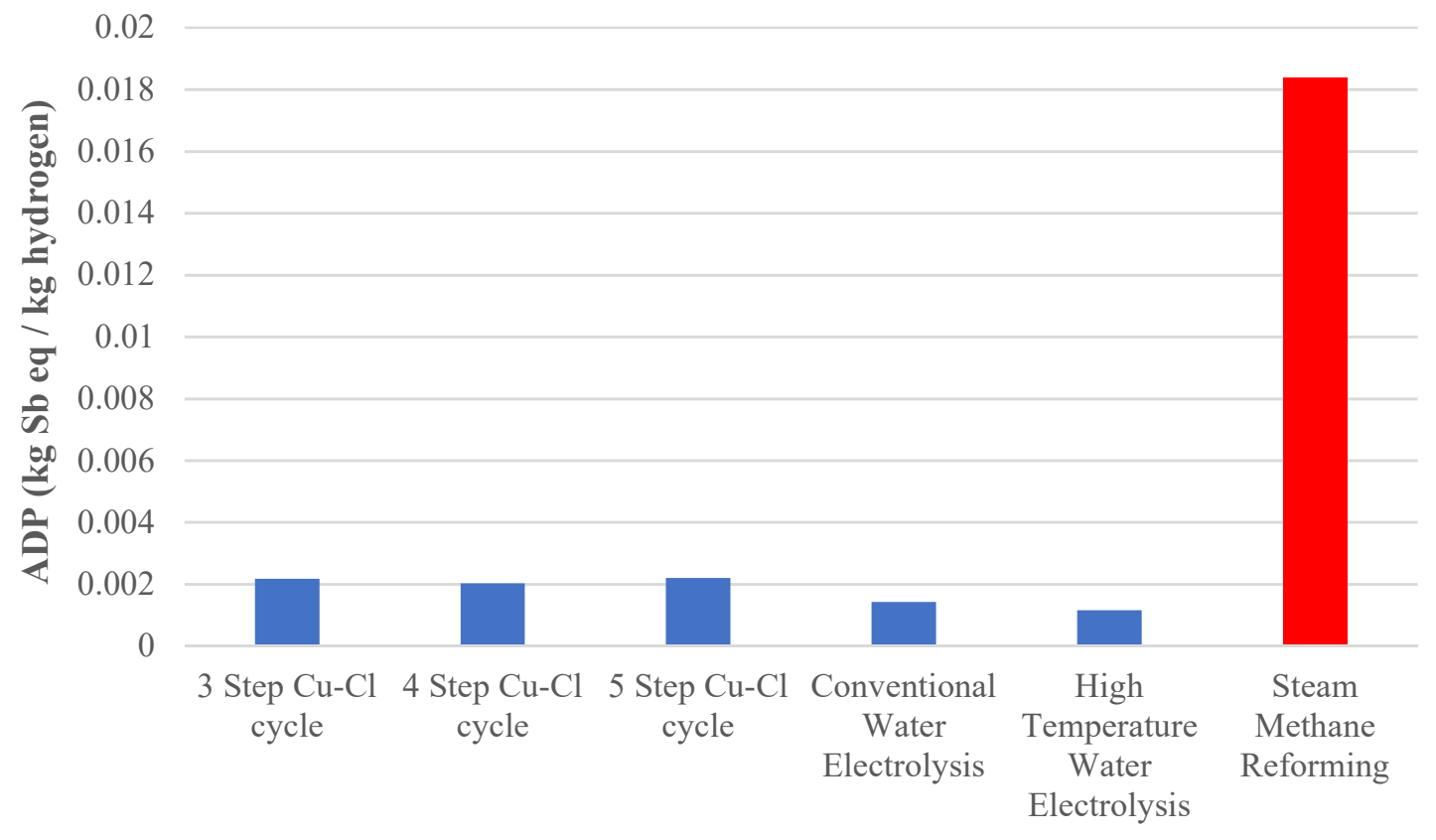

Figure 5. 23: Abiotic depletion potential (ADP) of nuclear-based ammonia production methods. 


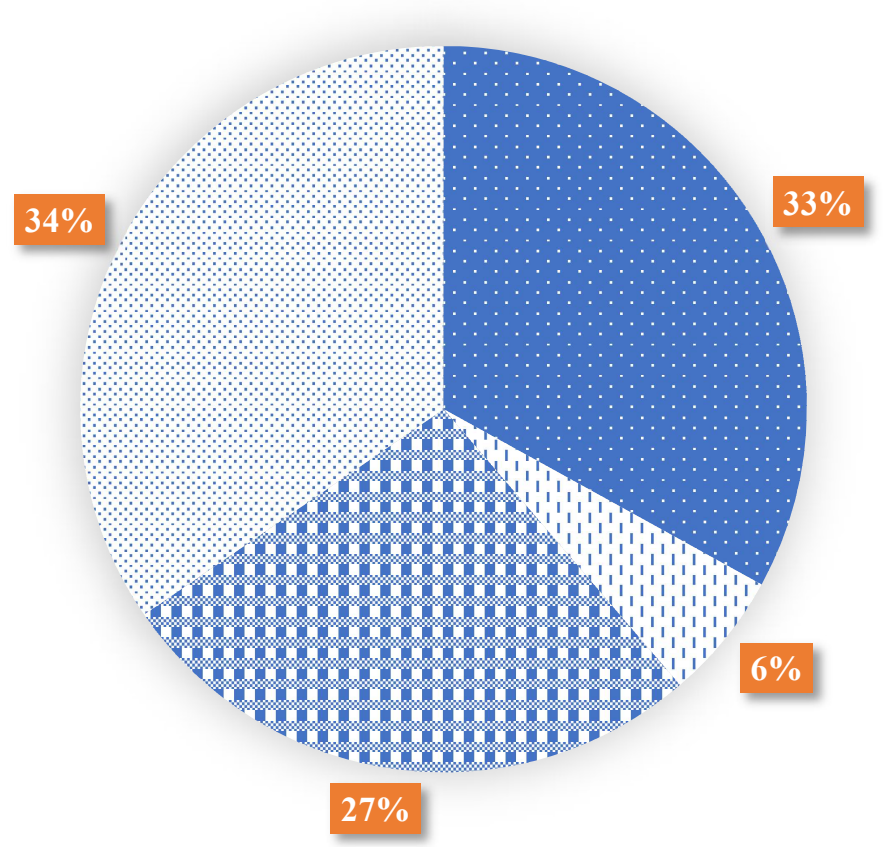

Remaining processes

' ' Natural gas, at production onshore/RU U

․ㅡㄹ Hard coal, at mine/RNA U

$\because$ Nitrogen, via cryogenic air separation, production mix, at plant, gaseous EU-27 S

Figure 5. 24: The share of sub-processes for ADP of nuclear-based ammonia production via thermoelectrical high temperature electrolysis.

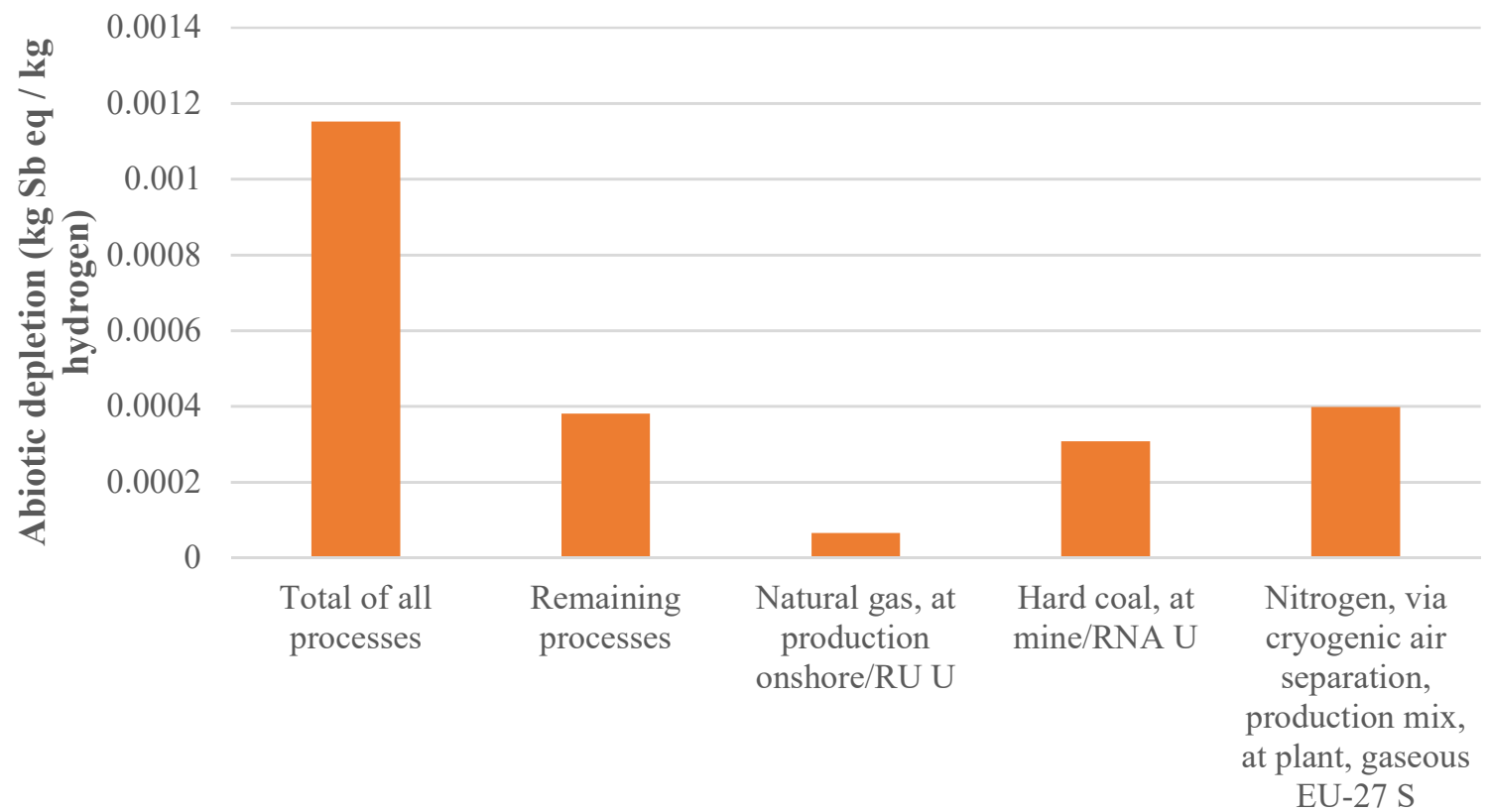

Figure 5. 25: Main contributors of ADP for nuclear-based ammonia production via thermoelectrical high temperature electrolysis (HTE). 


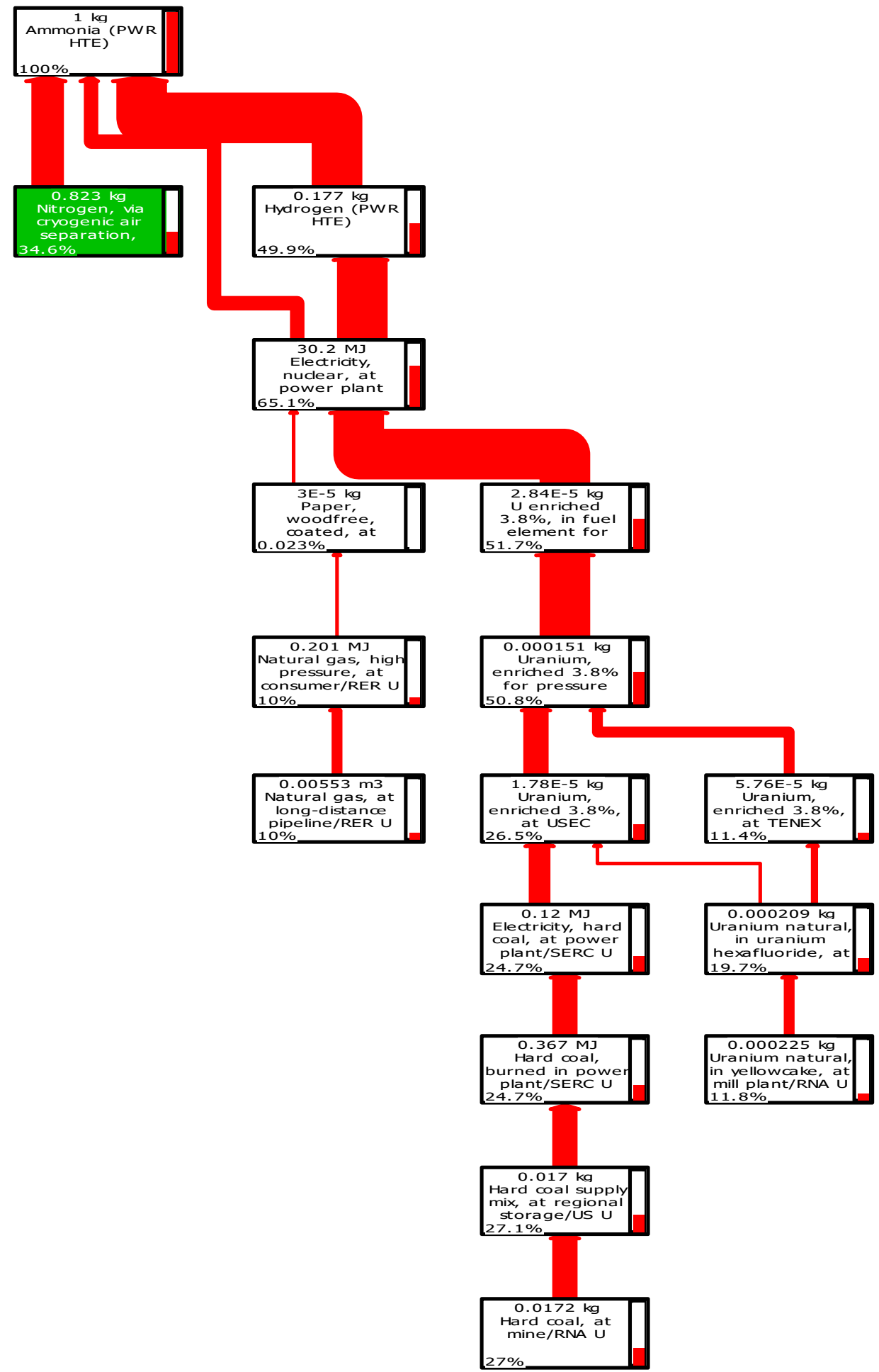

Figure 5. 26: LCA process flow chart for abiotic depletion potential (ADP) of ammonia production via HTE (cut-off 10\%). 
Nuclear-based high-temperature electrolysis yields the lowest AP with the value of 0.0014 $\mathrm{kg} \mathrm{SO}_{2}$ eq per $\mathrm{kg}$ of ammonia which is followed by conventional electrolysis $(0.0016 \mathrm{~kg}$ $\mathrm{SO}_{2}$ eq/ $\mathrm{kg}$ ammonia) as it is seen Figure 5.27. AP of thermochemical 5 step $\mathrm{Cu}-\mathrm{Cl}$ corresponds to $0.0024 \mathrm{~kg} \mathrm{SO} 2$ eq per $\mathrm{kg}$ ammonia which is the highest AP value from selected ammonia production methods. However, ammonia production via conventional SMR method yields much higher AP $(0.0037 \mathrm{~kg} \mathrm{SO}$ eq) than nuclear 5 step $\mathrm{Cu}-\mathrm{Cl}$ cycle as shown in Figure 5.27. The main sub-processes contributing to this impact category most are nitrogen production (34\%), hard coal burning (21\%) and other remaining sub-processes (27\%). Figure 5.28 and Figure 5.29 show the shares of contributors of AP for nuclear-based ammonia production via thermoelectrical conventional electrolysis (CE). Sulphuric acid $\left(\mathrm{H}_{2} \mathrm{SO}_{4}\right)$ consists the $7 \%$ of AP for conventional nuclear electrolysis. Sulphuric acid is used to prevent the formation of calcium on the surface of the condenser and heat exchanger tubes in the evaporative cooling water systems of the nuclear power plant. Figure 5.30 shows important sub-processes and their contribution to AP for nuclear-based ammonia production via thermoelectrical conventional electrolysis.

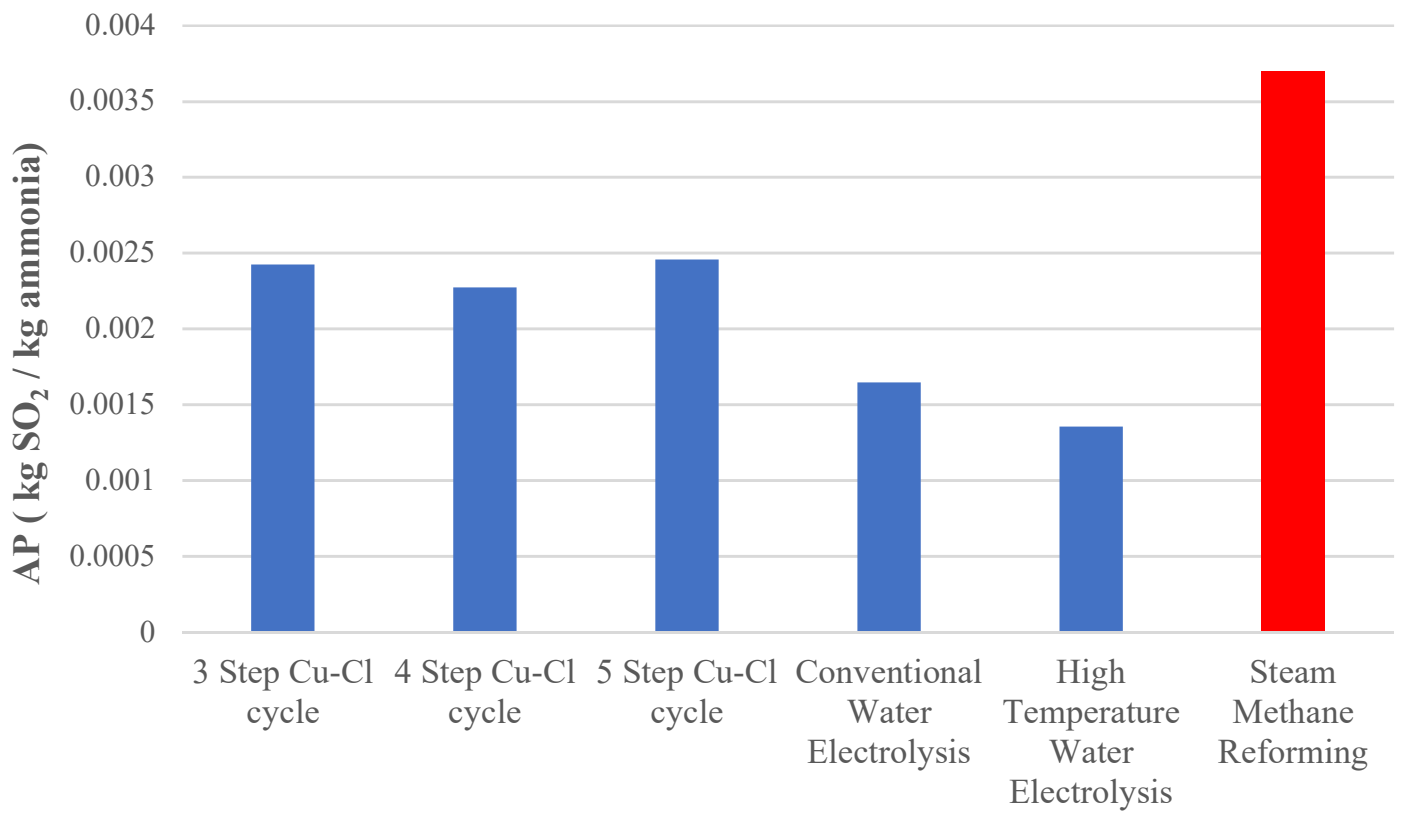

Figure 5. 27: Acidification potential (AP) of nuclear-based ammonia production methods. 


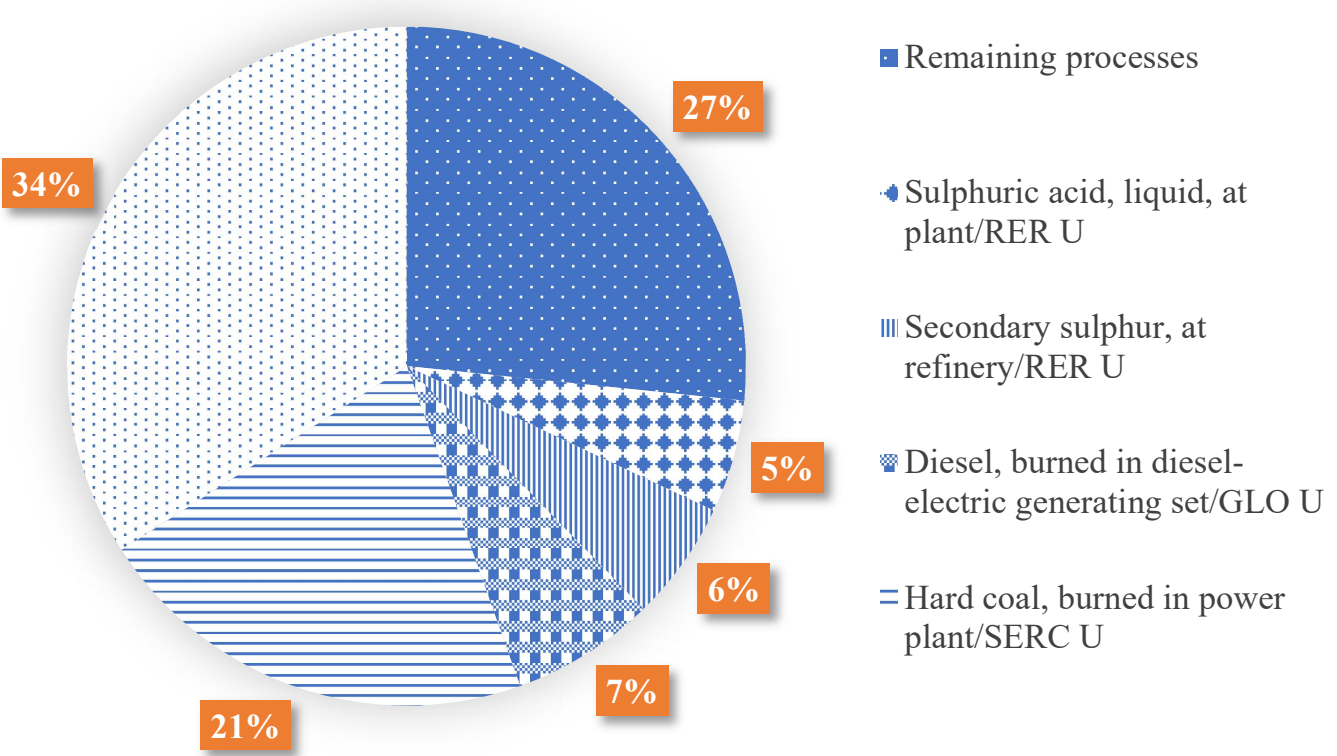

Figure 5. 28: The share of sub-processes for AP of nuclear-based ammonia production via thermoelectrical conventional electrolysis (CE).

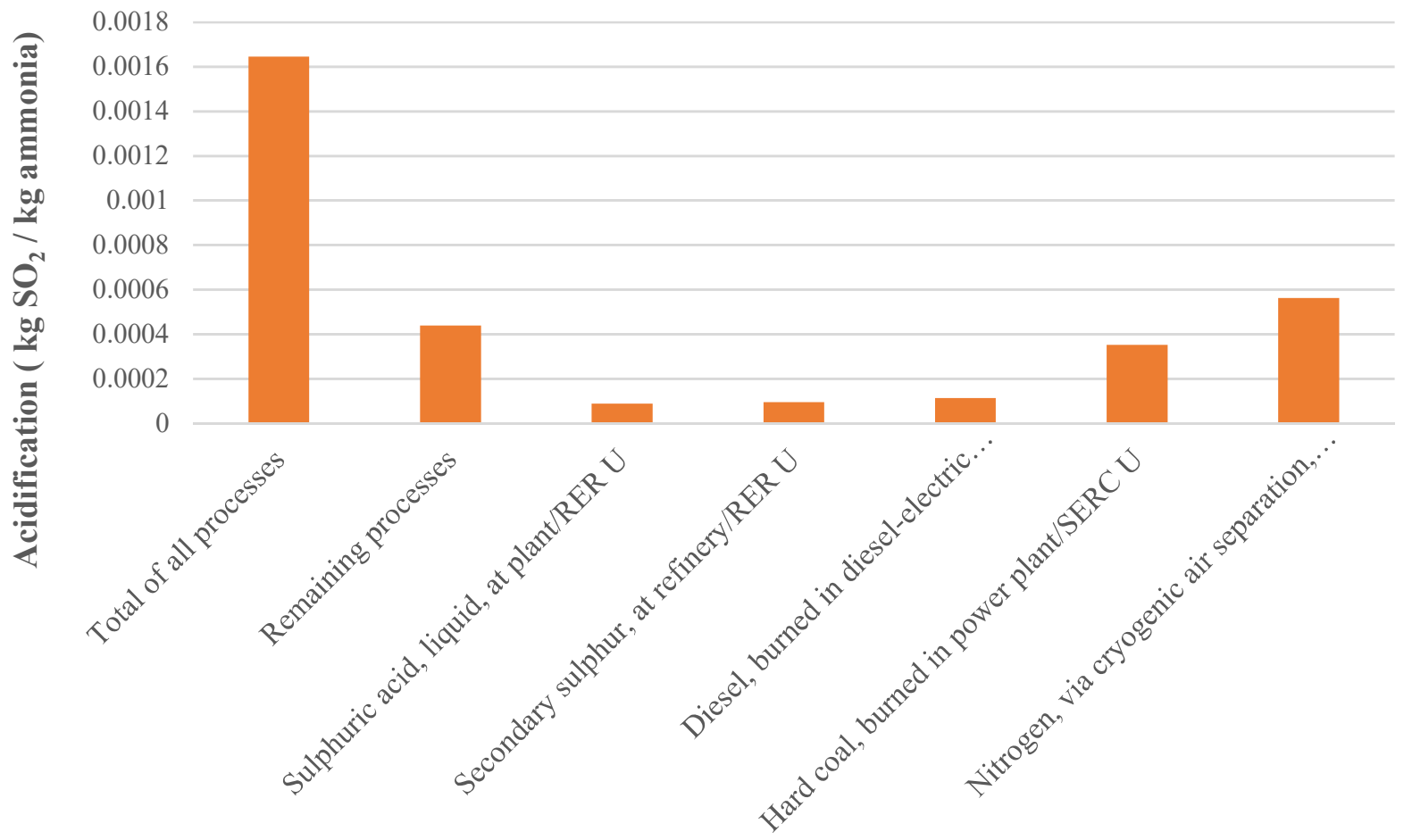

Figure 5. 29: Main contributors of AP for nuclear-based ammonia production via thermoelectrical Conventional Electrolysis (CE). 


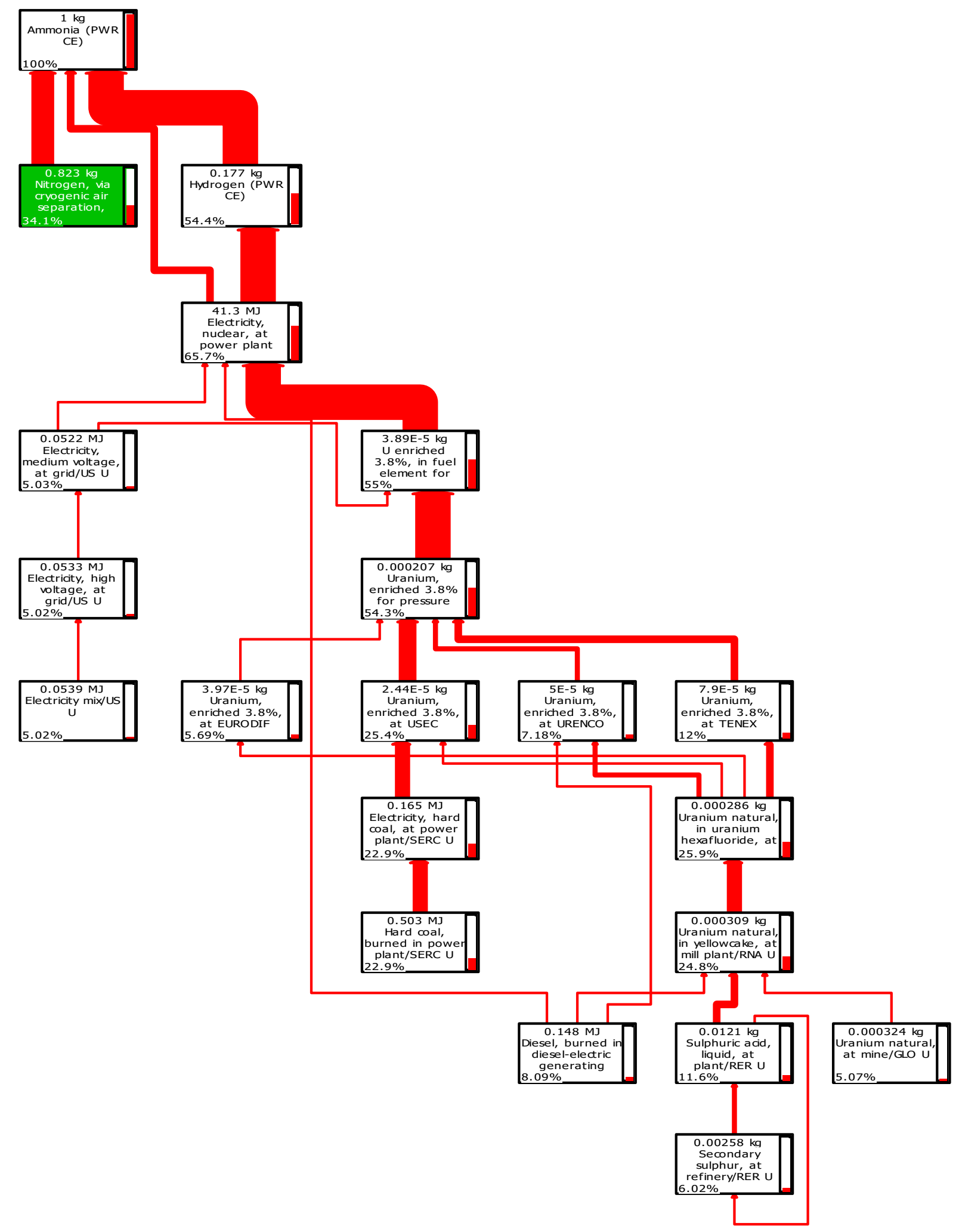

Figure 5. 30: LCA process flow chart for acidification potential (AP) of ammonia production via conventional electrolysis (CE) (cut-off 5\%). 
Nuclear high-temperature electrolysis method yields the lowest greenhouse gas (GHG) emission with the value of $0.183 \mathrm{~kg} \mathrm{CO}_{2}$ eq per kg of ammonia. As shown in Figure 5.31, GWP for SMR based ammonia production is very high (1.83 $\left.\mathrm{kg} \mathrm{CO}_{2} \mathrm{eq}\right)$. Global warming potential addresses GHG emission. As indicated earlier, today industrial ammonia production corresponds to $1 \%$ of global GHG emissions. Figure 5.31 shows that transition to nuclear-based ammonia from natural gas-based SMR could decrease the GHG emissions of industrial ammonia production drastically. Global warming potential of nuclear conventional electrolysis corresponds to $0.224 \mathrm{~kg} \mathrm{CO}_{2}$ eq per $\mathrm{kg}$ ammonia. Energy requirements of the process is a keystone determining the GWP of the process. Since they consume more energy, GWPs for thermochemical cycles are much higher than thermoelectrical periods. In this regard, 5 step $\mathrm{Cu}-\mathrm{Cl}$ cycle has the highest GWP with the value of with the value of $0.337 \mathrm{~kg} \mathrm{CO}_{2}$ eq per $\mathrm{kg}$ ammonia since it consumes energy most among the selected nuclear-based methods. Figure 5.32 and Figure 5.33 show the main contributors to this impact category for nuclear-based ammonia production via 3 step Cu$\mathrm{Cl}$ cycle. Most of the $\mathrm{GHG}$ emissions (40\%) from nuclear 3 step $\mathrm{Cu}-\mathrm{Cl}$ cycle caused by fossil fuel consumption in the uranium enrichment plant. Figure 5.34 shows the subprocesses and their share in GWP of nuclear-based ammonia production via 3 step $\mathrm{Cu}-\mathrm{Cl}$ cycle.

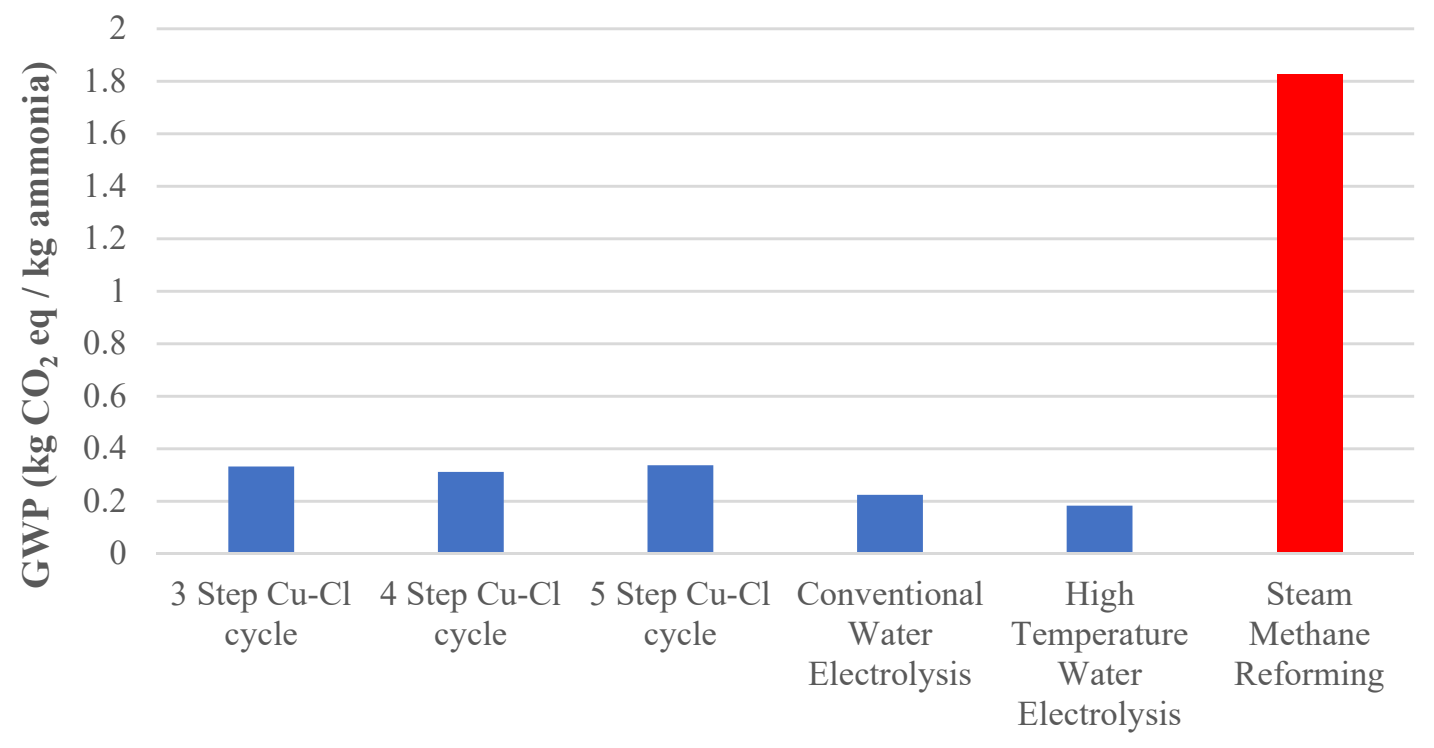

Figure 5. 31: Global warming potential (GWP) of nuclear-based ammonia production methods. 


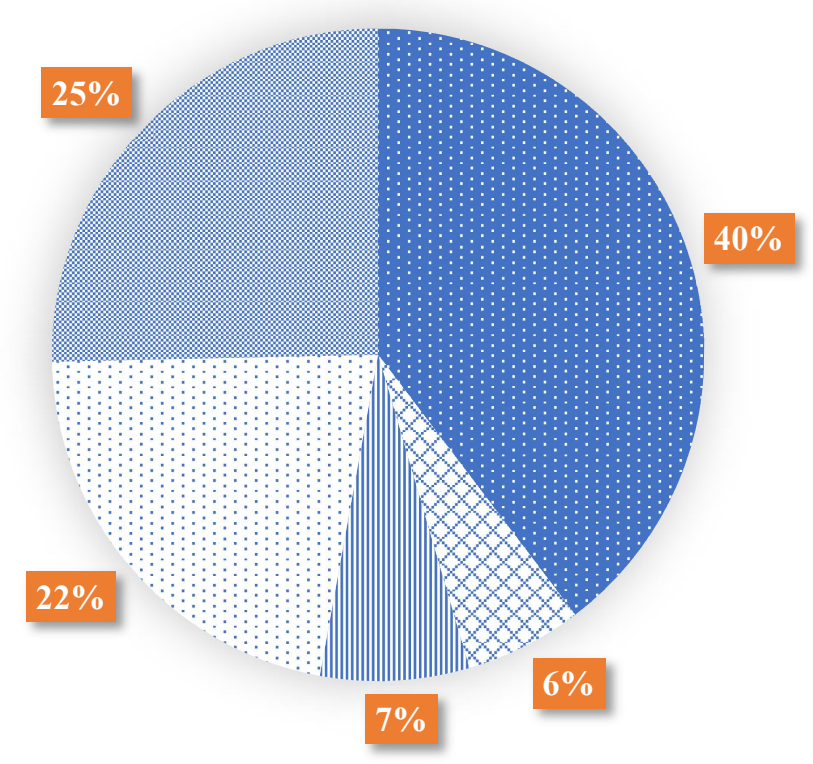

Remaining processes

$\succ$ Diesel, burned in diesel-electric generating set/GLO U

III Natural gas, burned in industrial furnace $>100 \mathrm{~kW} / \mathrm{RER} \mathrm{U}$

: Nitrogen, via cryogenic air separation, production mix, at plant, gaseous EU-27 S

Hard coal, burned in power plant/SERC U

Figure 5. 32: The share of sub-processes for GWP of nuclear-based ammonia production via thermochemical 3 step $\mathrm{Cu}-\mathrm{Cl}$ cycle.

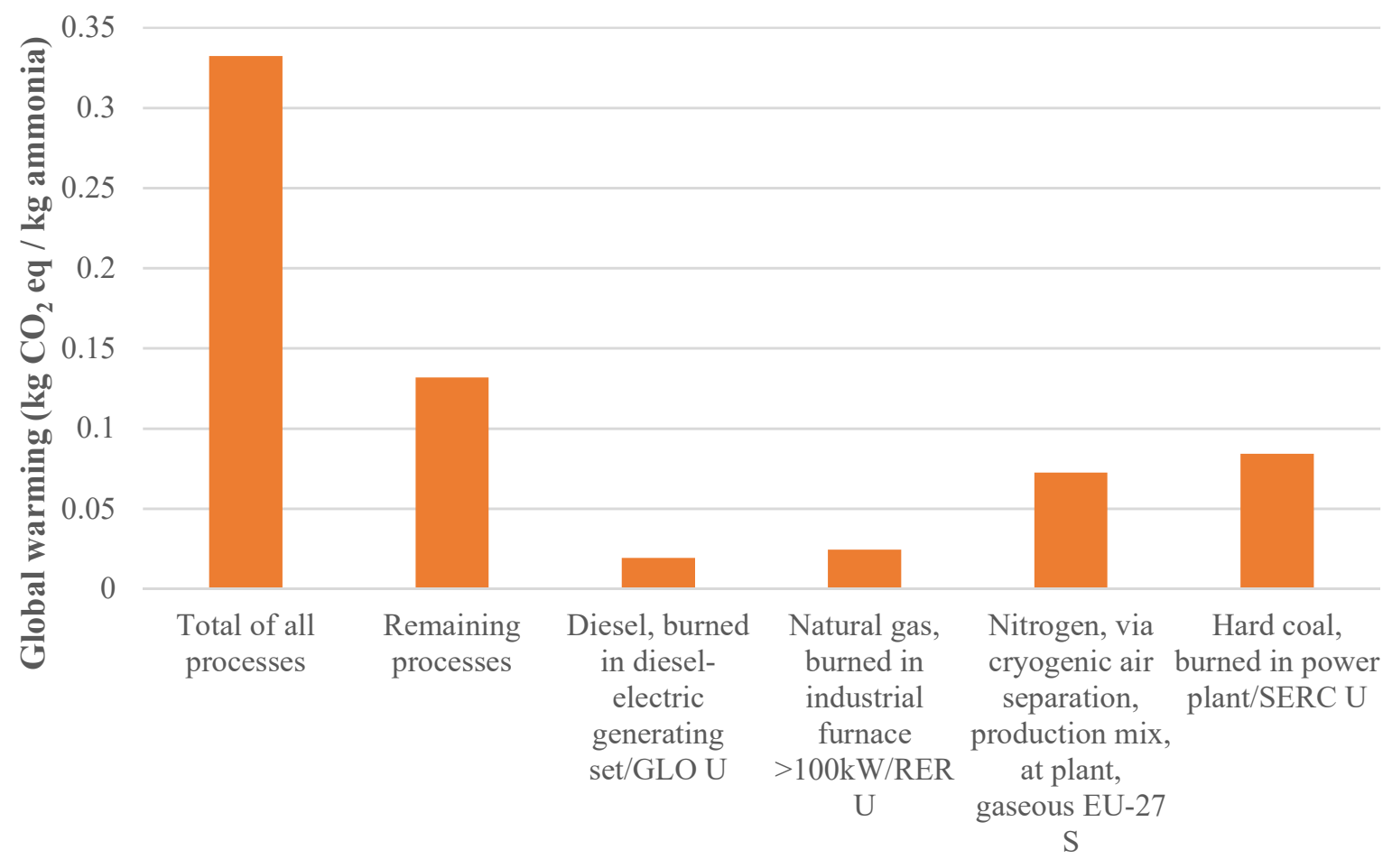

Figure 5. 33: Main contributors of GWP for nuclear-based ammonia production via thermochemical 3 step $\mathrm{Cu}-\mathrm{Cl}$ cycle. 


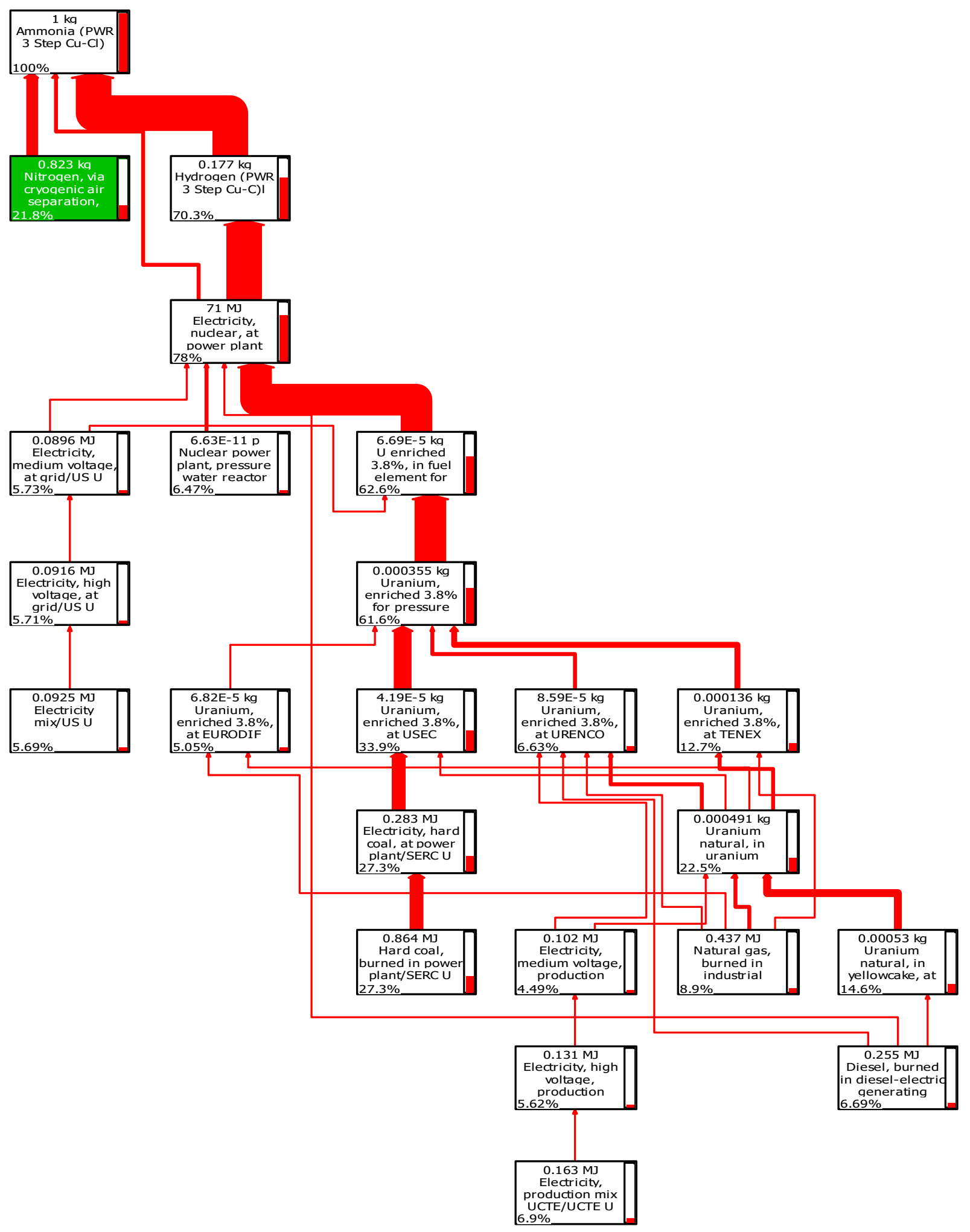

Figure 5. 34: LCA process flow chart for global warming potential (GWP) of ammonia production via 3 step $\mathrm{Cu}-\mathrm{Cl}$ cycle (cut-off $5 \%$ ). 
Ozone layer depletion is an important issue which needs to be addressed since a worn layer would absorb more harmful UV-B radiation from the sun to the surface of the earth. The main reason for ozone depletion is human-made ozone-depleting substances such as chlorofluorocarbons (CFCs). Figure 5.35 displays ozone depletion potentials (ODPs) of the employed ammonia production methods as well as SMR. It is seen that ODP of SMR (3.60E-07 kg CFC-11 eq/kg ammonia) much higher than nuclear-based thermochemical and thermoelectrical methods. Nuclear-based high-temperature electrolysis yields the lowest ODP with the value of $1.50 \mathrm{E}-08 \mathrm{~kg} \mathrm{CFC}-11$ eq per $\mathrm{kg}$ of ammonia which is, however, pretty close to other method's ODP. Primary contributors to this impact category are nitrogen production via cryogenic air separation, transportation of natural gas, onshore crude oil production, and other remaining processes. For instance, nitrogen production corresponds to $36 \%$ of ODP for nuclear-based ammonia production via thermochemical 4 step $\mathrm{Cu}-\mathrm{Cl}$ cycle as shown in Figure 5.36. The sub-processes of milling and mining operations of uranium are the main contributors of this category for nuclear 4 step $\mathrm{Cu}-\mathrm{Cl}$ cycle as indicated in Figure 5.37 and 5.38.

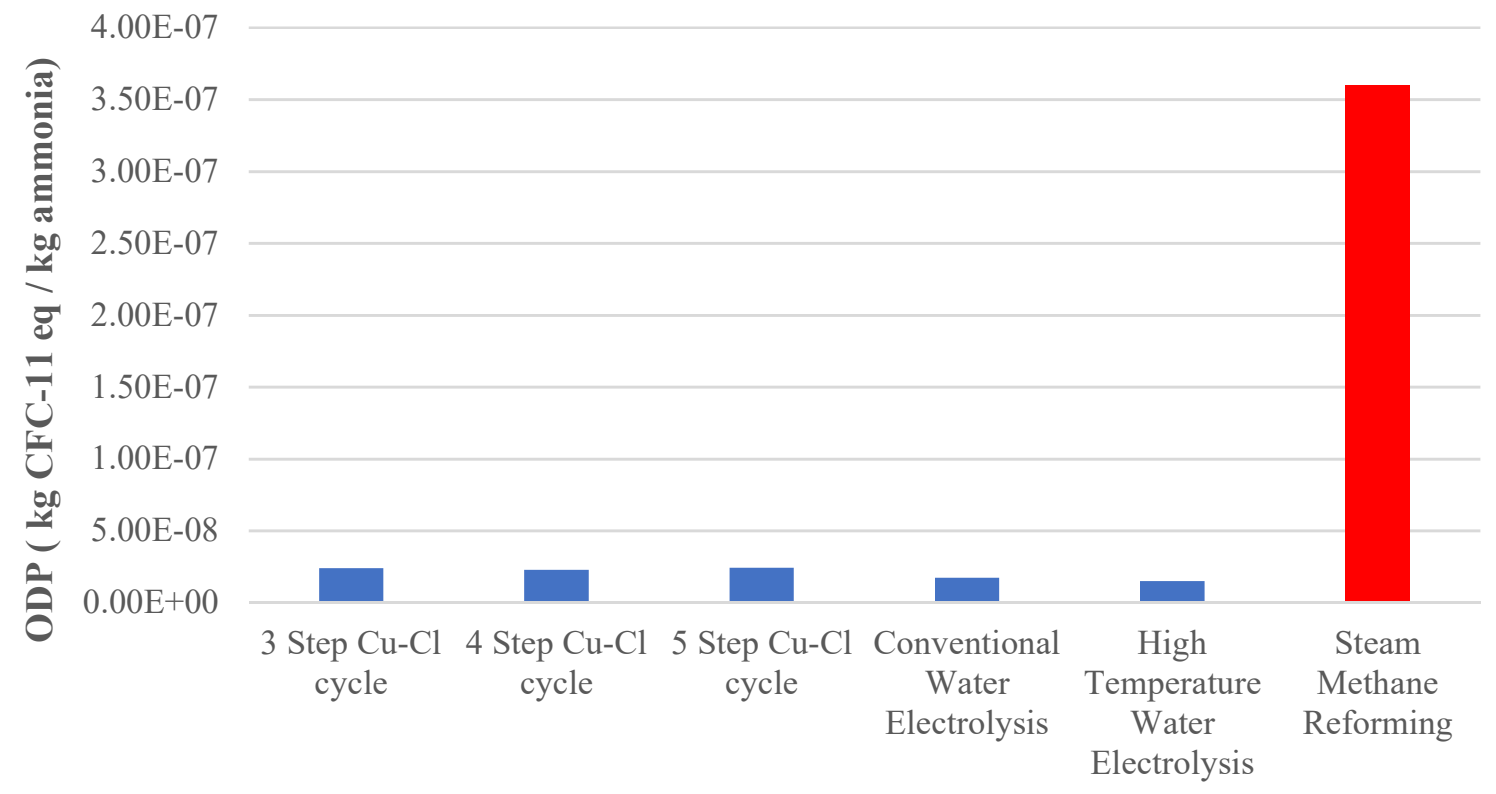

Figure 5. 35: Ozone depletion potential (ODP) of nuclear-based ammonia production methods. 


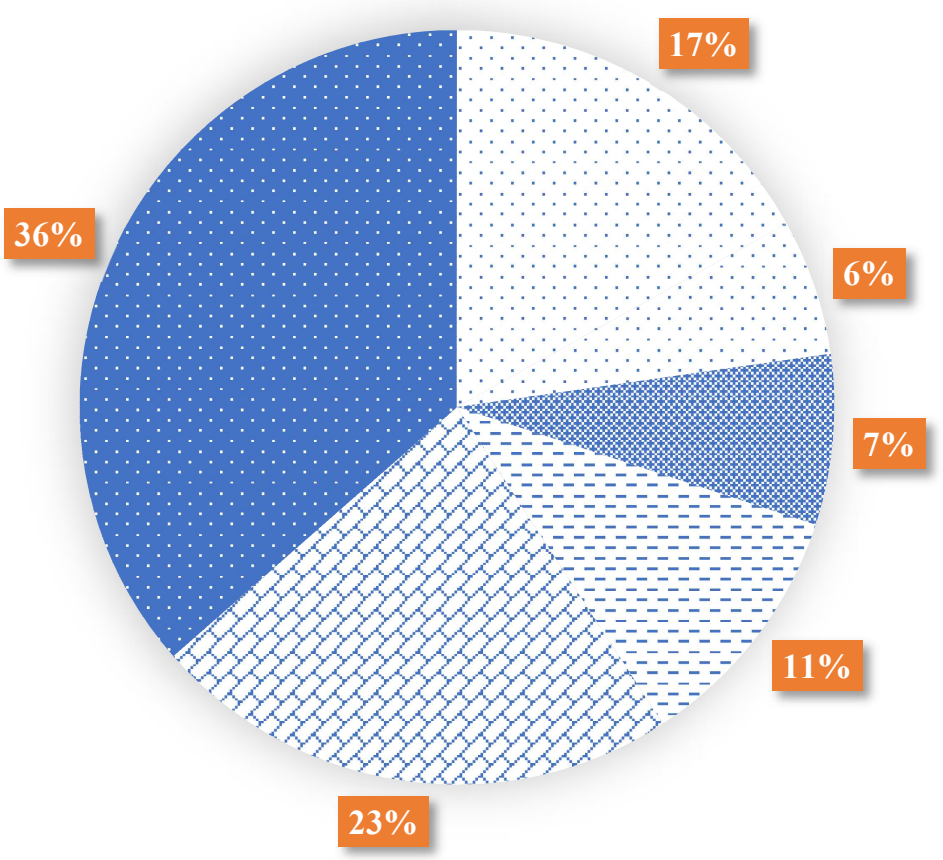

Remaining processes

Crude oil, at production onshore/RAF U

Crude oil, at production onshore/RU U

- Crude oil, at production onshore/RME U

Transport, natural gas, pipeline, long distance/RU U

- Nitrogen, via cryogenic air separation, production mix, at plant, gaseous EU-27 S

Figure 5. 36: The share of sub-processes for ODP of nuclear-based ammonia production via thermochemical 4 step $\mathrm{Cu}-\mathrm{Cl}$ cycle.

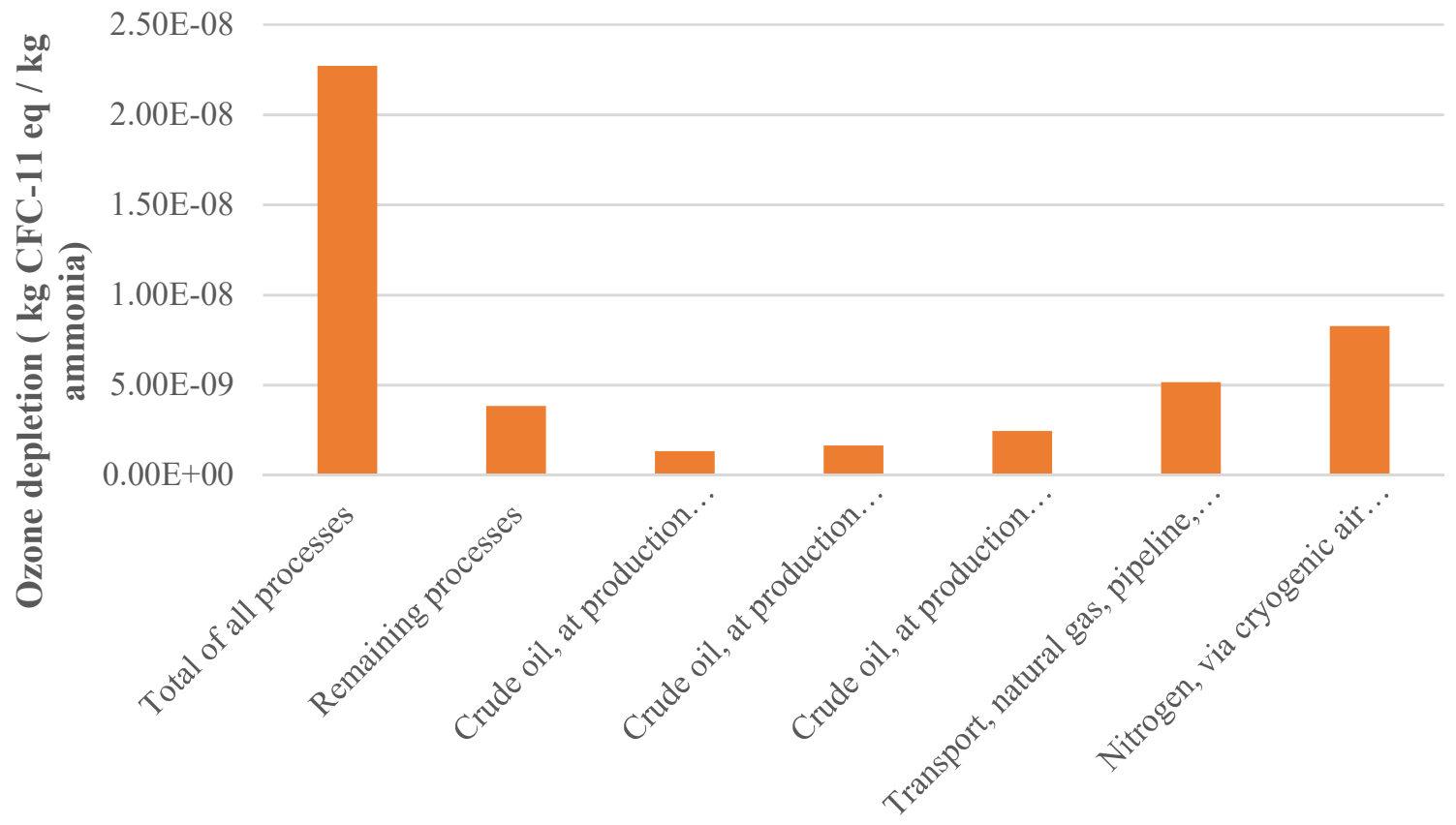

Figure 5. 37: Main contributors of ODP for nuclear-based ammonia production via thermochemical 4 step $\mathrm{Cu}-\mathrm{Cl}$ cycle. 


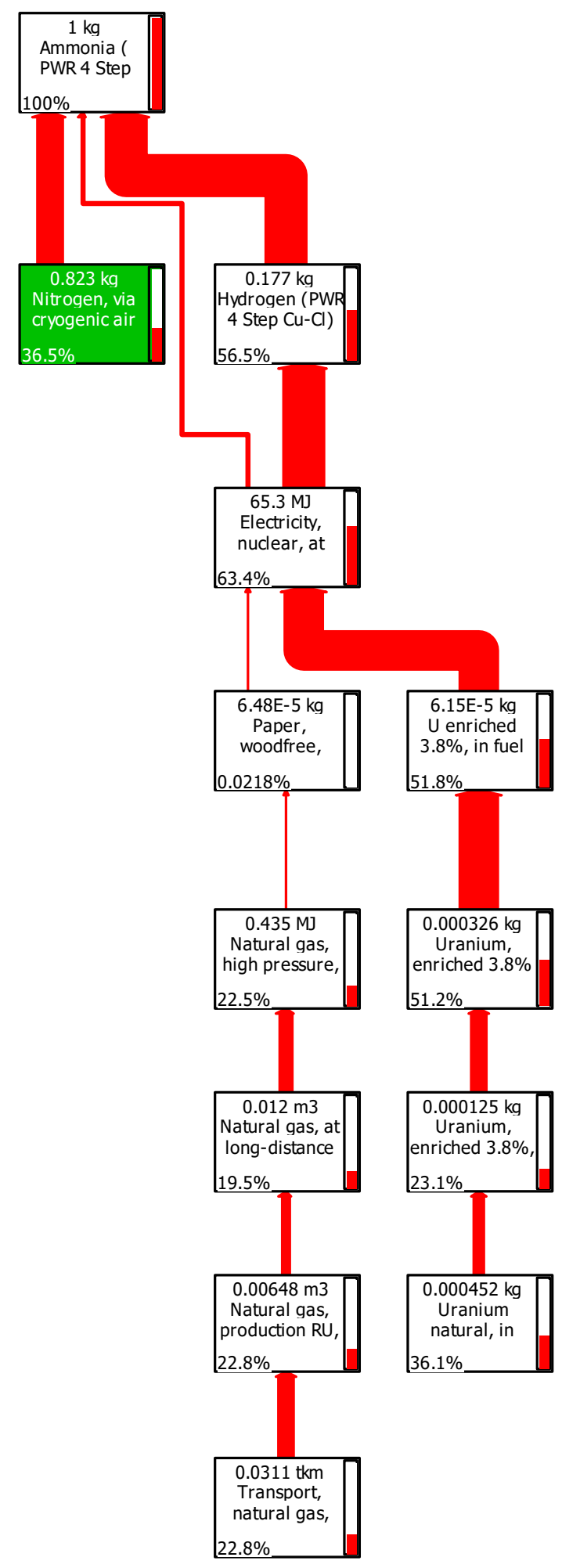

Figure 5. 38: LCA process flow chart for ozone depletion potential (ODP) of ammonia production via 4 step $\mathrm{Cu}-\mathrm{Cl}$ cycle (cut-off 5\%). 
Figure 5.39 shows human toxicity potential (HTP) of ammonia production methods. The impact on human health due to human toxicity potential (HTP) is maximum with the value of $2.423 \mathrm{~kg} 1,4 \mathrm{DB}$ eq per $\mathrm{kg}$ ammonia for the ammonia production from nuclear five-step $\mathrm{Cu}-\mathrm{Cl}$ cycle. Nuclear high temperature has the lowest ODP with the value of $1.013 \mathrm{~kg} 1,4$ DB eq per kg ammonia among the employed ammonia production processes. In contrast, SMR is less toxic than other methods, which only applies to this category of impact. This is due to the high volume of nuclear disposal process of uranium. Other selected ammonia production methods namely conventional electrolysis, 3-, and 4 step $\mathrm{Cu}-\mathrm{Cl}$ cycles' HTPs are 1.387, 2.380, and 2.188 1,4 DB eq per kg ammonia, respectively. Figure 5.40 and Figure 5.41 show the contributions of sub-processes to HTP for 5 step $\mathrm{Cu}-\mathrm{Cl}$ cycle. It is important to highlight that nitrogen production via cryogenic air separation does not make a significant contribution to human toxicity as seen in Figure 5.42. Uranium tailing and disposal processes correspond to $87 \%$ of human toxicity for nuclear-based ammonia production via thermochemical 5 step $\mathrm{Cu}-\mathrm{Cl}$ cycle.

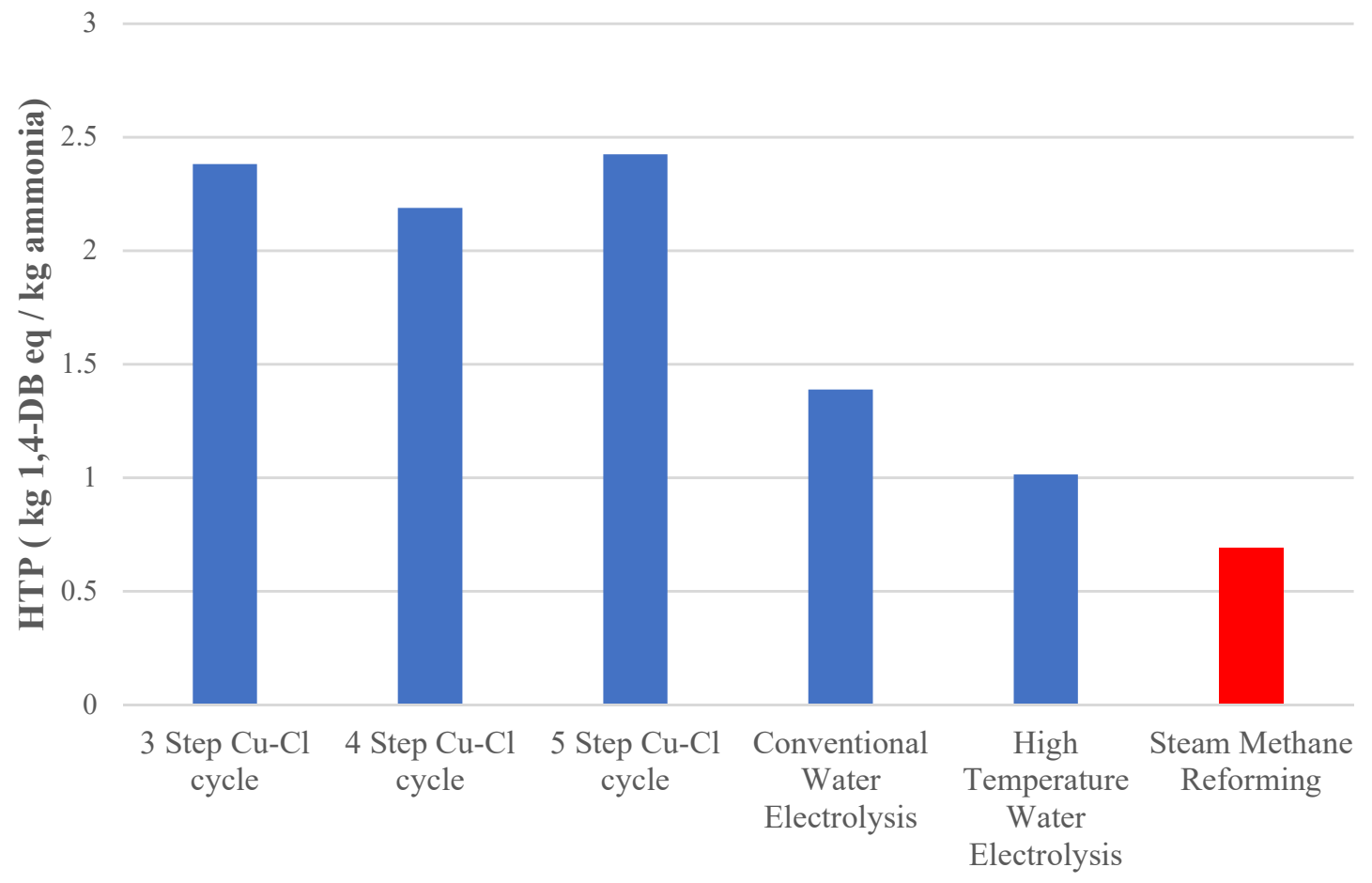

Figure 5. 39: Human toxicity potential (HTP) of nuclear-based ammonia production methods. 


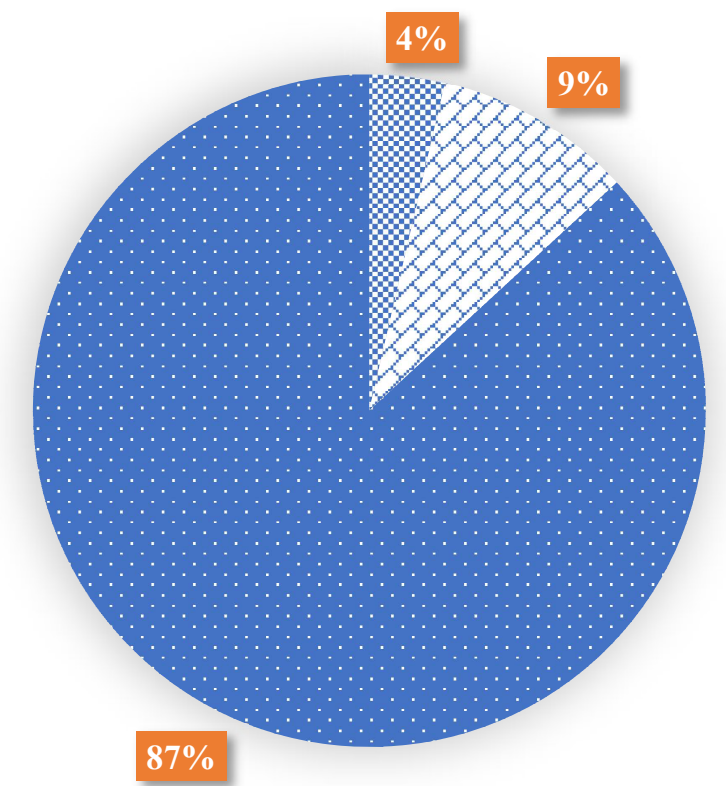

3 Remaining processes

$\checkmark$ Ferrochromium, high-carbon, 68\% $\mathrm{Cr}$, at plant/GLO U

- Disposal, uranium tailings, nonradioactive emissions/GLO U

Figure 5. 40: The share of sub-processes for HTP of nuclear-based ammonia production via thermochemical 5 step $\mathrm{Cu}-\mathrm{Cl}$ cycle.

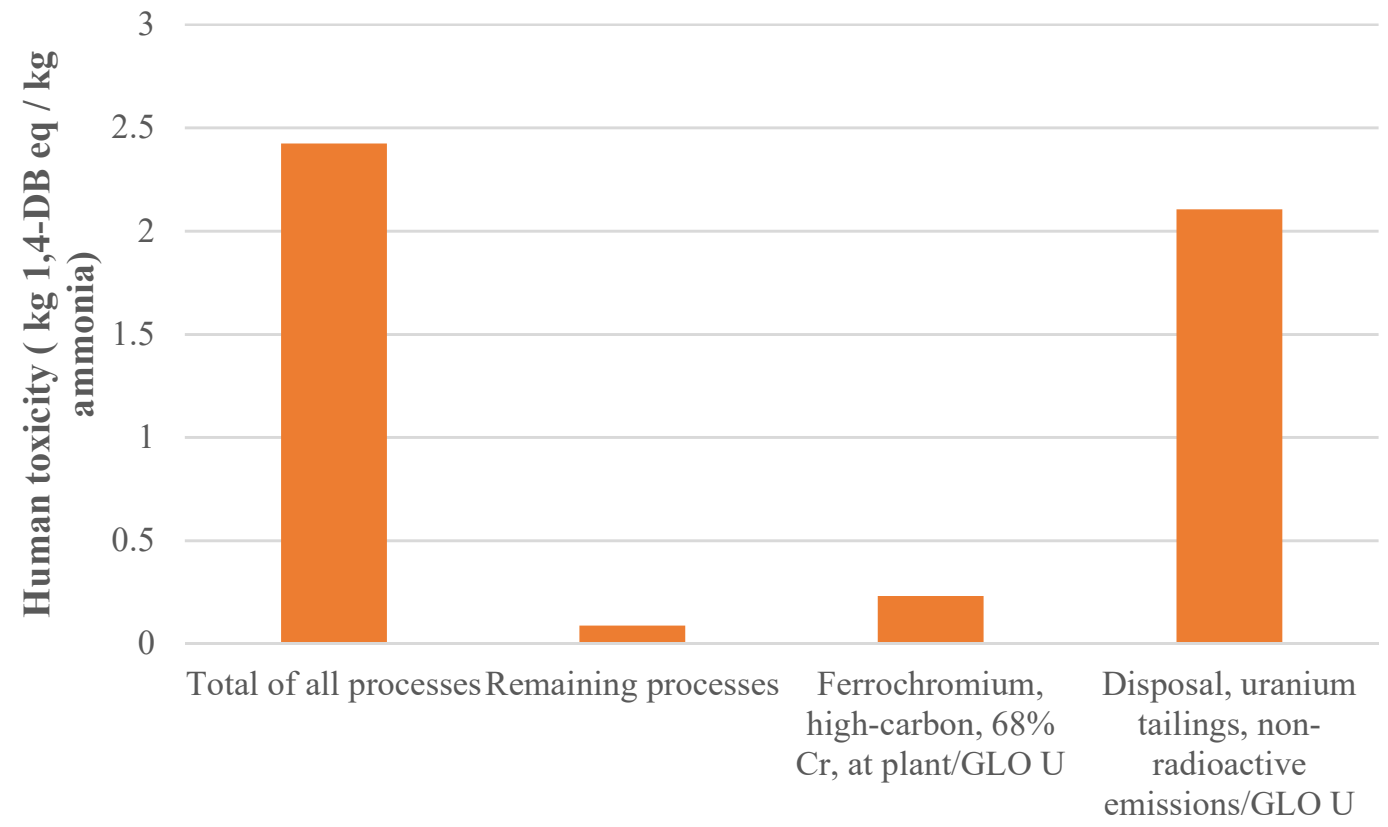

Figure 5. 41: Main contributors of HTP for nuclear-based ammonia production via thermochemical 5 step $\mathrm{Cu}-\mathrm{Cl}$ cycle. 


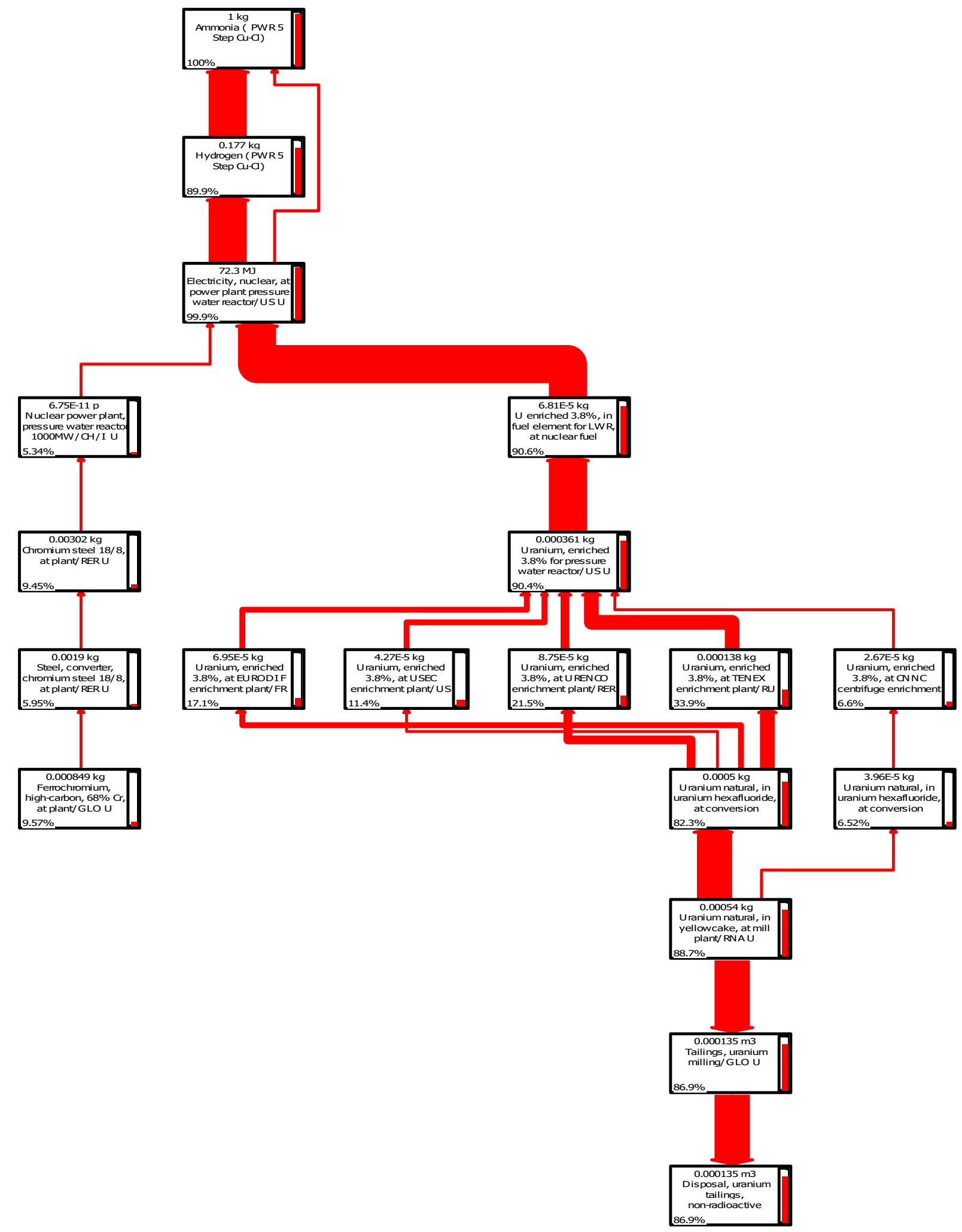

Figure 5. 42: LCA process flow chart for ozone depletion potential (ODP) of ammonia production via 4 step $\mathrm{Cu}-\mathrm{Cl}$ cycle (cut-off $5 \%$ ). 


\subsubsection{Impact of Nuclear Power Plant Selection on LCA Results}

This scenario is created to see the impact of nuclear power plant type on LCA results of hydrogen production. In this scenario, hydrogen production is achieved via hightemperature electrolysis, but in one case, required thermal and electrical energy is supplied from boiling water reactor (BWR), in another, pressurized water reactor is utilized as an energy supplier. Here, hydrogen production processes are named based on an energy supplier. For instance, hydrogen (BWR-HTE) stands for boiling water reactor powered hydrogen production via high-temperature electrolysis. It is observed that employing a boiling water reactor in the hydrogen production process yields lower environmental impacts in all categories except ozone depletion potential (ODP) as shown in Figure 5.44. For instance, global warming potential of hydrogen production via BWR-HTE corresponds to $0.434 \mathrm{~kg} \mathrm{CO}_{2}$ eq, whereas GWP of hydrogen production via PWR-HTE is $0.477 \mathrm{~kg} \mathrm{CO}_{2}$ eq per kg hydrogen. Table 5.3 shows the comparative LCA results of HTE based nuclear hydrogen production from BWR and PWR type reactors.

Table 5. 3: LCA results comparison of BWR-HTE and PWR-HTE nuclear hydrogen production.

\begin{tabular}{|l|c|c|}
\hline \multicolumn{1}{|c|}{ Impact category } & BWR-HTE & PWR-HTE \\
\hline $\mathrm{ADP}(\mathrm{kg} \mathrm{Sb}$ eq) & 0.0029 & 0.0032 \\
\hline $\mathrm{AP}\left(\mathrm{kg} \mathrm{SO}_{2}\right.$ eq $)$ & 0.0030 & 0.0034 \\
\hline $\mathrm{GWP}\left(\mathrm{kg} \mathrm{CO}_{2}\right.$ eq & 0.4345 & 0.4767 \\
\hline $\mathrm{ODP}(\mathrm{kg} \mathrm{CFC}-11 \mathrm{eq})$ & $3.74 \mathrm{E}-08$ & $2.88 \mathrm{E}-08$ \\
\hline $\mathrm{HTP}(\mathrm{kg} 1,4 \mathrm{DB}$ eq $)$ & 3.9749 & 4.3456 \\
\hline
\end{tabular}

Two main reasons for these differences in LCA results are reactor designs, and consumed uranium fuel types. Since the life cycle impact assessment (LCIA) technique investigates the processes from cradle to grave, any differences in a potential studied process give different LCA results. The design of a boiling water reactor is much simpler than PWRs' since they operate at lower temperatures and pressures. Furthermore, boiling water reactor plants don't include a separate steam generator unit. Instead, steam is generated in the reactor core and sent to a steam turbine to produce useful work. All these factors decrease 
the environmental impacts of energy input from BWR for hydrogen production. Moreover, the BWR consumes $3 \%$ enriched uranium fuel, whereas the PWR uses $3.8 \%$ enriched uranium. Lower enriched uranium yields lower environmental impacts since the number of sub-processes decrease.

However, it is observed that ozone depletion potential of hydrogen production via BWR HTE is higher than PWR-HTE. ODP of BWR-HTE is 3.74E-08, whereas this value is 2.88E-08 for PWR-HTE. When the sub-processes of BWR-HTE is investigated, it is noticed that the boiling water reactor has an anionic resin cycle (see Figure 5.45) for water purification in the plant different than PWRs. This sub-process occurs as the main reason for higher ODP for BWR-HTE. Figure 5.43 displays the main sub-processes contributing the ODP of BWR-HTE most.

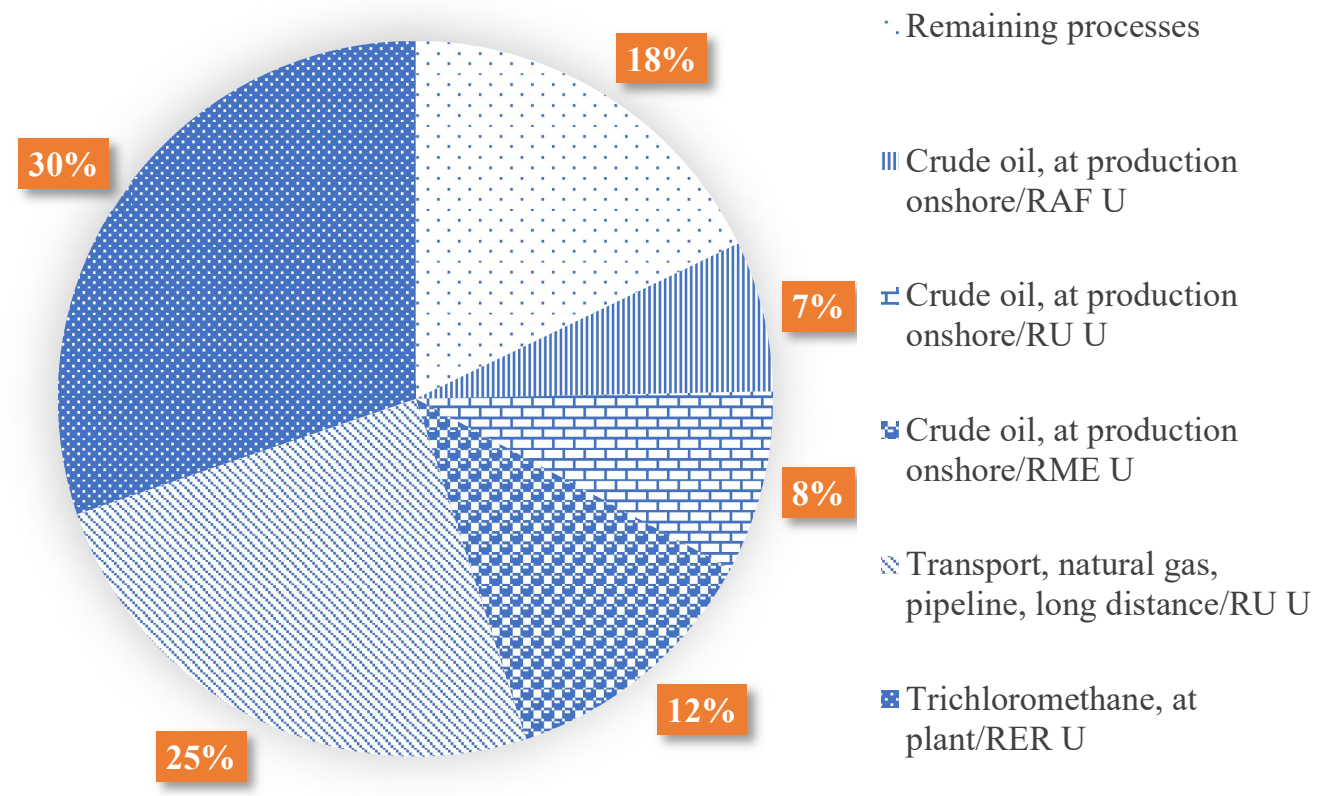

Figure 5. 43: Main ODP contributor sub-processes of BWR-HTE based nuclear hydrogen production. 


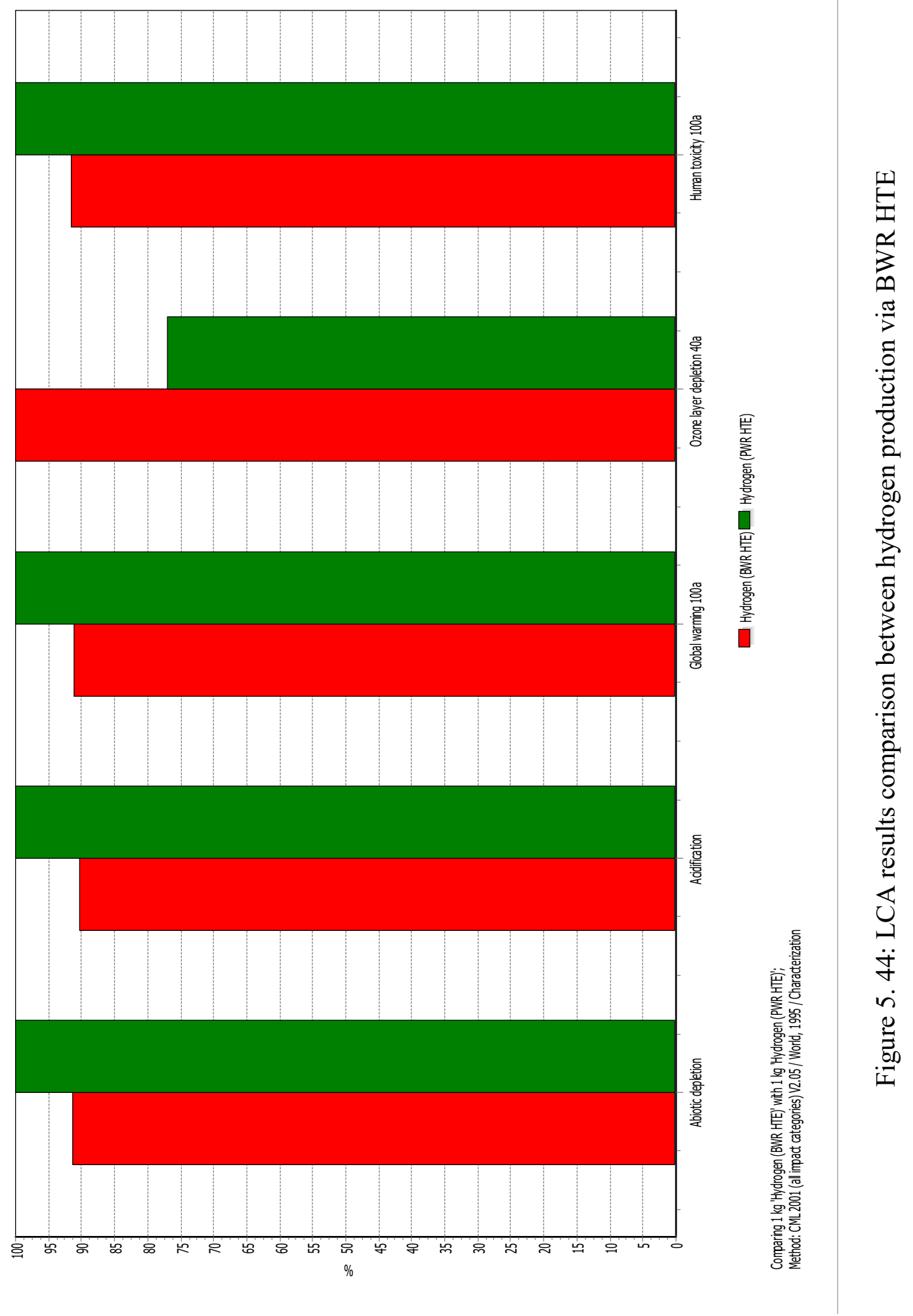




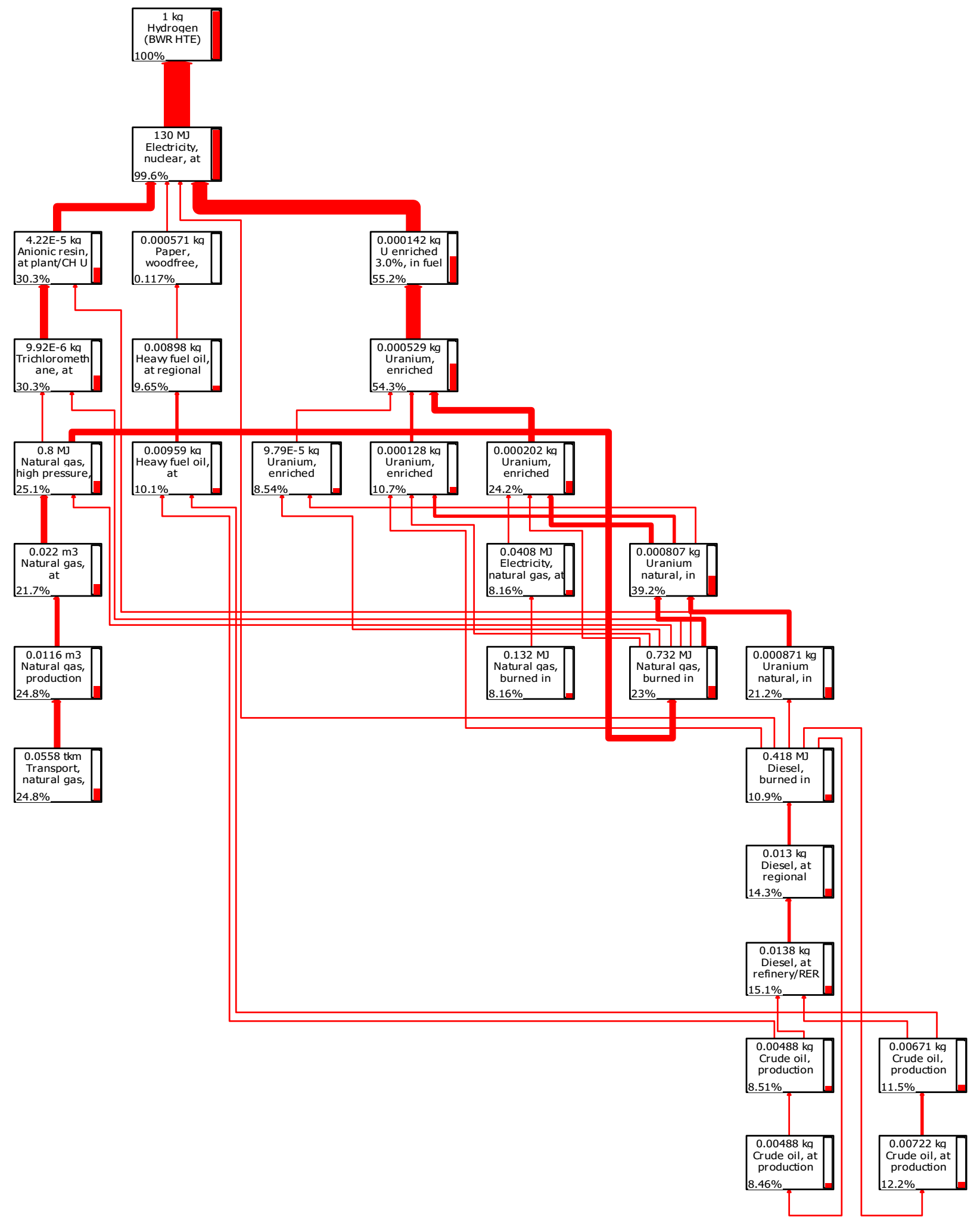

Figure 5. 45: LCA process flow chart for ozone depletion potential (ODP) of hydrogen production via BWR HTE (cut-off 5\%). 


\subsection{Cost Analysis of Nuclear-Based Hydrogen Production in the HEEP}

In this study, a comparative cost assessment of various nuclear-based hydrogen production methods is conducted by using HEEP software which was developed by the International Atomic Energy Agency (IAEA) . For hydrogen production, conventional electrolysis (CE), high-temperature steam electrolysis (HTSE), and sulfur-iodine thermochemical cycle (S-I cycle) are selected for comparative cost assessment. $\mathrm{Cu}-\mathrm{Cl}$ cycle could not be included in the cost assessment study since the HEEP's database does not include data for this method. Required thermal and electrical energy is provided from various types of advanced nuclear reactors for different scenarios, namely, pressurized water reactor (APWR), hightemperature gas cooled reactor (HTGR), and a high-temperature reactor (HTR_K).

Three different configuration is considered for cost comparison for nuclear-hydrogen production. In the first configuration, three different hydrogen production methods (HTSE, $\mathrm{CE}$, and S-I cycle) are compared, for which required energy for production processes is supplied from an advance pressurized water reactor (APWR), compressed gas storage is applied, and hydrogen is transported via trucks. In the second configuration, HTSE based hydrogen production cost is evaluated through three different hydrogen storage methods (compressed gas, liquefaction, and metal hydrides). In the third configuration, HTSE based hydrogen production is investigated through three different NPP types ( APWR, HTGR, and HTR_K).

The hydrogen production plant is considered as co-located with NPPs. In the performed cost assessment, hydrogen production plant, nuclear power plant, hydrogen storage methods (compressed gas, liquefaction, and metal hydrides), transportation ( truck) are taken into account. The results are shown for 126.000 ton of annual hydrogen production. The distance traveled for the transportation of hydrogen via trucks is taken as $200 \mathrm{~km}$. More detailed characteristics of the investigated hydrogen production process taken into account for comparative cost assessment are provided in the system description chapter. 


\subsubsection{Hydrogen Production Method based Cost Comparison}

Among the selected hydrogen production methods for the cost assessment, nuclear-based HTSE cost is the lowest with the value of $3.24 \$$ per $\mathrm{kg}$ of hydrogen, which is followed by $\mathrm{CE}$ and S-I cycle with the values of $4.4 \$$ and $4.51 \$ / \mathrm{kg}$ hydrogen as it is seen in Figure 5.46. Figure 5.47 display a significant contributor to the HTSE hydrogen production cost. Nuclear power plant utilization in the production process consists the $37 \%$ of the total hydrogen production cost, which is followed by the hydrogen production plant, hydrogen transportation, and hydrogen storage.

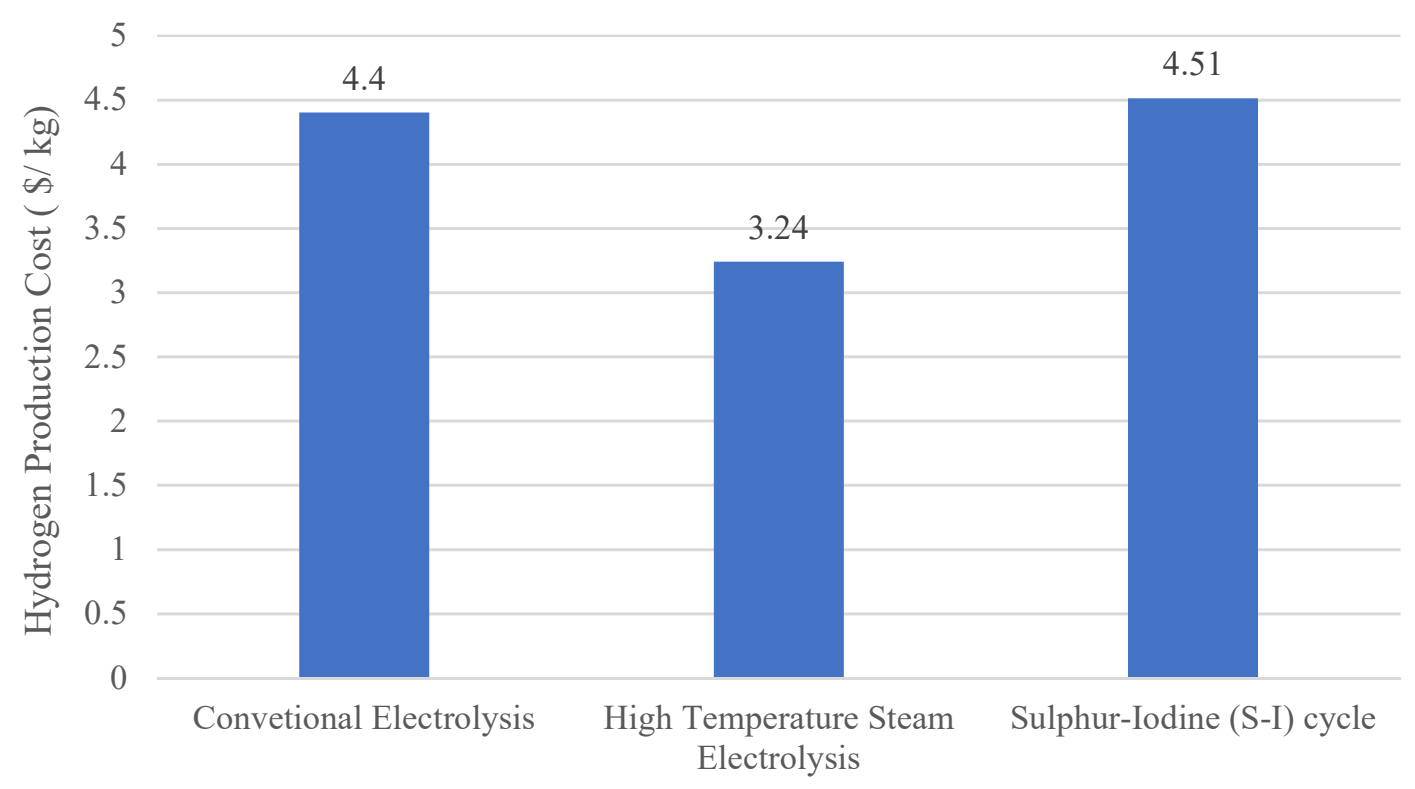

Figure 5. 46: Comparison of nuclear based hydrogen production costs.

Since HTSE hydrogen production method utilizes only the excess heat from the NPP, the cost of hydrogen production process via this method becomes lower than that of other selected methods that consume a massive amount of electricity in the production process as provided in the system description chapter. Figure 5.48 shows the cost breakup for one $\mathrm{kg}$ of hydrogen production via the S-I cycle. As an energy supplier, the APWR type nuclear power plant is the major contributor to hydrogen cost with the value of $2.63 \$$ per $\mathrm{kg}$ of hydrogen. 


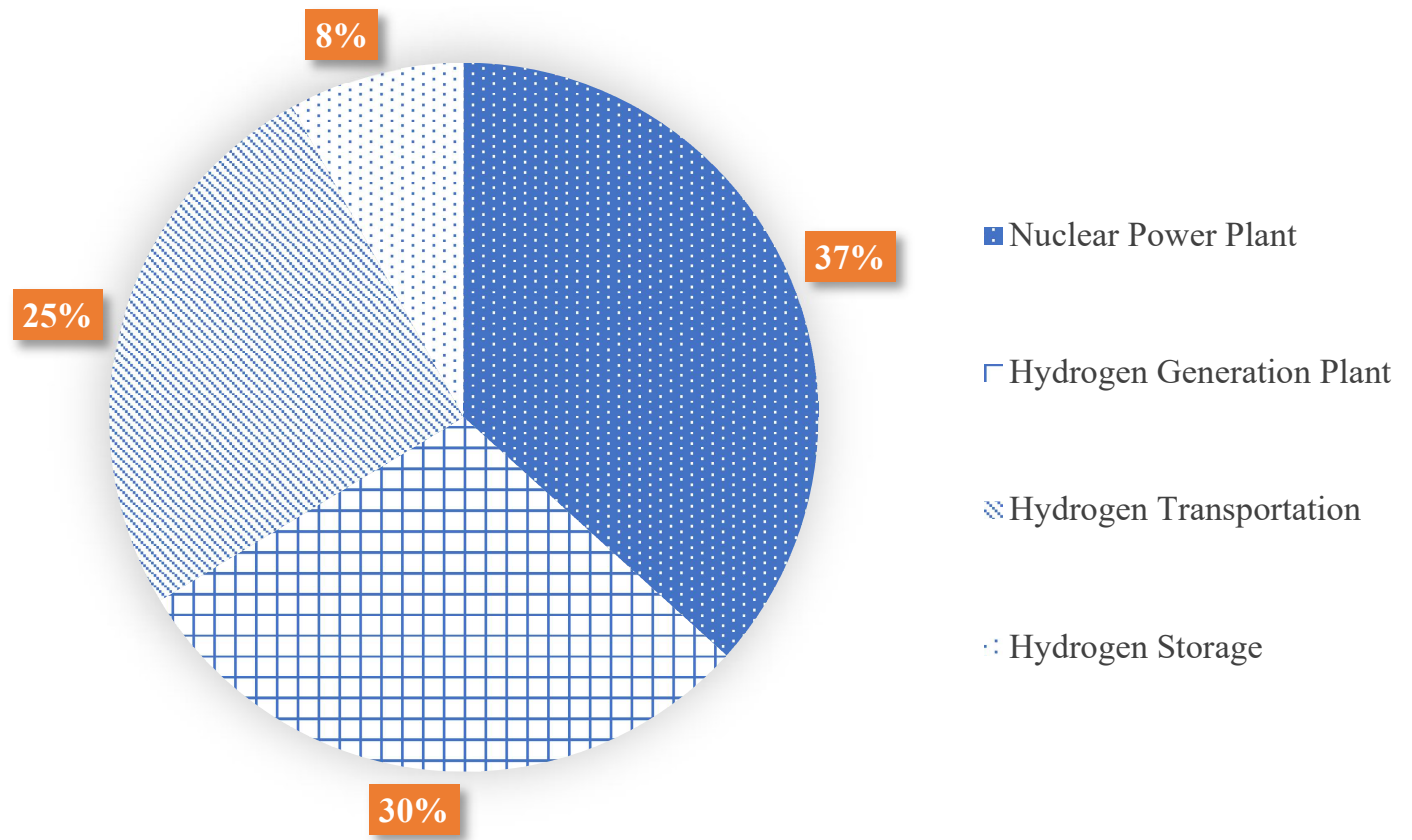

Figure 5. 47: Contribution percentages of plant units on nuclear-based HTSE hydrogen production cost.

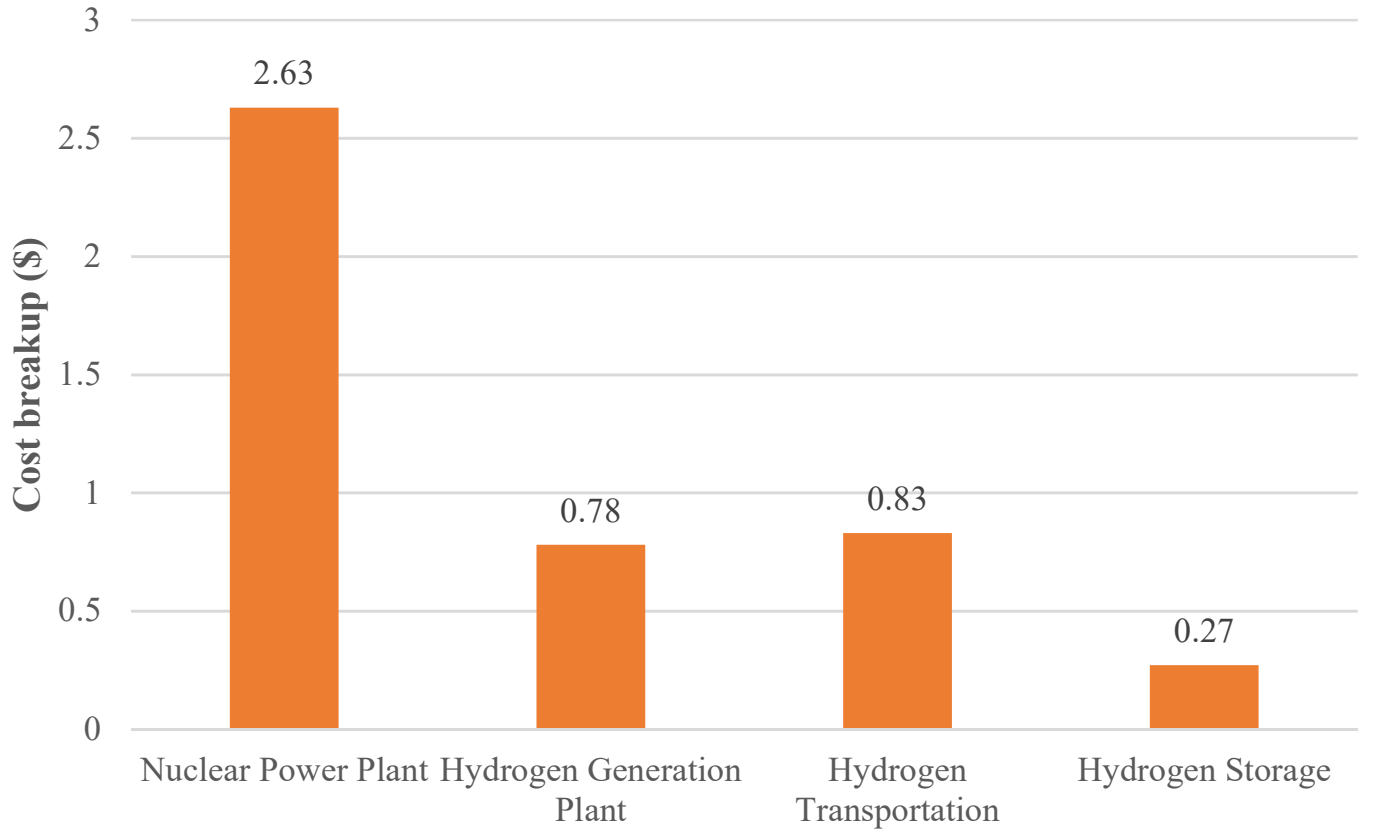

Figure 5. 48: Cost breakup for one hydrogen production via thermochemical S-I cycle. 


\subsubsection{Hydrogen Storage based Cost Comparison}

After finding that nuclear-based hydrogen production via HTSE technique is the most costeffective one among selected methods, HTSE will be further investigated through storage technique and type of selected NPP as an energy supplier. It is observed that the selected hydrogen storage method makes a significant difference in hydrogen cost. HEEP's database includes three different hydrogen storage technique data namely, compressed gas, liquefaction, and metal hydrides. As it can be seen in Figure 5.49, metal hydride hydrogen storage is a very costly technique that increases the hydrogen cost per $\mathrm{kg}$ almost double compared to compressed gas technique. The HTSE based hydrogen cost through storage technique is attained as $3.24 \$, 3.49$ \$, and $5.86 \$$ per $\mathrm{kg}$ of hydrogen for compressed gas, liquefaction, and metal hydrides, respectively.

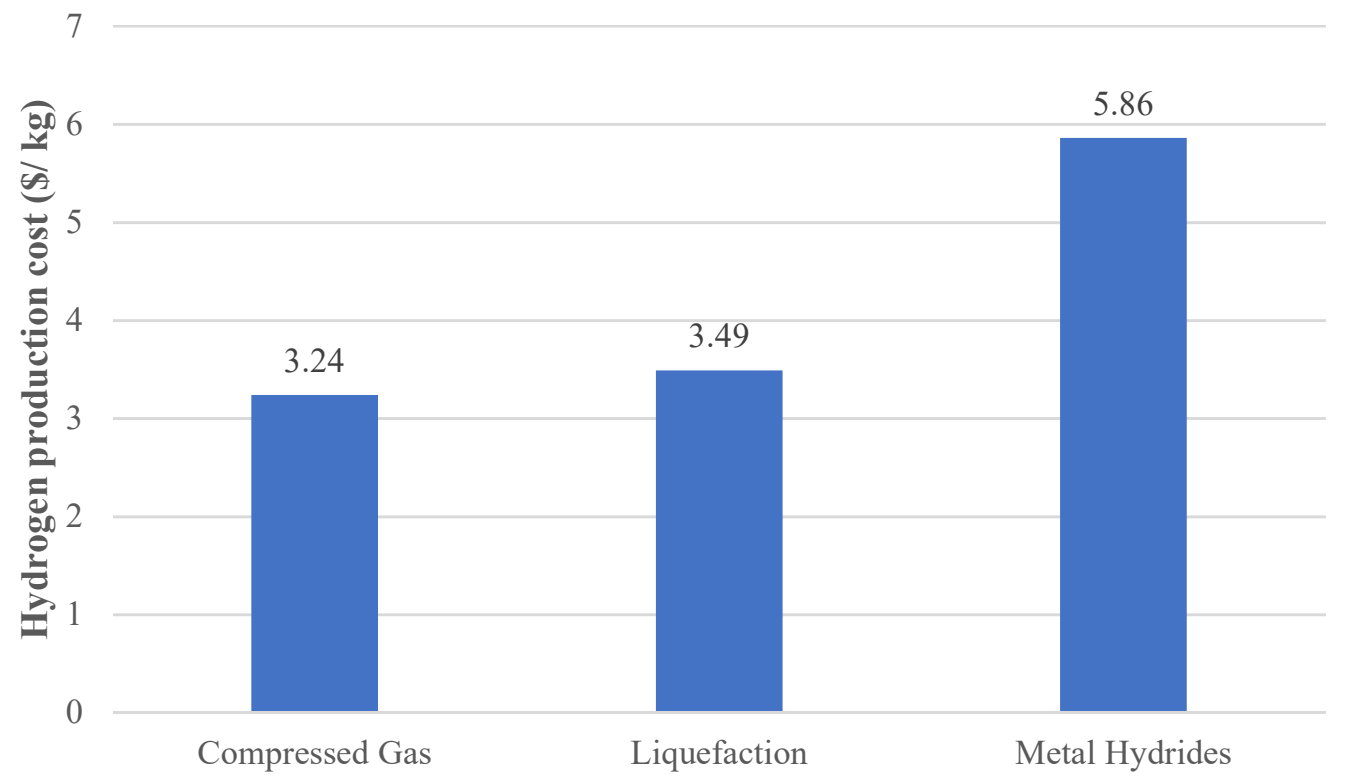

Figure 5. 49: HTSE hydrogen production costs in respect to hydrogen storage tecnique.

It is observed that NPP type selection is also significant on hydrogen cost. Three different NPP designs are employed for hydrogen production via HTSE technique to show the effect of the type of reactor on hydrogen production cost. Hydrogen storage is achieved by compressed gas technique this time, and hydrogen is transferred via trucks to end users. 


\subsubsection{NPP Type based Cost Comparison}

Figure 5.50 indicates hydrogen costs following the type of NPPs. Since the HEEP database does not include the capital cost of HTR_K type NPP, it is assumed that HTR_K has the same capital cost as HTGR, which is 605 M\$ per unit. HTGR and HTRK type NPPs consists of four units. It is also assumed that required electricity for the sub-systems of the hydrogen production process with HTR_K and HTGP type NPPs is supplied from the grid since the majority of thermal energy produced in these reactors is employed for HTSE based hydrogen production process. As indicated in the system description chapter, HTSE based hydrogen production process requires $1020 \mathrm{MW}$ th energy for 126.000-ton hydrogen production annually. HTR_K and HTGR type reactors have lower thermal rating per unit than that of APWR type reactor, which is $600 \mathrm{MWth}$ and $630 \mathrm{MWth}$, respectively. Thus, the majority of produced thermal energy in these two reactors is employed in the hydrogen production process. Therefore, the required electrical energy for sub-systems of hydrogen production with these two types of the reactor is supplied from the grid.

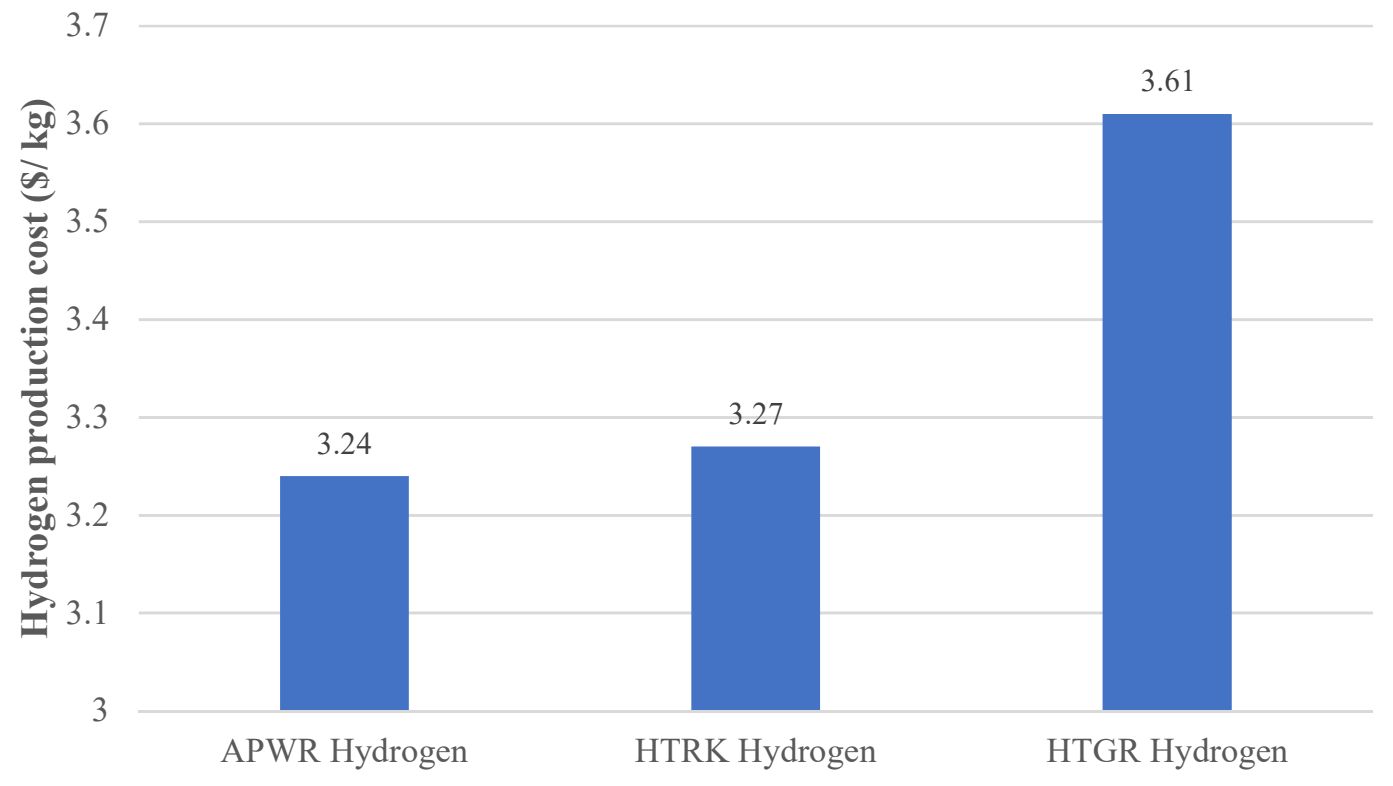

Figure 5. 50: HTSE hydrogen production cost based on the type of NPPs. 
As it can be seen in Figure 5.50, HTSE based hydrogen production cost with APWR reactor type is the lowest with the value of 3.24 \$ per kg of hydrogen, which is followed by HTR_K and HTGR hydrogen with the values of 3.27 and $3.61 \$$ per $\mathrm{kg}$ of hydrogen. The major contributors to these results are observed as capital costs and fuel costs of the reactors. For instance, the fuel cost for APWR type reactor is 1260 \$ per kg, whereas this value is 5535 $\$$ per kg of fuel for HTGR type reactor. Since the capital costs of the reactors are considered as fixed costs, they are not that effective on hydrogen production cost. On the other hand, fuel cost is operating cost and depends highly on the production rates and consumed energy rates of hydrogen production processes. Since consumed energy for the HTSE based hydrogen production with APWR and HTGR type reactor is the same, hydrogen production cost with APWR becomes lower than that of HTGR. Furthermore, as indicated earlier, the required electrical energy for sub-systems of hydrogen production with HTGR is supplied from the grid, which also increases the hydrogen production cost for HTGR.

According to HEEP's database, the fuel cost of HTRK type reactor is $250 \$$ per $\mathrm{kg}$. As shown in Figure 5.50, hydrogen production costs for APWR and HTRK are very close, which are $3.24 \$$ and 3.27 \$ per kg of hydrogen. Despite the lower fuel cost of HTRK, it is attained that the cost of hydrogen with HTRK is higher than that of APWR. This is due to using electricity from the grid.

All in all, it has been found that high-temperature steam electrolysis (HTSE) has the lowest cost among selected hydrogen production methods for the cost comparison via HEEP software. It is since the HTSE method consumes only excess heat from NPPs, whereas conventional electrolysis and S-I cycle consume both electrical and thermal energy provided from NPPs. Furthermore, it is observed that compressed gas storage method is more cost-effective than that of liquefaction method and metal hydrides since it requires lower electrical energy for the storage process of hydrogen production. Last but not least, APWR based nuclear hydrogen generation plant has the lower hydrogen cost compared to HTGR and HTR_K. The main reason for this result is lower fuel costs and higher thermal capacity of APWR type reactor. 


\section{CHAPTER 6: CONCLUSIONS AND RECOMMENDATIONS}

The main results of this thesis are summarized and briefly explained in this chapter. Further recommendations are made on the basis of results obtained for the future study in this area of research.

\subsection{Conclusions}

In this study, the results are obtained through modelling a comprehensive LCA study of nuclear-based hydrogen and ammonia production medthods in SimaPro software to reveal environmental impacts of production processes. For the study, five different hydrogen and ammonia production methods are selected from thermoelectrical and thermochemical segments, and LCA results are presented and assessed comperatively. The production methods selected for the study are conventional water electrolysis, high temperature water electrolysis, 3-, 4-, and 5 step $\mathrm{Cu}-\mathrm{Cl}$ cycles. This research carries out an LCA study that presents the environmental impact results in five impact categories namely; abiotic depletion potential (ADP), acidification potential (AP), global warming potential (GWP), ozone depletion potential (ODP), and human toxicity potential (HTP).

Even though hydrogen is clean energy carrier, there are some challeges with utilizing hydrogen as an energy substance regarding transportation and storage. In this thesis, ammonia $\left(\mathrm{NH}_{3}\right)$ is presented as a storage medium for hydrogen to overcome those challenges since ammonia is in liquid form at atmospheric temperatures and pressures with being a significant hydrogen carrier with high hydrogen content. Hydrogen and ammonia based energy applications are recognized as carbon-free energy production processes. However, environmental impacts of hydrogen and ammonia during production processes cannot be disregarded, therefore life cycle analysis of the employed production proccesses have been investigated.

The following concluding remarks can be extracted from this thesis:

- Hydrogen production via nuclear high temperature electrolysis (HTE) yields the lowest environmental impact in all selected impact categories. 
- Among thermochemical cycles, nuclear 4 step $\mathrm{Cu}-\mathrm{Cl}$ cycle has lower environmental impact due to lower enery inputs.

- Hydrogen production via nuclear 5 step $\mathrm{Cu}-\mathrm{Cl}$ cycle yields the highest environmental impact in all selected categories.

- The main sub-process of nuclear-based hydrogen production methods contributing to environmental impact categories most is the fuel-cycle, mainly mining and conversion stages due to fossil fuel use in this processes.

- Nuclear-based ammonia production via employed production processes has lower environmental impact than conventional natural gas feeded SMR method in all selected categories except human toxicity.

- Nuclear ammonia has higher HTP than SMR due to uranium tailing and disposal processes.

- Nuclear ammonia production via electrolysis methods yields lower environmental impacts than thermochemical methods.

- Nitrogen production via cryogenic air seperation does not make a significant contribution to human toxicity.

- Except human toxicity, nitrogen production via cryogenic air seperation is the main sub-process contributing to all impact categories for nuclear-based ammonia.

- Hydrogen production via boiling water reactor powered high temperature electrolysis (BWR-HTE) yields lower environmental impacts compared to PWRHTE in all selected categories except ozone depletion potential.

- Ozone depletion values for BWR-HTE is higher than PWR-HTE due to water purification sub-processes in boiling water reactor.

- By utilization of excess heat and electricity in nuclear power plant, hydrogen and ammonia can be produced in an environmentally benign manner.

- In the cost analysis study, high-temperature steam electrolysis (HTSE) has the lowest cost among selected hydrogen production methods for the cost comparison via HEEP software.

- Hydrogen storage via compressed gas method is more cost-effective than that of liquefaction method and metal hydrides due to lower energy consumption and lower capital costs. 
- Due to lower fuel costs and higher thermal capacity, nuclear hydrogen production with APWR type reactor is more cost-effective concept compared to HTGR and HTRK.

To sum up, hydrogen and ammonia are considered as promising options in sustainable development. However, instead of conventional methods such as steam methane reforming, more environmentally benign ways of producing these energy substances must take place in the field. This study has revealed that nuclear based hydrogen and ammonia production is a promising method for envrionmentally friendly hydrogen and ammonia.

\subsection{Recommendations}

Hydrogen and ammonia fed energy applications are widely investigated today in the context of carbon-free energy concept. Therefore, there will be an increasing demand for these substances. Based on the finding and observation of this study, it is highly suggested that nuclear-based hydrogen and ammonia production must be considered to produce more environmentally friendly hydrogen and ammonia.

Since thermochemical $\mathrm{Cu}-\mathrm{Cl}$ cycles employed in this study require high thermal energy inputs, certain assumptions for nuclear power plant have been made. In practice, these thermochemical $\mathrm{Cu}-\mathrm{Cl}$ cycles are mentioned together with GEN-4 nuclear reactor designs with thermal capacities such as super crital water reactors (SCWR). More accurate LCA study with more realistic assumptions can be conducted when these systems are industrialized.

Following recommendations are made for a potential future study in this field:

- Environmental impacts of nuclear-based hydrogen and ammonia productions are investigated with five most popular impact categories. Another LCA study in this field can be conducted to see environmental impacts of the production processes in different impact categories.

- LCA results of nuclear hydrogen production from a BWR type reactor and a PWR type reactor are comparatively investigated to reveal the impact of power plant type on LCA results. Another LCA study of nuclear hydrogen production can be 
conducted with more different types of reactors to see the impact of reactor type on LCA results further.

- In the future, the development of HEEP will continue to ensure that HEEP incorporates several key processes and technologies. The beta-version of HEEP can be downloaded free of charge from the IAEA web site. In this study, nuclear hydrogen production cost is evaluated by means of storage, transportation, hydrogen production method, and nuclear power plant type. More different configurations can be created for further investigation of nuclear hydrogen production costs. 


\section{REFERENCES}

Afif, A., Radenahmad, N., Cheok, Q., Shams, S., Kim, J. H., \& Azad, A. K. (2016). Ammonia-fed fuel cells: a comprehensive review. Renewable and Sustainable Energy Reviews, 60, 822-835.

Amar, I. A., Lan, R., Petit, C. T., \& Tao, S. (2011). Solid-state electrochemical synthesis of ammonia: a review. Journal of solid state electrochemistry, 15(9), 1845.

ASHRAE. (2017). Ammonia as a Refrigerant. Retrieved from https://www.ashrae.org/File Library/About/Position Documents/Ammonia-as-aRefrigerant-PD-2017.pdf.

BAINDUR, S., Nuclear Hydrogen Production: Scoping the Safety Issues, Presentation to the Canadian Nuclear Society, January 24 (2008).

Baumann H, Tillman AM. 2004. The Hitch Hiker's Guide to LCA. Student literature Lund. doi:10.1065/lca2006.02.008.

Bicer, Y., Dincer, I., Vezina, G., \& Raso, F. (2017). Impact assessment and environmental evaluation of various ammonia production processes. Environmental management, 59(5), 842-855.

Bicer, Y., Dincer, I., Zamfirescu, C., Vezina, G., Raso, F. (2016). Key lifecycle assessment numbers for NH3,green and brown energy. NH3 Fuel Conference. Retrieved from https://nh3fuel.files.wordpress.com/2016/09/greg-vezina-key-lifecycle-numbers-for-nh3-green-and-brown-energy-nh3fa20161.pdf.

Bicer, Y. (2017). Investigation of novel ammonia production options using photoelectrochemical hydrogen. Retrieved from https://ir.library.dcuoit.ca/handle/10155/780.

Bicer, Y., \& Dincer, I. (2017). Life cycle assessment of nuclear-based hydrogen and ammonia production options: A comparative evaluation. International Journal of Hydrogen Energy, 42(33), 21559-21570. 
Bicer, Y., Dincer, I., Zamfirescu, C., Vezina, G., \& Raso, F. (2016). Comparative life cycle assessment of various ammonia production methods. Journal of Cleaner Production, 135, 1379-1395.

Boggs, B. K., \& Botte, G. G. (2009). On-board hydrogen storage and production: an application of ammonia electrolysis. Journal of Power Sources, 192(2), 573-581.

Brisse A., Schefold J., Zahid M., "High temperature water electrolysis in solid oxide cells”, International Journal of Hydrogen Energy, vol. 33, pp. 5375-5382, 2008.

Cetinkaya, E., Dincer, I., \& Naterer, G. F. (2012). Life cycle assessment of various hydrogen production methods. International journal of hydrogen energy, 37(3), 2071-2080.

Christopher, K., \& Dimitrios, R. (2012). A review on exergy comparison of hydrogen production methods from renewable energy sources. Energy \& Environmental Science, 5(5), 6640-6651.

Curran, M. A. (Ed.). (2012). Life cycle assessment handbook: a guide for environmentally sustainable products. John Wiley \& Sons.

Curran MA. (2006). Life Cycle Assessment: Principles and Practice. National Risk Management Research Laboratory, Office of Research and Development, US Environmental Protection Agency. 1-80.

Daggupati, V. N., Naterer, G. F., Gabriel, K. S., Gravelsins, R. J., \& Wang, Z. L. (2010). Solid particle decomposition and hydrolysis reaction kinetics in $\mathrm{Cu}-\mathrm{Cl}$ thermochemical hydrogen production. International Journal of Hydrogen Energy, 35(10), 4877-4882.

Del Borghi A. 2013. LCA and communication: Environmental product declaration. The International Journal of Life Cycle Assessment.18(2):293-295.

Dincer, I., \& Acar, C. (2015). Review and evaluation of hydrogen production methods for better sustainability. International journal of hydrogen energy, 40(34), 1109411111. 
Dincer, I. (2012). Green methods for hydrogen production. International journal of hydrogen energy, 37(2), 1954-1971.

Ecoinvent. 2013. Ecoinvent Database 3.0. Ecoinvent Cent. doi:10.4018/978-1-59140342-5.ch003.

El-Emam, R. S., Ozcan, H., \& Dincer, I. (2015). Comparative cost evaluation of nuclear hydrogen production methods with the Hydrogen Economy Evaluation Program (HEEP). International journal of hydrogen energy, 40(34), 11168-11177.

Environment and Climate Change Canada. (2016). Canada's mid-century long-term lowgreenhouse gas development strategy. Retrieved from http://unfccc.int/files/focus/long-term_strategies/application/pdf/canadas_midcentury_long-term_strategy.pdf

Environment and Climate Change Canada. (2018). National Inventory Report 1990 2016: Greenhouse gas sources and sinks in Canada. Retrieved from https://www.canada.ca/content/dam/eccc/documents/pdf/climatechange/emissions-inventories-reporting/nir-executive-summary/National Inventory Report Executive Summary 2018.pdf.

European Environment Agency. 2006. Life cycle assessment (LCA): a guide to approaches, experiences and information sources. Environ. Issues Ser.1-6. doi:10.1016/B978-0-12-801775-3.00024-X.

Finnveden G, Hauschild MZ, Ekvall T, Guinée J, Heijungs R, Hellweg S, Koehler A, Pennington D, Suh S. 2009. Recent developments in Life Cycle Assessment. LCA. 91:1-21.

Firth P. 2012. Environmental Product Declarations. Environ. Des. Constr.:33-39.

Frischknecht R, Niels J. 2007. Overview and Methodology - Data v2.0. Ecoinvent Rep. No1. 1:1-77.

Frydendal J, Hansen LE, Bonou A. 2017. Environmental labels and declarations. Life Cycle Assess. Theory Pract., pp 577-604. doi:10.1007/978-3-319-56475-3_24. 
Ganley, J. C., Holbrook, J. H., \& McKinley, D. E. (2007, October). Solid state ammonia synthesis. In Ammon. Fuel Netw. Conf.

Giddey, S., Badwal, S. P. S., \& Kulkarni, A. (2013). Review of electrochemical ammonia production technologies and materials. International Journal of Hydrogen Energy, 38(34), 14576-14594.

GIF. (2010, July). GEN-IV International Forum: 2009 Annual Report. Retrieved from https://www.gen-4.org/gif/jcms/c_43527/2009-annual-report

GIF. (2017). Generation IV Goals. Retrieved from https://www.gen4.org/gif/jcms/c_9502/generation-iv-goals

Gilbert, P., \& Thornley, P. (2010, September). Energy and carbon balance of ammonia production from biomass gasification. In Poster at Bio-Ten Conference, Birmingham.

Gong, W., \& Willi, M. L. (2010). U.S. Patent Application No. 12/219,418.

Hacatoglu, K., Rosen, M. A., \& Dincer, I. (2012). Comparative life cycle assessment of hydrogen and other selected fuels. international journal of hydrogen energy, 37(13), 9933-9940.

Hofstrand, D. (2009, May). Ammonia as a Transportation Fuel. Retrieved from https://www.agmrc.org/renewable-energy/renewable-energy/ammonia-as-atransportation-fuel

Honnery, D., \& Moriarty, P. (2009). Estimating global hydrogen production from wind. International journal of hydrogen energy, 34(2), 727-736.

International Energy Agency (IEA). (2017). World Energy Outlook 2017. Retrieved from https://www.iea.org/weo2017/

International Enegy Agency (IEA). (2017). CO2 Emissions from Fuel Combustions.

Retrieved from

https://www.iea.org/publications/freepublications/publication/CO2Emissionsfrom FuelCombustionHighlights2017.pdf. 
International Enegy Agency (IEA). (2017). Key World Energy Statistics. Retrieved from https://www.iea.org/publications/freepublications/publication/KeyWorld2017.pdf. International Atomic Energy Agency (IAEA). (2017). Energy, Electricity and Nuclear Power Estimates for the Period up to 2050.

International Atomic Energy Agency (IAEA). (2018, December). Nuclear Hydrogen Production. Retrieved from https://www.iaea.org/topics/non-electricapplications/nuclear-hydrogen-production

International Fertilizer Association (IFA). (2009). Energy Efficiency and $\mathrm{CO}_{2}$ Emissions in Ammonia Production. Feeding the Earth. Retrieved from https://www.fertilizer.org/images/Library_Downloads/2009_IFA_energy_efficien cy.pdf.

International Organization for Standardization (ISO), ISO 14040, “Environmental Management - Life Cycle Assessment - Principles and Framework”, 1997.

ISO. 2006. Environmental management-life cycle assessment-principles and framework. ISO 14040: 46. doi:10.1136/bmj.332.7550.1107.

Jimenez-Guerrero JF, Gazquez-Abad JC, Ceballos-Santamaría G. 2015. Innovation in eco-packaging in private labels. Innov. Manag. Policy Pract. 17:81-90.

Karasu, H. (2018). Life cycle assessment of conventional and alternative fuels for vehicles (Doctoral dissertation).

Khamis, I., \& Malshe, U. D. (2010). HEEP: a new tool for the economic evaluation of hydrogen economy. International journal of hydrogen energy, 35(16), 8398-8406.

Kyriakou, V., Garagounis, I., Vasileiou, E., Vourros, A., \& Stoukides, M. (2017). Progress in the electrochemical synthesis of ammonia. Catalysis Today, 286, 213.

Lan R and Tao S (2014) Ammonia as a suitable fuel for fuel cells. Front. Energy Res. 2:35. doi: 10.3389/fenrg.2014.00035. 
Marnellos, G., Zisekas, S., \& Stoukides, M. (2000). Synthesis of ammonia at atmospheric pressure with the use of solid state proton conductors. Journal of Catalysis, 193(1), 80-87.

McAloone TC, Pigosso DCA. 2017. Ecodesign implementation and LCA. Life Cycle Assess. Theory Pract., pp 545-576. doi:10.1007/978-3-319-56475-3_23.

Modak, J. M. (2002). Haber process for ammonia synthesis. Resonance, 7(9), 69-77.

Morgan, E., Manwell, J., \& McGowan, J. (2014). Wind-powered ammonia fuel production for remote islands: A case study. Renewable Energy, 72, 51-61.

Naterer, G. F., Gabriel, K., Wang, Z. L., Daggupati, V. N., \& Gravelsins, R. (2008). Thermochemical hydrogen production with a copper-chlorine cycle. I: oxygen release from copper oxychloride decomposition. International Journal of Hydrogen Energy, 33(20), 5439-5450.

Naterer, G., Suppiah, S., Lewis, M., Gabriel, K., Dincer, I., Rosen, M. A., ... \& Kaye, M. H. (2009). Recent Canadian advances in nuclear-based hydrogen production and the thermochemical $\mathrm{Cu}-\mathrm{Cl}$ cycle. International Journal of Hydrogen Energy, 34(7), 2901-2917.

Naterer, G. F., Suppiah, S., Stolberg, L., Lewis, M., Wang, Z., Daggupati, V., ... \& Lvov, S. N. (2010). Canada's program on nuclear hydrogen production and the thermochemical $\mathrm{Cu}-\mathrm{Cl}$ cycle. international journal of hydrogen energy, 35(20), 10905-10926.

Natural Resources Canada. (2018, August 24). Uranium and nuclear power facts. Retrieved from https://www.nrcan.gc.ca/energy/facts/uranium/20070

Ontario Ministry of Energy. (2017, March 7). Retrieved from http://www.energy.gov.on.ca/en/ontarios-electricity-system/ontarios-electricitysystem-faqs/

Orhan, M. F., Dincer, I., \& Rosen, M. A. (2008). Energy and exergy assessments of the hydrogen production step of a copper-chlorine thermochemical water splitting 
cycle driven by nuclear-based heat. International Journal of Hydrogen Energy, 33(22), 6456-6466.

Ozbilen, A., Dincer, I., \& Rosen, M. A. (2013). Comparative environmental impact and efficiency assessment of selected hydrogen production methods. Environmental Impact Assessment Review, 42, 1-9.

Ozbilen, A., Dincer, I., \& Rosen, M. A. (2012). Life cycle assessment of hydrogen production via thermochemical water splitting using multi-step $\mathrm{Cu}-\mathrm{Cl}$ cycles. Journal of Cleaner Production, 33, 202-216.

Ozbilen, A., Dincer, I., \& Rosen, M. A. (2011). A comparative life cycle analysis of hydrogen production via thermochemical water splitting using a $\mathrm{Cu}-\mathrm{Cl}$ cycle. International Journal of Hydrogen Energy, 36(17), 11321-11327.

Ozbilen, A. Z. (2010). Life cycle assessment of nuclear-based hydrogen production via thermochemical water splitting using a copper-chlorine $(\mathrm{Cu}-\mathrm{Cl})$ cycle (Doctoral dissertation, UOIT).

Pérez-Herranz, V., Pérez-Page, M., \& Beneito, R. (2010). Monitoring and control of a hydrogen production and storage system consisting of water electrolysis and metal hydrides. International journal of hydrogen energy, 35(3), 912-919.

Pilavachi, P. A., Chatzipanagi, A. I., \& Spyropoulou, A. I. (2009). Evaluation of hydrogen production methods using the analytic hierarchy process. International Journal of hydrogen energy, 34(13), 5294-5303.

Pre’ Consultants. 2014. SimaPro Database Manual. PRe’:1-48. doi:10.1017/CBO9781107415324.004.

Prosini, P. P., Cento, C., Giaconia, A., Caputo, G., \& Sau, S. (2009). A modified sulphur-iodine cycle for efficient solar hydrogen production. International Journal of Hydrogen Energy, 34(3), 1218-1225.

Ratlamwala, T. A. H., \& Dincer, I. (2012). Energy and exergy analyses of a $\mathrm{Cu}-\mathrm{Cl}$ cycle based integrated system for hydrogen production. Chemical engineering science, 84, 564-573. 
Rosen, M. A., Naterer, G. F., Chukwu, C. C., Sadhankar, R., \& Suppiah, S. (2012).

Nuclear-based hydrogen production with a thermochemical copper-chlorine cycle and supercritical water reactor: equipment scale-up and process simulation. International Journal of Energy Research, 36(4), 456-465.

Scepanovic, V. (2003). NRCan Hydrogen and Fuel Cell R\&D Program. The PEI WindHydrogen Symposium. Retrieved from http://www.gov.pe.ca/photos/original/dev_nrcan_hydro.pdf

Schenck R. 2005. Why LCA? Building Design and Construction supply. 4-5. Available from http://search.ebscohost.com/login.aspx

Simpson, A. P., \& Lutz, A. E. (2007). Exergy analysis of hydrogen production via steam methane reforming. International Journal of Hydrogen Energy, 32(18), 48114820.

Shin, Y., Park, W., Chang, J., \& Park, J. (2007). Evaluation of the high temperature electrolysis of steam to produce hydrogen. International Journal of Hydrogen Energy, 32(10-11), 1486-1491.

Sto E, Strandbakken P. 2005. Eco-labels and consumers. Futur. eco-labelling. Mak. Environ. Prod. Inf. Syst. Eff., pp 92-119.

Suzuki, S., Muroyama, H., Matsui, T., \& Eguchi, K. (2012). Fundamental studies on direct ammonia fuel cell employing anion exchange membrane. Journal of Power Sources, 208, 257-262.

The Essential Chemical Industry (ECI). (2016, October 12). Oxygen, nitrogen and the rare gases. Retrieved from http://www.essentialchemicalindustry.org/chemicals/oxygen.html

Tillman AM. 2000. Significance of decision-making for LCA methodology. Environ. Impact Assess. Rev. 20:113-123.

Ursua, A., Gandia, L. M., \& Sanchis, P. (2012). Hydrogen production from water electrolysis: current status and future trends. Proceedings of the IEEE, 100(2), 410-426. 
Utgikar, V., \& Thiesen, T. (2006). Life cycle assessment of high temperature electrolysis for hydrogen production via nuclear energy. International Journal of Hydrogen Energy, 31(7), 939-944.

Vayenas, C. G., \& Farr, R. D. (1980). Cogeneration of electric energy and nitric oxide. Science, 208(4444), 593-594.

Vojvodic, A., Medford, A. J., Studt, F., Abild-Pedersen, F., Khan, T. S., Bligaard, T., \& Nørskov, J. K. (2014). Exploring the limits: a low-pressure, low-temperature Haber-Bosch process. Chemical Physics Letters, 598, 108-112.

Wang, Z. L., Naterer, G. F., Gabriel, K. S., Gravelsins, R., \& Daggupati, V. N. (2009). Comparison of different copper-chlorine thermochemical cycles for hydrogen production. International Journal of Hydrogen Energy, 34(8), 3267-3276.

Wojcik, A., Middleton, H., \& Damopoulos, I. (2003). Ammonia as a fuel in solid oxide fuel cells. Journal of Power Sources, 118(1-2), 342-348.

Xu, G., Liu, R., \& Wang, J. (2009). Electrochemical synthesis of ammonia using a cell with a Nafion membrane and $\mathrm{SmFe} 0.7 \mathrm{Cu} 0.3-\mathrm{x}$ Ni x O $3(x=0-0.3)$ cathode at atmospheric pressure and lower temperature. Science in China Series B: Chemistry, 52(8), 1171-1175.

Zamfirescu, C., \& Dincer, I. (2009). Ammonia as a green fuel and hydrogen source for vehicular applications. Fuel processing technology, 90(5), 729-737.

Zamfirescu, C., \& Dincer, I. (2008). Using ammonia as a sustainable fuel. Journal of Power Sources, 185(1), 459-465. 